\title{
PROJETO EVOLUCIONÁRIO DE REDES NEURAIS ARTIFICIAIS PARA AVALIAÇÃO DE CRÉDITO FINANCEIRO
}

\author{
Elson Felix Mendes Filho \\ Orientador: Prof. Dr. André Carlos Ponce de \\ Leon Ferreira de Carvalho
}




\section{PROJETO EVOLUCIONÁRIO DE REDES NEURAIS ARTIFICIAIS PARA AVALIAÇÃO DE CRÉDITO FINANCEIRO}

\section{Elson Felix Mendes Filho}

Orientador: Prof. Dr. André Carlos Ponce de Leon Ferreira de Carvalho

Dissertação apresentada ao Instituto de Ciências Matemáticas de São Carlos, da Universidade de São Paulo, como parte dos requisitos para obtenção do título de Mestre em Ciências Área: Ciências de Computação e Matemática Computacional.

São Carlos

1997 
Aos meus pais, Elson e Heloisa, meus irmãos Rodrigo e Renata e minha avó Celina pelo amor, carinho, paciência e incentivo. 


\section{AGRADECIMENTOS}

Ao Professor André pela excelente orientação, pela amizade e incentivo em todos os momentos.

À Professora Carolina e ao Professor Aluísio membros da banca de qualificação pelas críticas, colaborações e sugestões.

Ao Professor Alberto Matias da FEA pelas valiosas contribuições, pelo apoio e incentivo indispensáveis à realização deste trabalho e pela atenção sempre concedida.

Aos Professores Odelar Leite Linhares e Maria Augusta Brandão do IBILCE pela amizade e incentivos dados ao iniciar este mestrado.

Às Professoras Rosely, Solange e Graça e à todos os colegas do LABIC pela colaboração e paciência durante a realização dos experimentos.

Às secretarias da pós-graduação Beth, Laura e Marília pela simpatia, atenção e eficiência com que sempre me atenderam.

À todos os professores e funcionários do ICMSC que de algum modo colaboraram durante meus estudos realizados neste instituto.

Aos colegas Hélio, Rodrigo e Ivan pelo auxílio nos experimentos, no desenvolvimento dos protótipos e na configuração das máquinas.

Aos amigos e colegas da pós-graduação Patrícia, Andréa, Cláudia e Gustavo pela colaboração e companheirismo.

Aos amigos que direta ou indiretamente contribuíram com seu apoio e amizade durante estes anos em São Carlos, em especial: Boca, Trolha, Miúdo, Welton, Freddy, Rosângela, Cilene, Jacques, Robson e Rogério; aos amigos de Botucatu:, Marcos, Newber, Alexandre, Furlan, Fabio, Rodolfo, Maurício, Flávio, Ricardo,Victor, Luciano e D. Quiquita; aos amigos de Rio Preto: Rafael, Luciana, Dirschel, Porps, Fabrício, Walid e Topo; e à minha querida Marta.

Ao CNPq pelo apoio financeiro fornecido durante o desenvolvimento deste trabalho. 


\section{SUMÁRIO}

LISTA DE FIGURAS

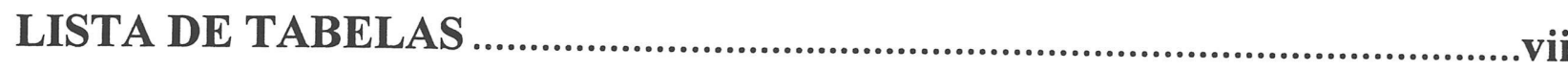

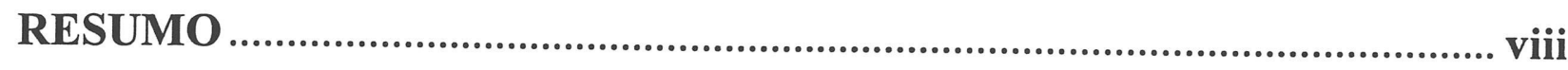

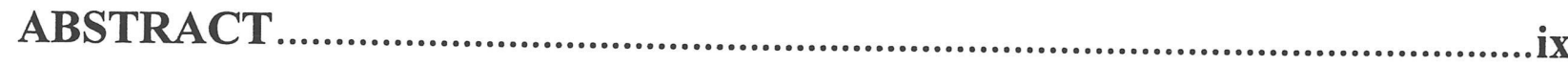

1. INTRODUÇÃO

1.1 Caracterização da Área...................................................................................................... 02

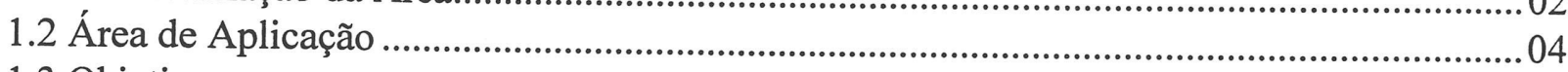

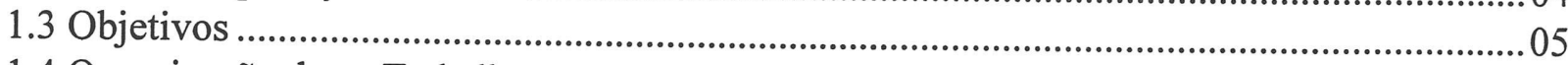

1.4 Organização deste Trabalho ................................................................................................ 06

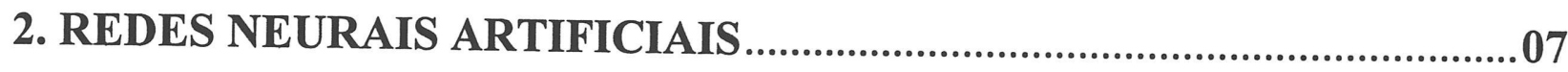

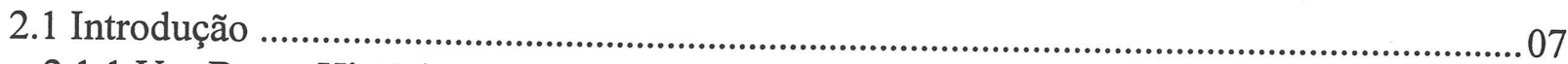

2.1.1 Um Breve Histórico ................................................................................................ 08

2.1.2 Características Gerais das Redes Neurais ..................................................................... 08

2.1.3 Processos de Aprendizado ....................................................................................... 10

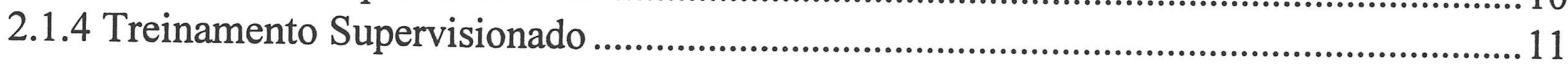

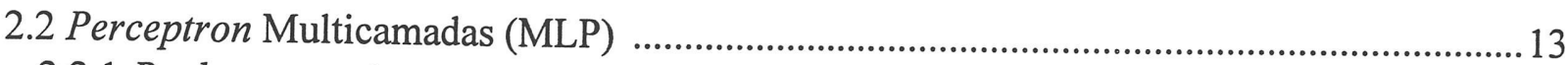

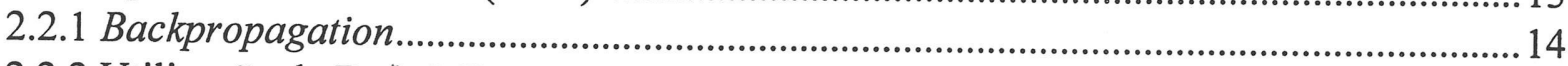

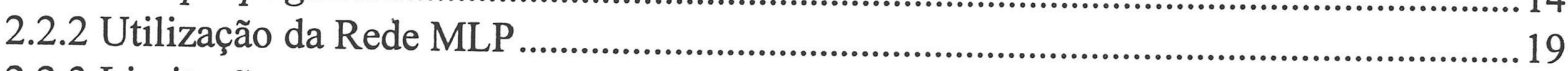

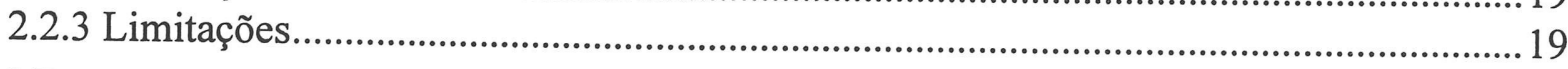

2.3 Desenvolvimento de Aplicações ....................................................................................22

2.4 Considerações Finais......................................................................................................24

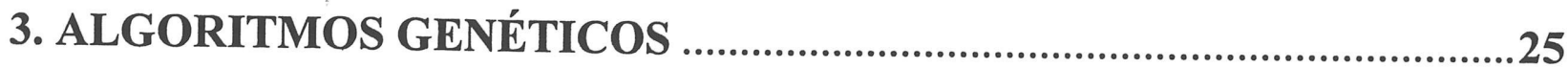

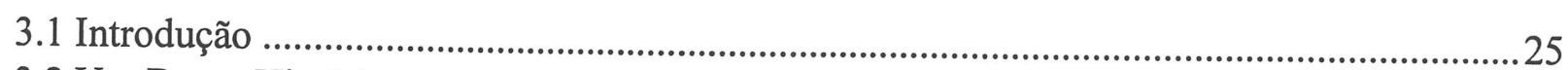

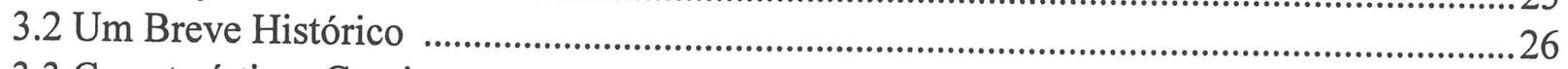

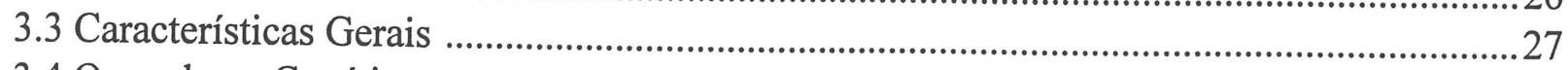

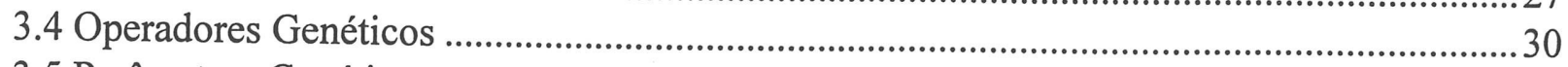

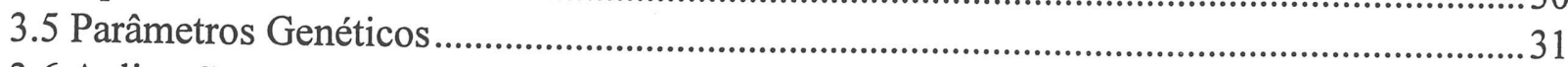

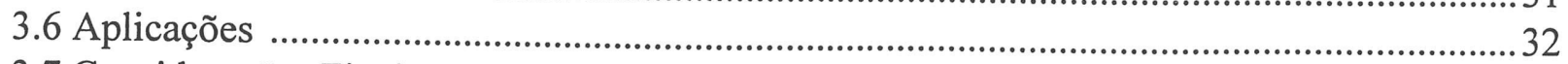

3.7 Considerações Finais....................................................................................................... 
4. EVOLUÇÃO EM REDES NEURAIS .....................................................3

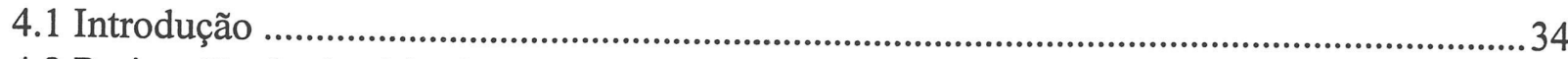

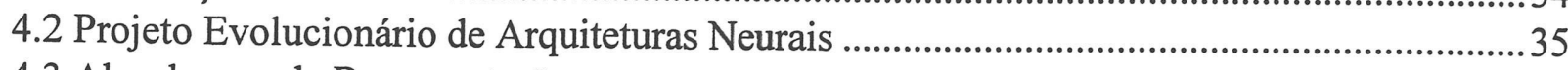

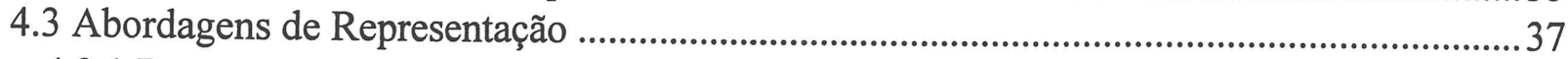

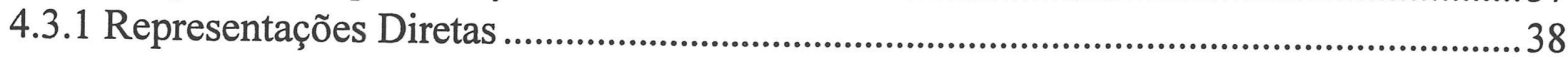

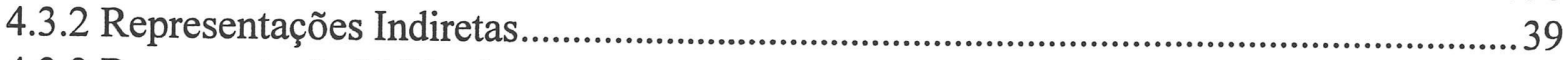

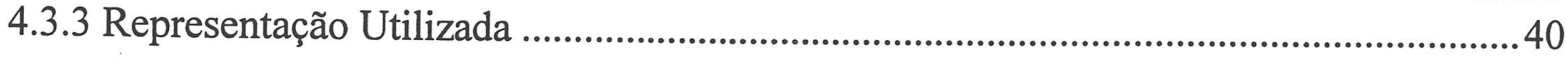

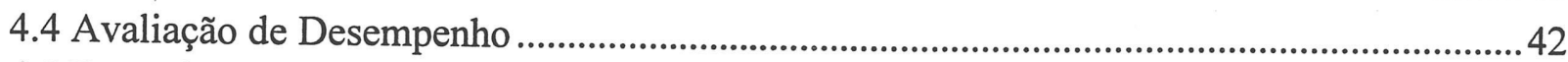

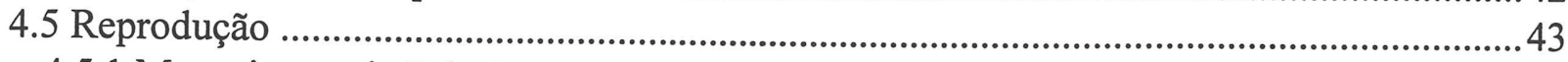

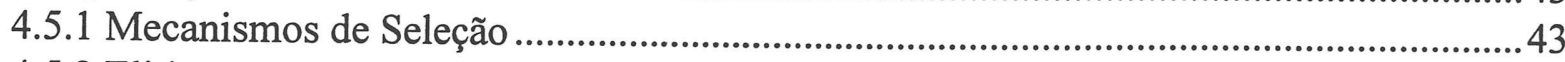

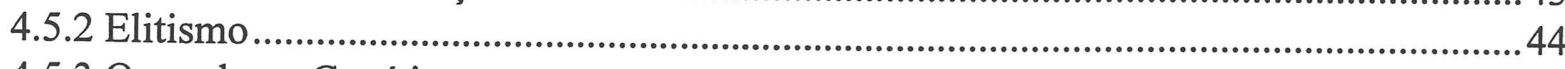

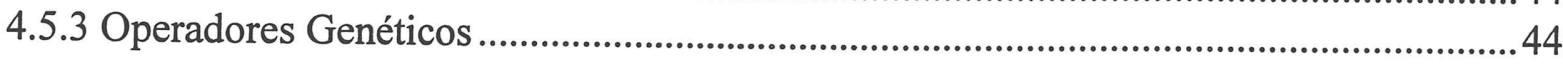

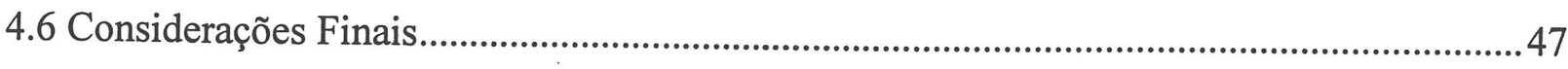

5. AVALIAÇÃO DE CRÉDITO …..........................................................48

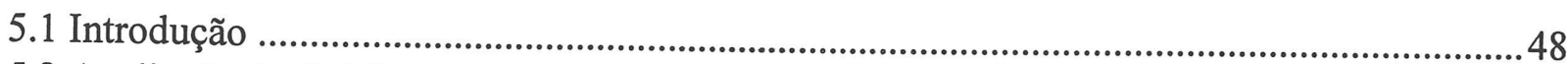

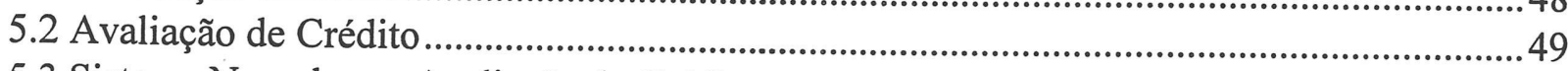

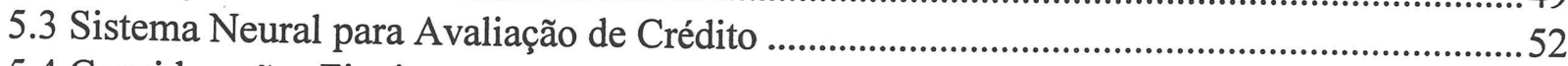

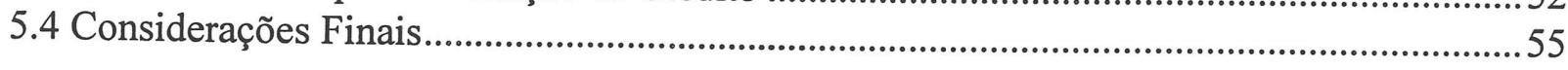

6. METODOLOGIA, RESULTADOS E DISCUSSÕES.............................56

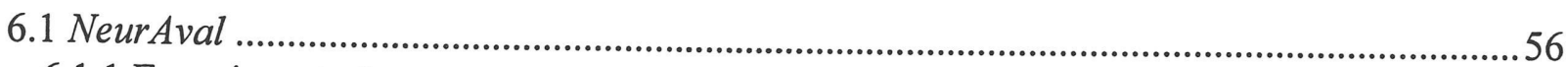

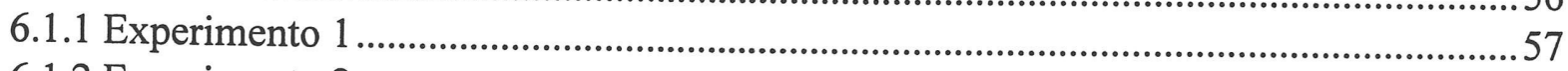

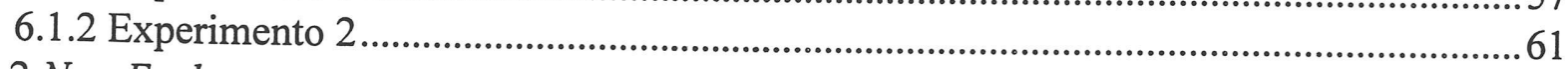

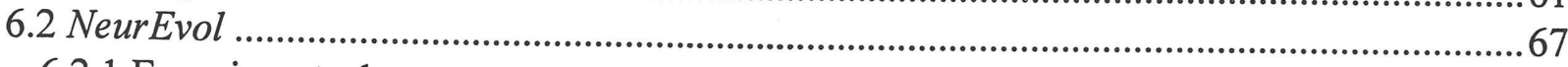

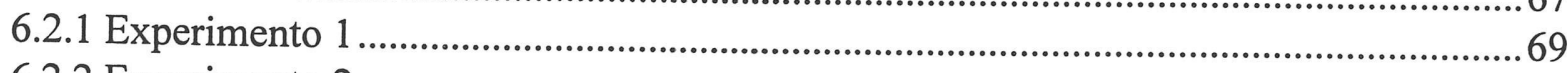

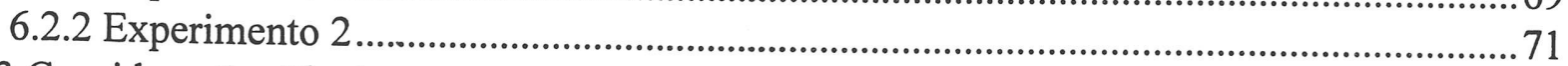

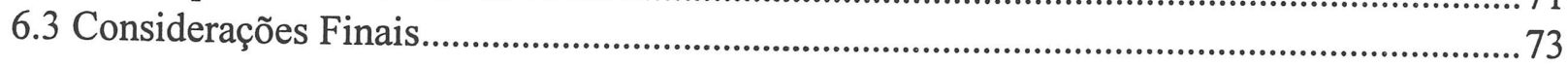

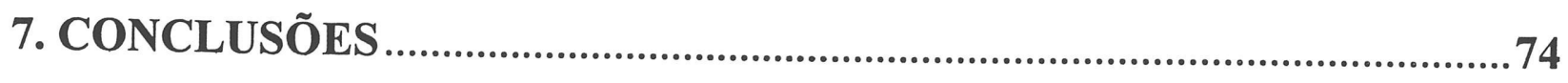

7.1 Considerações ...................................................................................................... 74

7.2 Contribuições deste Trabalho .................................................................................. 75

7.3 Propostas para Trabalhos Futuros ................................................................................ 77

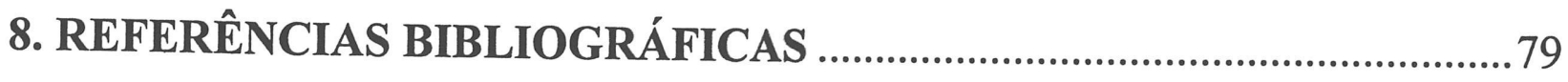




\section{LISTA DE FIGURAS}

FIGURA 1 - Célula neuronal

FIGURA 2 - Esquema de unidade McCullock - Pitts

FIGURA 3 - Organização em camadas 10

FIGURA 4 - Esquema de treinamento do Perceptron 12

FIGURA 5 - Funções de ativação 12

FIGURA 6 - Treinamento de uma unidade com função sigmoid 13

FIGURA 7 - Backpropagation 15

FIGURA 8 - Esquema de treinamento backpropagation

FIGURA 9 - Exemplo de superfície de erro

FIGURA 10 - Superfície de erro e treinamento backpropagation

FIGURA 11 - Utilização da rede MLP

FIGURA 12 - Indivíduos de uma população e a sua correspondente roleta de seleção

FIGURA 13 - Um algoritmo genético

FIGURA 14 - Exemplo de mutação

FIGURA 15 - Um exemplo de cruzamento de um ponto

FIGURA 16 - Processos da abordagem evolucionária para projeto de arquiteturas neurais 37

FIGURA 17 - Exemplo de representação direta 38

FIGURA 18 - Exemplo de representação indireta. 40

FIGURA 19 - Exemplo da representação utilizada 41

FIGURA 20 - Um exemplo de seleção pelo método da roleta 44

FIGURA 21 - Exemplo do operador de cruzamento utilizado 45

FIGURA 22 - Caso especial de cruzamento que pode gerar uma arquitetura inválida .45

FIGURA 23 - Exemplo do operador de mutação utilizado .46

FIGURA 24 - Caso especial de mutação que pode gerar uma arquitetura inválida .46

FIGURA 25 - Modelo de integração de módulos do NeurAval 
FIGURA 26 - Um modelo básico de proposta de cartão de crédito ............................................58

FIGURA 27 - Gráfico de erro de treinamento e validação........................................................60

FIGURA 28 - Informações sobre uma transação de crédito.....................................................662

FIGURA 29 - Exemplo de um padrão resultante do pré-processamento ....................................62

FIGURA 30 - Efeito dos parâmetros e da arquitetura ...........................................................64

FIGURA 31 - Gráfico de erro (EQM) de treinamento e validação ..............................................64

FIGURA 32 - Esquema de funcionamento e módulos do NeurEvol ..........................................68

FIGURA 33 - Evolução do melhor indivíduo durante as 10 gerações do Experimento 1 ...........69

FIGURA 34 - Evolução da média da população durante as 10 gerações do Experimento 1 .......70

FIGURA 35 - Evolução do melhor indivíduo durante as 10 gerações do Experimento 2 ........... 72

FIGURA 36 - Evolução da média da população durante as 10 gerações do Experimento 2 .......72 


\section{LISTA DE TABELAS}

TABELA 1 - Separação dos dados em conjuntos - Experimento 1............................................59

TABELA 2 - Resultados nos conjuntos de dados ............................................................5

TABELA 3 - Resultados dos Modelos ............................................................................60

TABELA 4 - Separação dos dados em conjuntos - Experimento 2 ...........................................63

TABELA 5 - Desempenho das redes nos testes ...............................................................65

TABELA 6 - Resultados do Teste 2 separados por classes .....................................................65

TABELA 7 - Matriz de custos de padrões classificados erradamente.........................................66

TABELA 8 - Resultados do Experimento 2 × Análise Discriminante .......................................66

TABELA 9 - Resultados (MPPEC) nos conjuntos de dados do Experimento 1.......................... 70

TABELA 10 - Resultados (Custos) nos conjuntos de dados do Experimento 1.......................... 70

TABELA 11 - Resultados (MPPEC) nos conjuntos de dados do Experimento 2........................ 73

TABELA 12 - Resultados (Custos) nos conjuntos de dados do Experimento 2. ......................... 73 


\section{RESUMO}

MENDES, E.F.F. (1997). Projeto Evolucionário de Redes Neurais Artificiais para Avaliação de Crédito Financeiro. São Carlos, 1997. 85 p. Dissertação (Mestrado) - Instituto de Ciências Matemáticas de São Carlos, Universidade de São Paulo.

O risco de crédito a pessoas físicas tem sido avaliado empiricamente ou por sistemas de credit score. No entanto, com o crescimento do mercado de crédito ao varejo, o assunto passou a merecer maior preocupação em razão da elevação das taxas de inadimplência, que vem causando enormes prejuízos aos doadores de recursos.

Redes Neurais Artificiais (RNA) podem ser treinadas utilizando grandes quantidades de exemplos significativos. Utilizando esta técnica, as avaliações podem ser modeladas através de exemplos encontrados nos históricos dos clientes das aplicações de crédito.

Contudo, a topologia e os parâmetros de aprendizado das RNA precisam ser apropriadamente estabelecidos para que a rede funcione eficientemente. Para resolver este tipo de problema, recentemente vêm sendo utilizados Algoritmos Genéticos (AG), algoritmos baseados em mecanismos genéticos e de seleção natural, que podem ser utilizados para encontrar as arquiteturas mais eficientes.

O objetivo deste projeto é investigar como o projeto de RNA pode se beneficiar de AG para a determinação de sua arquitetura e o comportamento de RNA como técnica para análise de risco crédito financeiro.

Para avaliar os modelos desenvolvidos, foram utilizados dois conjuntos de dados diferentes, compostos de informações sobre aplicações reais de crédito. O primeiro deles é constituído por dados de aplicações de cartão de crédito, cujo objetivo do modelo é "imitar" a avaliação humana. O segundo é constituído por dados de clientes de crédito bancário e seus históricos de pagamento com o objetivo de prever o comportamento de futuros clientes.

Palavras-chave: Redes Neurais, Algoritmos Genéticos, Crédito, Finanças. 


\section{ABSTRACT}

MENDES, E.F.F. (1997). Evolutionary Design of Artificial Neural Networks for Credit Evaluation. São Carlos, 1997. 85 p. Dissertação (Mestrado) - Instituto de Ciências Matemáticas de São Carlos, Universidade de São Paulo.

he risk of credit evaluation has been estimated empirically or through credit score systems. However, with the growth of the massive credit market, this activity attracted more attention, mainly due to the increase of indebt rates, which has occasioned large losses to the donors of the resources.

Artificial Neural Networks (ANN) can be trained using a very large quantity of significant examples. Using this technique, the credit evaluation can be modeled through the examples found in the historical data of the credit applicants.

Nevertheless, the topology and the learning parameters of ANNs must be adequately set for an efficient performance to be achieved. Recently Genetic Algorithms (GA) have been proposed to overcome these problems. These algorithms are based on natural selection and genetic mechanisms, that can be used to find adequate neural architectures.

The objectives of this work is to investigate how the ANN design can benefit from the use of GA to the determination of its architecture and the behavior of ANN as a tool for financial credit analysis.

To evaluate the models developed two different data sets, composed by real information about credit applications, were used. The first of these data sets is composed by data from credit card applications, whose purpose is to imitate the human evaluation. The second data set is composed by information about banking credit customers and their payment historical data. Its purpose is to predict the behavioral of new customers.

Keyworks: Neural Networks, Genetic Algorithms, Credit, Finance. 


\section{Introdução}

Nas últimas décadas, a área de Inteligência Artificial tem progredido rapidamente em suas pesquisas sobre o raciocínio humano e sua aplicação em sistemas computacionais, que podem solucionar problemas complexos e se adaptar a novas situações. Dentro desta área, temos o conexionismo, que estuda os sistemas neurais biológicos com o objetivo de projetar sistemas computacionais, inspirados no funcionamento do cérebro, através de Redes Neurais Artificiais. Atualmente, Redes Neurais Artificiais estão sendo utilizadas em diversos sistemas computacionais e vêm apresentando sucesso em um grande número de aplicações.

Entre as áreas que têm usufruído desta tecnologia está a área financeira. A crescente automação de atividades comerciais e bancárias requer a utilização de tecnologias cada vez mais sofisticadas. Como consequência, o mercado financeiro está sempre buscando novas técnicas computacionais que satisfaçam suas necessidades mais refinadas. Entre estas técnicas estão Redes Neurais Artificiais.

Uma aplicação na qual esta técnica pode ser bem sucedida é em um sistema para auxílio à decisão na gestão de crédito financeiro. Um dos módulos desse sistema consistituir-se-ia de uma Rede Neural, treinada com dados representativos deste problema. A rede poderia ser utilizada, por exemplo para sugerir a aprovação, ou não, de uma solicitação de crédito, ou avaliar o risco de uma operação.

Com este trabalho, busca-se analisar as características das Redes Neurais Artificiais que utilizam algoritmos de aprendizado do tipo backpropagation; como essas redes podem se beneficiar de Algoritmos Genéticos para definição de sua arquitetura; e de que maneira estas técnicas podem ser utilizadas em aplicações reais. Ou seja, todos os aspectos que envolvem a construção de um sistema inteligente de avaliação de crédito.

Nas próximas seções serão apresentadas as características das áreas de pesquisa deste projeto: Redes Neurais Artificiais e Algoritmos Genéticos, as características da área da aplicação desenvolvida: Avaliação de Crédito Financeiro; os objetivos pretendidos com esta dissertação; e finalmente, a organização deste trabalho. 


\subsection{Caracterização da Área}

Segundo os autores dos principais livros da área de Inteligência Artificial, RICH \& KNIGHT (1991); WINSTON (1992); GINSBERG (1992), existem, atualmente, dois grandes objetivos nas pesquisas realizadas nas diversas subáreas de Inteligência Artificial. O primeiro é cientifico, no qual pesquisadores procuram entender a natureza da inteligência e do raciocínio humano. O segundo é tecnológico, no qual pesquisadores procuram criar modelos inteligentes que realizam tarefas práticas, desenvolvendo sistemas computacionais que possam resolver problemas complexos e se adaptar a novas situações.

Estes objetivos são muito evidentes dentro dos paradigmas que envolvem o Aprendizado de Máquina. Segundo CARBONELL (1989), existem atualmente muitos projetos de pesquisa explorando os métodos de aprendizado de máquina, muitos enfocando a teoria de aprendizado e outros sendo empregados para melhorar o desempenho na solução de problemas em domínios complexos. CARBONELL (1989) também identifica os quatro maiores paradigmas do aprendizado de máquina, cada um com múltiplos subparadigmas, sendo investigados atualmente:

\section{- Aprendizado Indutivo (ex. aquisição de conceitos através de exemplos positivos e negativos) \\ - Aprendizado Analítico (ex. aprendizado baseado em explicação e certas formas de aprendizado analógico e baseado em casos)}

- Algoritmos Evolucionários (ex. algoritmos genéticos, sistemas classificadores, programação genética)

\section{- Conexionismo (ex. redes neurais artificiais)}

Estes paradigmas emergiram de diferentes raízes científicas e empregam diferentes métodos computacionais, embora compartilhem do mesmo objetivo, construir máquinas capazes de aprender a solucionar problemas ou resolver tarefas em uma grande variedade de domínios.

Conexionismo é um paradigma de Aprendizado de Máquina que se reporta aos dois objetivos: estuda a cognição humana, procurando entender os mecanismos cerebrais de aprendizado e aplicação de conhecimentos, mas também é uma nova tecnologia de construção de sistemas computacionais, utilizando Redes Neurais Artificiais que podem resolver problemas até então considerados intratáveis pelos sistemas tradicionais.

As Redes Neurais Artificiais são modelos de processamento de informação inspirados numa estrutura física natural, o cérebro humano, e motivadas pelos recentes progressos da neurociência no estudo sobre o sistema nervoso, principalmente o cérebro. Estes modelos não pretendem replicar a operação do cérebro humano, apenas utilizam como inspiração fatores conhecidos sobre o seu funcionamento. 
Redes Neurais Artificiais são sistemas inerentemente paralelos e distribuídos, compostos por unidades de processamento simples (neurônios) que computam certas funções matemáticas. Estas unidades podem estar dispostas em estruturas interligadas por um grande número de conexões (sinapses). Geralmente estas conexões estão associadas a pesos, os quais armazenam o conhecimento representado no modelo e servem para ponderar a entrada recebida por cada unidade da rede.

Existem várias classes diferentes de Redes Neurais que podem ser identificadas principalmente em relação à sua arquitetura e à forma como os pesos, associados às suas conexões, são ajustados durante o processo de aprendizado. É nesta característica que se observa uma das maiores qualidades desta abordagem: a capacidade de aprender através de exemplos e de generalizar sobre os padrões das classes de treinamento, tornando possível o reconhecimento de outros padrões similares, mas não necessariamente idênticos aos utilizados durante o aprendizado.

Atualmente, muitos estudos vêm sendo realizados para a utilização de Redes Neurais Artificiais em tarefas práticas, nas quais as abordagens computacionais tradicionais não vêm obtendo bons resultados. Entre estas tarefas podem ser citados:

- Reconhecimento de Padrões

- Processamento de Sinais

- Controle de Processos

- Otimização

- Previsão

Redes Neurais Artificiais têm propriedades particulares muito interessantes, como capacidade de se adaptar ou aprender, de generalizar e de agrupar ou organizar dados. Por isso, são mais apropriadas em aplicações nas quais:

- É necessário capturar associações ou descobrir regularidades num conjunto de padrões;

- O volume, número de variáveis ou a diversidade dos dados são muito grandes;

- As relações não são claramente compreendidas;

- Descrições adequadas das relações são de difícil obtenção através de métodos convencionais.

A área de Redes Neurais Artificiais vem vivenciando um rápido crescimento e recebendo grande atenção por parte da mídia e em conferências técnicas. Muitos sistemas computacionais vêm sendo implementados utilizando Redes Neurais em aplicações nas mais diversas áreas, tais como: engenharia, medicina, biologia, sociologia, linguística, finanças, administração. E um grande número de trabalhos têm sido apresentados nos mais importantes congressos desta área: IEEE INTERNATIONAL CONFERENCE ON NEURAL NETWORKS (1994); II SIMPÓSIO 


\section{BRASILEIRO DE REDES NEURAIS (1995); III SIMPÓSIO BRASILEIRO DE REDES NEURAIS (1996).}

No projeto de Redes Neurais, vários parâmetros precisam ser apropriadamente estabelecidos para que a rede funcione eficientemente, por exemplo: taxas de aprendizado, número de camadas, número de neurônios nas camadas intermediárias, funções de ativação utilizadas, etc.

A determinação destes parâmetros não é uma tarefa fácil, uma vez que diferentes aplicações podem requerer diferentes valores. As abordagens usualmente utilizadas para a realização desta tarefa apresentam custos muito elevados e não garantem que um conjunto de paramêtros ótimo seja encontrado. Para resolver este tipo de problema, recentemente vêm sendo utilizadas abordagens evolucionárias, como heurística de busca de arquiteturas neurais adequadas.

Esta abordagem utiliza Algoritmos Genéticos, que são algoritmos de busca baseados em mecanismos genéticos e de seleção natural. Esta técnica, desenvolvida por HOLLAND (1975), procura produzir os melhores indivíduos de uma espécie, baseada em um dado critério, a partir de um conjunto inicial de indivíduos.

Um algoritmo genético pode ser utilizado para encontrar arquiteturas de Redes Neurais eficientes automaticamente, eliminando muitas armadilhas associadas às abordagens de engenharia humana. Neste caso, cada indivíduo poderia ser visto como uma particular arquitetura neural do espaço de possíveis Redes Neurais.

\section{2 Área de Aplicação}

A área de Finanças sempre teve grande interesse em aplicações da Inteligência Computacional, como mostram APTÉ \& KASTNER (1987); TRELEAVEN \& GONNATILAKE (1992). Sistemas especialistas de suporte a decisões financeiras vêm sendo utilizados com sucesso já há algum tempo. Estes sistemas tratam eficientemente os ambientes de decisões estáticas e estruturadas. Mas o processo de extração de conhecimento, através de especialistas de uma determinada área, e a construção de bases de conhecimento, utilizando regras, demandam muito tempo e têm um custo elevado. Além disso, estes sistemas podem apresentar um tempo de vida útil muito curto, já que a maioria dos ambientes financeiros apresentam um comportamento dinâmico.

$\mathrm{Na}$ maioria dos ambientes de decisão financeira, utiliza-se uma enorme gama de informações vindas das mais diversas fontes, que podem apresentar diversos tipos de problemas. Os gerentes financeiros analisam estas informações de forma subjetiva e dificilmente conseguem formalizar os seus processos de decisão. Além disso, estes ambientes são dinâmicos, com constantes alterações, e as decisões devem ser tomadas rapidamente.

Os sistemas neurais oferecem uma nova alternativa para tratar informações dessa natureza, uma vez que são de utilização rápida, podem ser modificados mais facilmente que sistemas convencionais e são, geralmente, mais simples que os métodos convencionais na modelagem de 
sistemas não lineares. Segundo MEDSKER et. al. (1996), estas características lhes dá uma grande vantagem sobre vários métodos atualmente utilizados em economia e finanças.

MEDSKER et. al. (1996) ainda afirmam que os sistemas neurais de suporte a decisões da área financeira mais promissores são:

- Projeção de autorização de crédito;

- Avaliação de risco de hipoteca;

- Gerenciamento de projetos e estratégias de oferta;

- Previsão econômica e financeira;

- Avaliação de risco de investimentos;

- Detecção de regularidades nos movimentos de preços;

- Previsão de falência;

- Simulação de comportamento de mercado;

- Identificação de fatores econômicos explicativos.

A projeção de autorização de crédito pode ocorrer em diversas modalidades de aplicação, tais como: solicitação de cartão de crédito, crediário ou cheque especial, autorização de compra e empréstimos bancários. Para todas estas modalidades, os dados relativos à operação são avaliados para se decidir quanto à aceitação ou rejeição da determinada aplicação. Esta é uma tarefa muito dispendiosa, demorada e que tem um grande impacto nos lucros da maioria das empresas. As decisões devem ser muito rápidas e criteriosas.

Para a solução deste tipo de problema, podem ser utilizados sistemas neurais para auxílio à decisão na gestão de crédito financeiro, nos quais Redes Neurais treinadas com padrões exemplares (dados das operações de crédito efetuadas anteriormente, com os seus respectivos resultados de avaliação) representativos das diversas classes da avaliação seriam utilizadas para classificar novos padrões (dados de novas operações a serem avaliadas).

\subsection{Objetivos}

O objetivo deste projeto é investigar como o projeto de sistemas neurais pode se beneficiar de Algoritmos Genéticos para a determinação de sua arquitetura (topologia da rede e parâmetros de aprendizado), levando ao projeto evolucionário de arquiteturas neurais, e analisar o comportamento de Redes Neurais Artificiais como técnica para avaliação de crédito financeiro.

Para analisar o modelo desenvolvido, foi utilizado primeiramente um conjunto de dados para benchmark de algoritmos de aprendizado, compostos de aplicações reais para cartões de crédito junto com a decisão tomada pela instituição bancária (ou instituição semelhante), obtidos do 
conjunto de bases de dados para aprendizado de máquina da UCI, University of California, Irvine, organizados por MURPHY \& AHA (1994).

Posteriormente, foi utilizado um conjunto de dados de um banco estadual brasileiro, compostos de aplicações reais de crédito bancário junto com o histórico de adimplência destas aplicações. Estes dados foram obtidos junto ao Centro de Pesquisas em Crédito e Banking, da Faculdade de Economia e Administração, da Universidade de São Paulo.

Durante o andamento deste projeto, foram criadas e utilizadas ferramentas para coleta e préprocessamento de dados; sistemas simuladores para o projeto e treinamento das redes; ferramentas de diagnóstico para validação e teste; e ambientes evolucionários, para a otimização das redes. Também foi implementado um protótipo de um sistema de avaliação de crédito financeiro e um protótipo de um sistema evolucionário de arquiteturas neurais.

\subsection{Organização deste Trabalho}

Este trabalho está organizado em capítulos que cobrem cada uma das partes deste projeto, como segue:

No Capítulo 2 são apresentados os conceitos básicos e as características gerais das Redes Neurais Artificiais, com atenção especial às Redes Perceptron Multicamadas. Neste mesmo capítulo é descrita a metodologia de desenvolvimento de aplicações utilizando esta abordagem.

No Capítulo 3 são apresentadas as principais características dos Algoritmos Genéticos como método de busca e otimização.

No Capítulo 4 são analisados as motivações e os principais aspectos que envolvem o projeto evolucionário de arquiteturas neurais.

No Capítulo 5 é apresentado o problema de avaliação de crédito, são analisadas as abordagens existentes e é proposto um sistema neural para o seu modelamento.

No Capítulo 6 são apresentadas as metodologias utilizadas na construção dos protótipos e nos experimentos realizados, além de discussões sobre os resultados obtidos nos experimentos.

No Capítulo 7 são apresentadas as conclusões e propostas para trabalhos futuros.

E, finalmente, no Capítulo 8, é apresentada a bibliografia utilizada neste trabalho. 


\section{Redes Neurais Artificiais}

\subsection{Introdução}

Redes Neurais Artificiais são técnicas computacionais que apresentam um modelo matemático inspirado no sistema nervoso e que adquirem conhecimento através da experiência. Uma grande rede neural artificial pode ter centenas ou milhares de unidades de processamento; já o cérebro de um mamífero pode ter muitos bilhões de neurônios, como afirma LLINÁS (1989).

O sistema nervoso é formado por um conjunto extremamente complexo de células, os neurônios. Segundo EIMÁS \& GALABURDA (1990), os neurônios têm um papel essencial na determinação do funcionamento e comportamento do corpo humano e da mente. Os neurônios são formados pelos dendritos, que são um conjunto de terminais de entrada, pelo corpo central, e pelos axônios, que são longos terminais de saída, conforme pode ser visto na FIGURA 1.

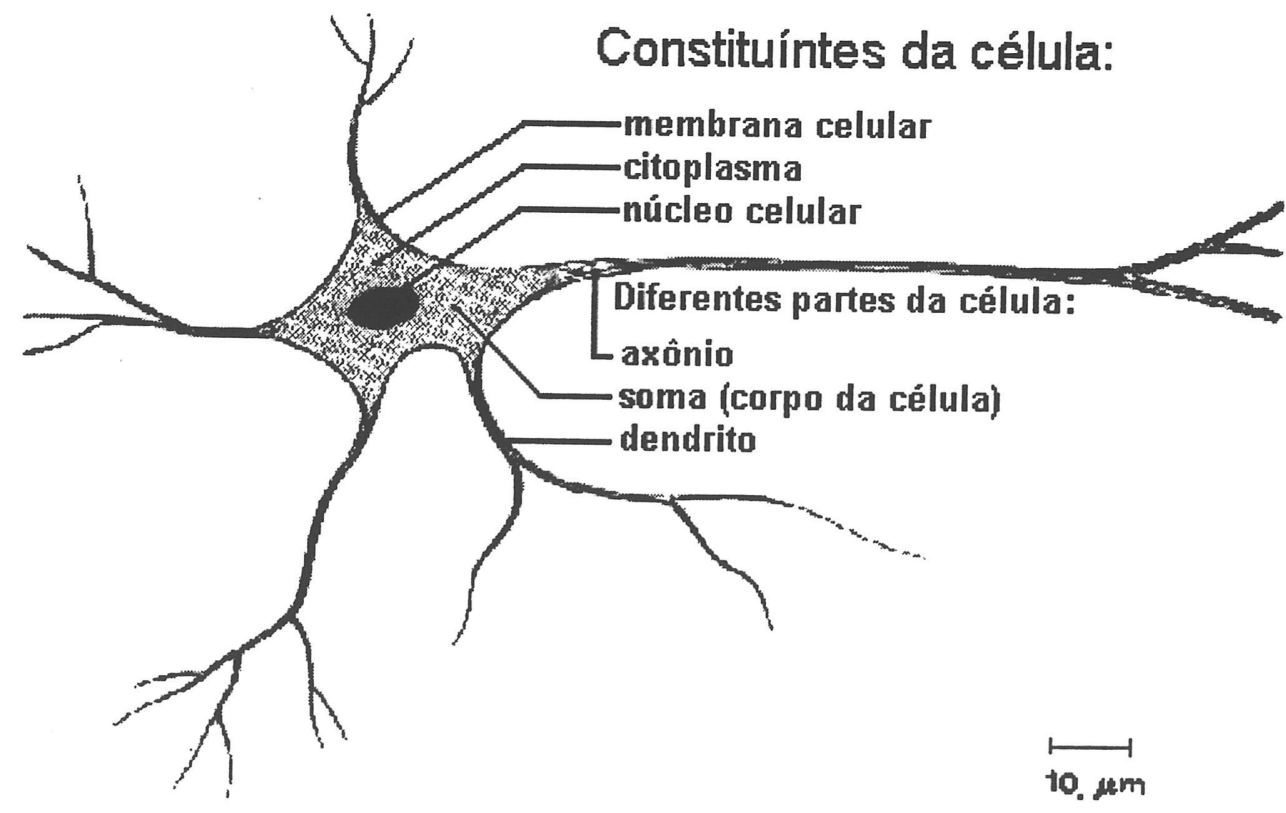

FIGURA 1 - Célula neuronal. 
Os neurônios se comunicam através de sinapses. Sinapse é a região onde dois neurônios entram em contato e através da qual os impulsos nervosos são transmitidos entre eles. Os impulsos recebidos por um neurônio $A$, em um determinado momento, são processados e, após atingir um dado limiar de ação, o neurônio $A$ dispara, produzindo uma substância neurotransmissora que flui do corpo celular para o axônio, que pode estar conectado a um dendrito de um outro neurônio $B$. O neurotransmissor pode diminuir ou aumentar a polaridade da membrana pós-sináptica, inibindo ou excitando a geração dos pulsos no neurônio $B$. Este processo depende de vários fatores, como a geometria da sinapse e o tipo de neurotransmissor.

Em média, cada neurônio forma entre mil e dez mil sinapses. O cérebro humano possui cerca de $10^{11}$ neurônios e o número total de sinapses é de mais de $10^{14}$, possibilitando a formação de redes muito complexas.

\subsubsection{Um Breve Histórico}

Um histórico resumido sobre Redes Neurais Artificiais deve começar por três das mais importantes publicações iniciais, MCCULLOCK \& PITTS (1943), que apresentou o primeiro modelo de Redes Neurais simulando "máquinas", HEBB (1949), que introduziu o modelo básico de rede de auto-organização e ROSENBLATT (1958), que apresentou o modelo Perceptron de aprendizado supervisionado.

Alguns históricos sobre as pesquisas na área costumam esquecer os anos 60 e 70 e apontar um reínicio do interesse na área com a publicação dos trabalhos: HOPFIELD (1982), relatando a utilização de redes simétricas para otimização, e RUMELHART et. al. (1986), que introduziu uma técnica de treinamento para redes com mais de uma camada, o algorítmo Backpropagation.

Entretanto, para se ter um histórico completo, devem ser citados alguns pesquisadores que realizaram, nos anos 60 e 70, importantes trabalhos sobre modelos de Redes Neurais em visão, memória, controle e auto-organização, como: Amari, Anderson, Cooper, Cowan, Fukushima, Grossberg, Kohonen, von der Malsburg, Werbos e Widrow, vide ARBIB (1995).

\subsubsection{Características Gerais das Redes Neurais}

Uma Rede Neural Artificial é composta por várias unidades de processamento, cujo funcionamento é bastante simples. Essas unidades geralmente são conectadas por canais de comunicação que estão associados a determinados pesos. As unidades executam operações apenas sobre seus dados locais, que são entradas recebidas pelas suas conexões. O comportamento "inteligente" de uma Rede Neural Artificial vem das interações entre as suas unidades de processamento. 
A operação de uma unidade de processamento, baseada no modelo proposto por MCCULLOCK \& PITTS (1943), ver FIGURA 2, pode ser resumida da seguinte maneira:

- sinais são apresentados à entrada.

- cada sinal é multiplicado por um valor, ou peso, que indica a sua influência na saída da unidade.

- é realizada a soma ponderada dos sinais que produz um nível de atividade.

- se este nível de atividade exceder um certo limite (threshold) a unidade produz uma saída igual a 1 ; caso contrário, a saída será igual a 0 .

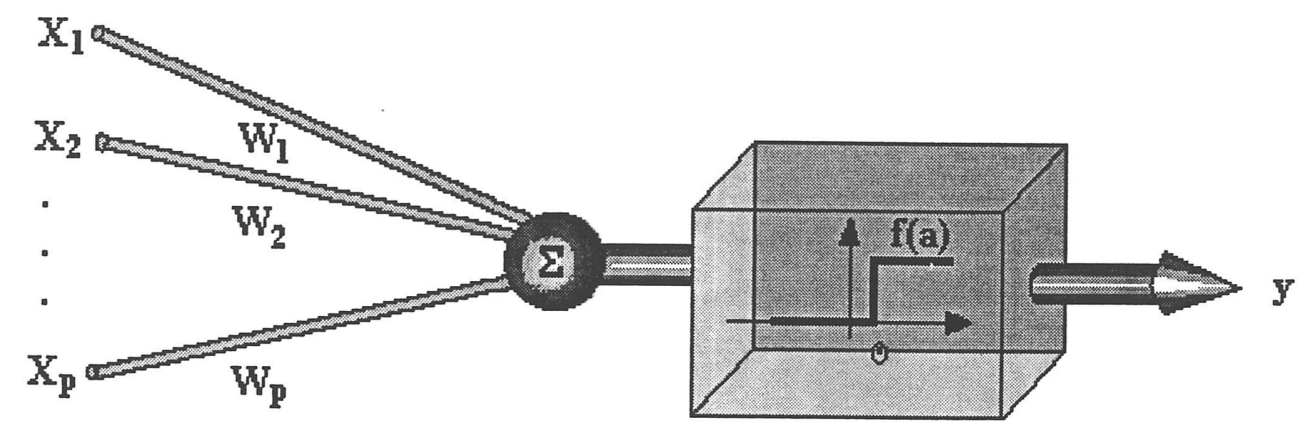

FIGURA 2 - Esquema de unidade McCullock - Pitts.

Para formalizar o funcionamento deste modelo, suponha que existam $p$ sinais de entrada $X_{1}$, $X_{2}, \ldots, X_{p}, p$ pesos $w_{1}, w_{2}, \ldots, w_{p}$ e um limitador $\theta$, com sinais assumindo valores binários $(0$ ou $1)$ e pesos assumindo valores reais.

Neste modelo, o nível de atividade $a$ é dado pela eq. (1) e a saída $y$ é dada pela eq. (2).

$$
\begin{gathered}
a=\sum_{i=1}^{p} w_{i} . X_{i} \\
y=\left\{\begin{array}{l}
1 \text { se } a>\theta \\
0 \text { se } a \leq \theta
\end{array}\right.
\end{gathered}
$$

A maioria dos modelos de Redes Neurais possui alguma regra de treinamento, pela qual pesos de suas conexões são ajustados de acordo com os padrões apresentados. Em outras palavras, elas aprendem através de exemplos. Redes Neurais têm um grande potencial de paralelismo e, em seu funcionamento, os cálculos realizados por uma unidade dependem apenas dos cálculos feitos pelas unidades antecessoras.

Ao invés de executar um programa de instruções sequenciais, como num computador de Von Neumann, uma Rede Neural responde às entradas que lhe são apresentadas em paralelo. Os 
resultados não são armazenados em uma determinada posição de memória, mas são dados pelo estado geral da rede. Assim, o conhecimento está na forma com que as unidades estão interconectadas e na importância (peso) de cada entrada em uma determinada unidade.

Topologias neurais são tipicamente organizadas em camadas, com unidades que podem estar conectadas às unidades da camada posterior, como é ilustrado na FIGURA 3. Usualmente as camadas são classificadas em três grupos:

- Camada de Entrada: onde os padrões são apresentados à rede;

- Camadas Intermediárias ou Escondidas: onde é feita a maior parte do processamento, através das conexões ponderadas; podem ser consideradas como extratoras de características.

- Camada de Saída: onde o resultado final é definido e apresentado.

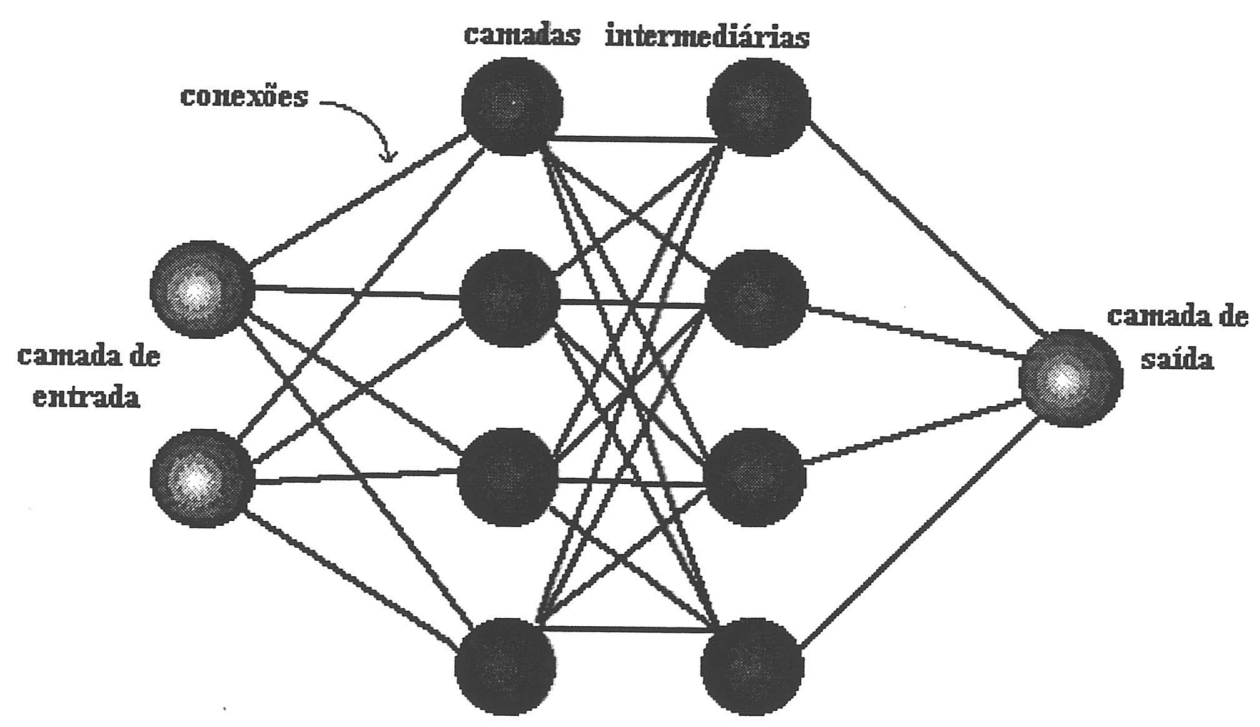

FIGURA 3 - Organização em camadas.

Uma Rede Neural é especificada, principalmente pela sua topologia, pelas características dos nós, pelas regras de treinamento e parâmetros de treinamento. A seguir, serão analisados os processos de aprendizado.

\subsubsection{Processos de Aprendizado}

A propriedade mais importante das Redes Neurais é a habilidade de aprender de seu ambiente e, com isso, melhorar seu desempenho. Isso é feito através de um processo iterativo de ajustes aplicados a seus pesos, o treinamento. $\mathrm{O}$ aprendizado ocorre quando a rede neural atinge uma solução generalizada para um dado problema. 
Denomina-se algoritmo de aprendizado um conjunto de regras bem definidas para a solução de um problema de aprendizado. Existem muitos tipos de algoritmos de aprendizado específicos para determinados modelos de Redes Neurais. Estes algoritmos diferem entre si principalmente pelo modo como os pesos são modificados.

Outro fator importante é a maneira pela qual uma rede neural se relaciona com o ambiente. Nesse contexto, existem os seguintes paradigmas de aprendizado:

- Aprendizado Supervisionado, quando é utilizado um agente externo que indica à rede a resposta desejada para o padrão de entrada;

- Aprendizado Não Supervisionado (auto-organização), quando não existe um agente externo indicando a resposta desejada para os padrões de entrada;

- Reforço, quando um crítico externo avalia a resposta fornecida pela rede.

O Aprendizado geralmente ocorre através de ciclos iterativos de treinamanto. Denomina-se ciclo uma apresentação de todos os $N$ pares (entrada e saída) do conjunto de treinamento no processo de aprendizado. A correção dos pesos em um ciclo pode ser executado de dois modos:

1) Modo Padrão: A correção dos pesos acontece a cada apresentação à rede de um exemplo do conjunto de treinamento. Cada correção de pesos baseia-se somente no erro do exemplo apresentado naquela iteração. Assim, em cada ciclo ocorrem $N$ correções.

2) Modo Batch: Apenas uma correção é feita por ciclo. Todos os exemplos do conjunto de treinamento são apresentados à rede, seu erro médio é calculado e, a partir deste erro, fazemse as correções dos pesos.

Neste trabalho foi utilizado o paradigma de aprendizado supervisionado devido às características inerentes do problema de avaliação de crédito. O modelo de redes escolhido foi o Perceptron Multicamadas e o algoritmo Backpropagation de correção do erro, por se tratar do modelo mais utilizado atualmente e por ser adequado para o projeto evolucionário de arquiteturas neurais. Os dois modos de atualização foram analisados.

A seguir, será analisado o treinamento supervisionado de uma unidade Perceptron de uma só camada.

\subsubsection{Treinamento Supervisionado}

O treinamento supervisionado do modelo de rede Perceptron consiste em ajustar os pesos e os thresholds de suas unidades para que a classificação desejada seja obtida. Para a adaptação do threshold juntamente com os pesos, podemos considerá-lo como sendo o peso associado a uma conexão, cuja entrada é sempre igual a -1 e adaptar o peso relativo a essa entrada. Quando um padrão é inicialmente apresentado à rede, ela produz uma saída. Se a saída da rede for diferente 
da resposta desejada, são realizados os ajustes apropriados nos pesos das conexões, de modo a reduzir este erro Este procedimento é conhecido como Regra Delta e foi introduzido por ROSENBLATT (1958).

Deste modo, temos o seguinte esquema de treinamento, FIGURA 4:

Iniciar todas as conexões com pesos aleatórios;

Repita até que o erro $E$ seja satisfatoriamente pequeno $(E=\varepsilon)$

Para cada par de treinamento $(\mathbf{X}, \mathbf{d})$, faça:

Calcular a resposta obtida $\mathbf{O}$;

Calcular o erro $\mathbf{E}=\mathbf{O}$ - d;

Se o erro não for satisfatoriamente pequeno $E>\varepsilon$, então:

Atualizar pesos: $\mathbf{W n o v o}=\mathbf{W}$ anterior $+\eta \mathbf{E X}$;

Nos quais:

O par de treinamento $(\mathbf{X}, \mathbf{d})$ corresponde ao padrão de entrada e a sua respectiva resposta desejada;

O erro E é definido como: Resposta Desejada - Resposta Obtida (d - O);

A taxa de aprendizado $\eta$ é uma constante positiva, que corresponde à velocidade do aprendizado.

FIGURA 4 - Esquema de treinamento do Perceptron.

As respostas geradas são calculadas através de uma função de ativação. Existem vários tipos de função de ativação. As mais utilizadas são: Hard Limiter, Threshold Logic e Sigmoid, mostradas na FIGURA 5. Na FIGURA 6, pode ser visto um esquema de treinamento utilizando uma função de ativação sigmoid.

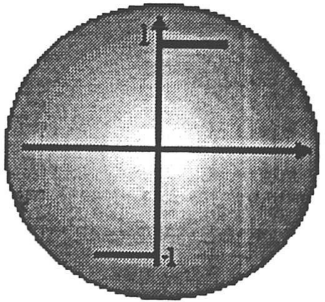

Hard Limiter

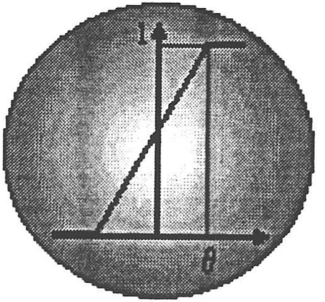

Threshold Logic

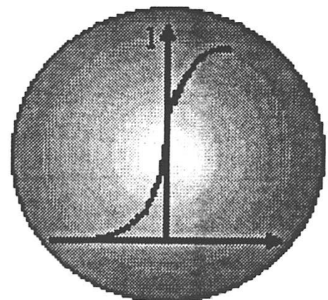

Sigmoid

FIGURA 5 - Funções de ativação. 


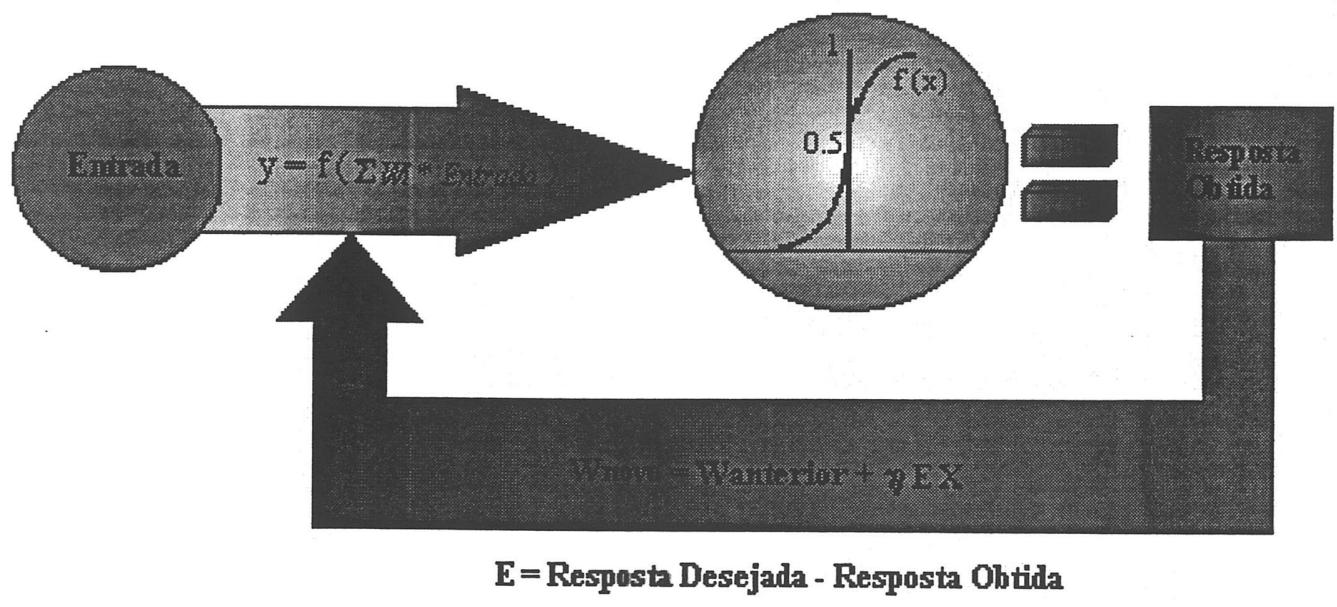

FIGURA 6 - Treinamento de uma unidade com função sigmoid.

Nas próximas seções serão analisadas, em maiores detalhes, as características do modelo de Redes Neurais que será utilizado neste trabalho, o Perceptron Multicamadas (MLP). Serão analisadas também suas limitações e as principais fases do desenvolvimento de aplicações utilizando este modelo.

\subsection{Perceptron Multicamadas}

Quando Redes Neurais Artificiais de uma só camada são utilizadas, os padrões de treinamento apresentados à entrada são mapeados diretamente em um conjunto de padrões de saída da rede, ou seja, não é possível a formação de uma representação interna. Neste caso, como observam RUMELHART et. al. (1986), a codificação proveniente do mundo exterior deve ser suficiente para implementar esse mapeamento.

Tal restrição implica que padrões de entrada similares resultem em padrões de saída similares, o que leva o sistema à incapacidade de aprender importantes mapeamentos. Como resultado, padrões de entrada com estruturas similares, fornecidos do mundo externo, que levem a saídas diferentes não são possíveis de serem mapeados por redes sem representações internas, isto é, sem camadas intermediárias. Um exemplo clássico deste caso é a função ou-exclusivo (XOR).

MINSKY \& PAPERT (1969) analisaram matematicamente o Perceptron e demostraram que redes de uma camada não são capazes de solucionar problemas que não sejam linearmente separáveis. Como não acreditavam na possibilidade de se construir um método de treinamento para redes com mais de uma camada, eles concluíram que as Redes Neurais seriam sempre suscetíveis a essa limitação. 
Contudo, o desenvolvimento do algoritmo de treinamento backpropagation, por Rumelhart, Hinton e Williams em 1986, RUMELHART et. al. (1986), precedido por propostas semelhantes ocorridas nos anos 70 e 80, WERBOS (1974); PARKER (1985), mostrou que é possível treinar eficientemente Redes Neurais com camadas intermediárias, resultando no modelo mais utilizado atualmente, as redes Perceptron Multicamadas (MLP), treinadas com o algoritmo backpropagation.

Nessas redes, cada camada tem uma função específica. A camada de saída recebe os estímulos das camadas intermediárias e constrói o padrão que será a resposta. As camadas intermediárias funcionam como extratoras de características, seus pesos são uma codificação de características apresentadas nos padrões de entrada e permitem que a rede crie sua própria representação, mais rica e complexa, do problema.

Segundo seus autores, se existirem as conexões certas entre as unidades de entrada e um conjunto suficientemente grande de unidades intermediárias, pode-se sempre encontrar a representação que irá produzir o mapeamento correto da entrada para a saída através das unidades intermediárias.

Como provou CYBENKO (1988), a partir de extensões do Teorema de Kolmogoroff, são necessárias no máximo duas camadas intermediárias, com um número suficiente de unidades por camada, para se produzirem quaisquer mapeamentos. Também foi provado por CYBENKO (1989) que apenas uma camada intermediária é suficiente para aproximar qualquer função contínua. No entanto, em problemas muito complexos a utilização de três camadas intermediárias pode facilitar o treinamento ou melhorar a capacidade de generalização das redes MLP.

\subsubsection{Backpropagation}

Durante o treinamento com o algoritmo backpropagation, a rede opera em uma sequência de dois passos, como mostra a FIGURA 7. Primeiro, um padrão é apresentado à camada de entrada da rede. A atividade resultante flui através da rede, camada por camada, até que a resposta seja produzida pela camada de saída. No segundo passo, a saída obtida é comparada à saída desejada para esse padrão particular. Se estas não forem iguais, o erro é calculado. O erro é propagado a partir da camada de saída até a camada de entrada. Os pesos das conexões das unidades da camada de saída e das camadas intermediárias vão sendo modificados conforme o erro é retropropagado. A FIGURA 8 apresenta o algoritmo de treinamento backpropagation. 


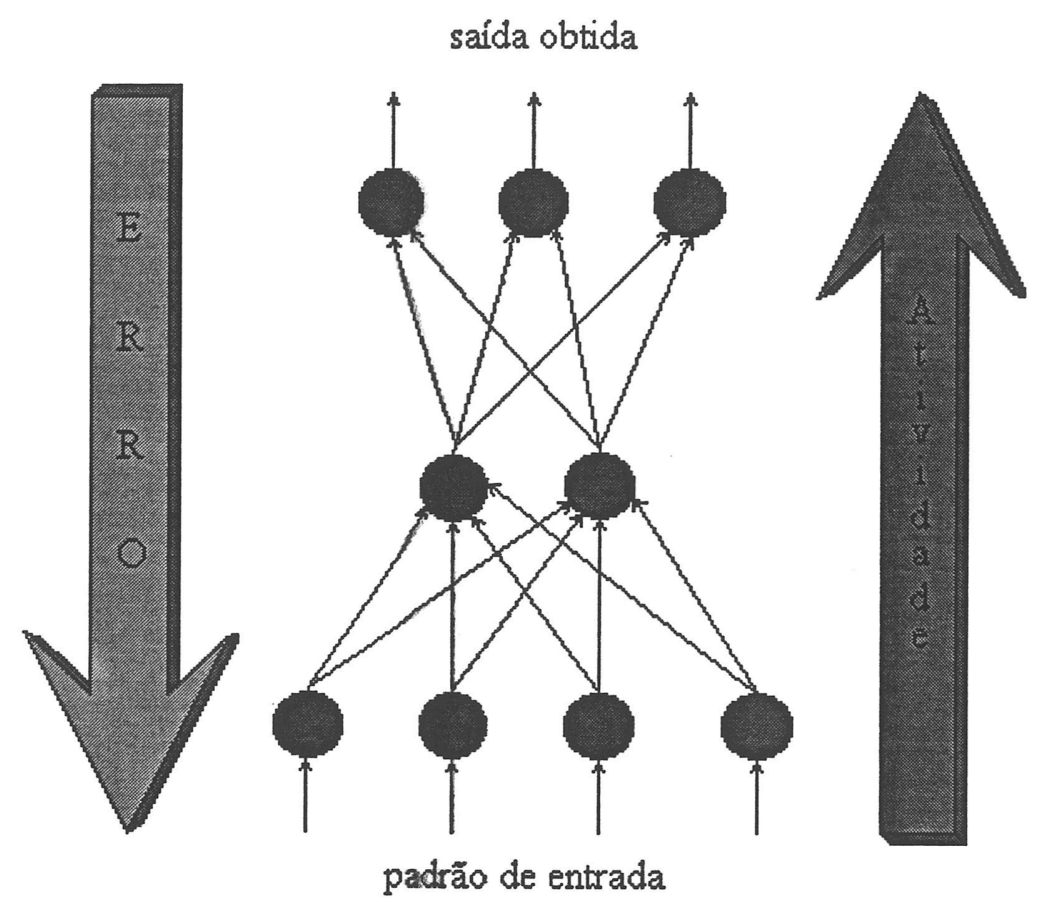

FIGURA 7 - Backpropagation.

Iniciar todas as conexões com pesos aleatórios;

Repita até que o erro seja satisfatoriamente pequeno $($ erro $<\varepsilon)$

Para cada par de treinamento $(X, d)$ faça :

Para $j$ de 1 a num-cam e

Para $i$ de 1 a num-neu, faça:

Calcular $\boldsymbol{o}_{\text {II }}$

Para $i$ de 1 a num-neu num-cam $_{\text {faça: }}$

Calcular o erro: erro $=$ erro $+\frac{1 / 2}{2}\left(d_{1}-0_{\text {I num-cam }}\right)^{2}$;

Se não for satisfatório (erro $>\varepsilon$ ) então:

Para $j$ de num-cam a $1 \mathrm{e}$

Para $i$ de 1 a num-neu, faça:

Atualizar pesos do neurônio $\mathbf{n}_{\|}$

Nos quais:

num-neu ${ }_{j}$ : número de neurônios da camada $j$

num-cam : número de camadas da rede

$o_{i i}$ : saída obtida pelo $i$-ésimo neurônio da j-ésima camada

$d_{i}$ : saída desejada para o iésimo neurônio da última camada.

FIGURA 8 - Esquema de treinamento Backpropagation.

As redes que utilizam backpropagation trabalham com uma variação da regra delta, apropriada para redes com múltiplas camadas: a regra delta generalizada. A regra delta padrão essencialmente implementa um gradiente descendente no quadrado da soma do erro para funções 
de ativação lineares. Redes sem camadas intermediárias podem resolver problemas nos quais a superfície de erro tem a forma de um parabolóide com apenas um mínimo.

Entretanto, a superfície do erro pode não ser tão simples, como a ilustrada na FIGURA 9, e suas derivadas mais difíceis de serem calculadas. Nestes casos, devem ser utilizadas redes com camadas intermediárias. Ainda assim, as redes ficam sujeitas aos problemas de procedimentos "hill-climbing", ou seja, ao problema de mínimos locais.

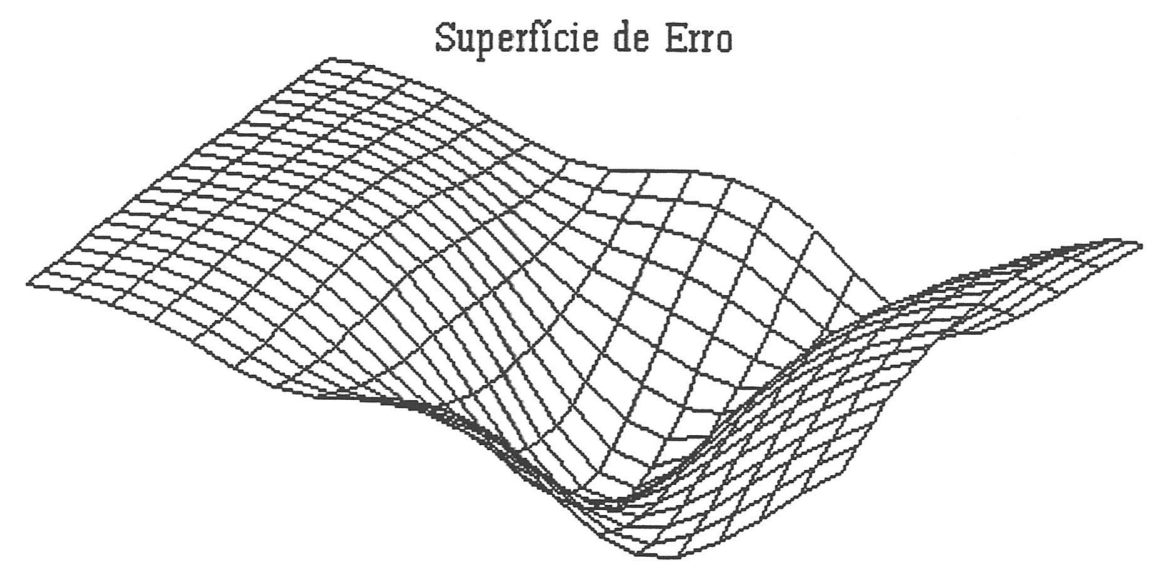

FIGURA 9 - Exemplo de superfície de erro.

A FIGURA 10 ilustra o processo de redução dos erros utilizando o backpropagation. Como pode ser visto nessa figura, o erro vai sendo progressivamente diminuído, podendo chegar ao mínimo global.

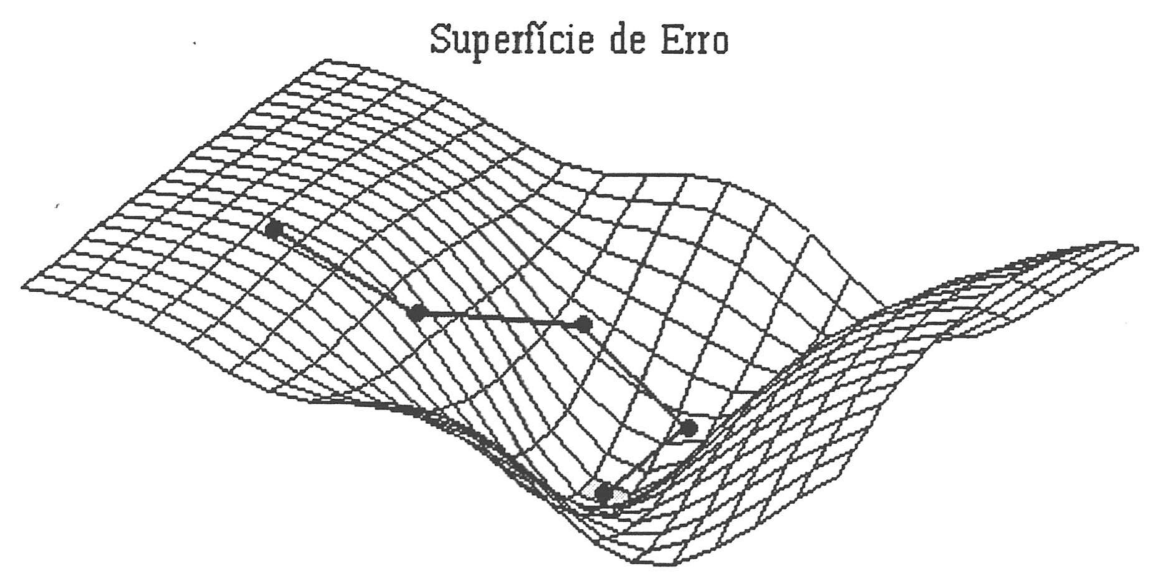

FIGURA 10 - Superfície de erro e treinamento backpropagation. 
A seguir, serão analisadas, em maiores detalhes, as três principais diferenças entre os algoritmos da Regra Delta e da Regra Delta Generalizada.

(1) É calculado o nível de ativação net de cada unidade $i$ no tempo $t$, ponderando cada entrada $X_{j}$ da rede pelo seu respectivo peso $w_{i j}$, através da eq. (3).

$$
\operatorname{net}_{i}(t)=\sum_{j=1}^{n} w_{i j} \cdot X_{j}
$$

(2) É aplicada, a cada nível de ativação net ${ }_{i}$, uma função de ativação $F$, calculando sua saída $o i$ através da eq. (4).

$$
o_{i}(t+1)=F\left(\text { net }_{i}(t)\right)
$$

A regra delta generalizada funciona quando são utilizadas na rede unidades com função de ativação semi-linear, que é uma função diferenciável e não decrescente. Note que a função threshold não se enquadra nesse requisito. Uma função de ativação amplamente utilizada nestes casos, é a função sigmoid, vide eq.(5).

$$
F\left(\operatorname{net}_{i}(t)\right)=\frac{1}{1+e^{- \text {net }_{i}(t)}}
$$

A função sigmoid tem a conveniente propriedade de que sua derivada é extremamente fácil de ser calculada:

Fazendo: $u=n e t_{\mathrm{i}}(t)$, e derivando temos a eq. (6).

$$
\frac{\partial f(u)}{\partial u}=\frac{e^{-u}}{\left(1+e^{-u}\right)^{2}}=\frac{\left(\left(1+e^{-u}\right)-1\right)}{\left(1+e^{-u}\right)^{2}}=\frac{1}{\left(1+e^{-u}\right)} \cdot\left(1-\frac{1}{1+e^{-u}}\right)=F(u) \cdot(1-F(u))
$$

(3) Assim, a mudança nos pesos deve ser feita através da eq. (7):

$$
\Delta w_{i j}=\eta o_{i} \delta_{i}
$$

Nos quais: $\eta$ é a taxa de aprendizado, e $\delta_{i}$ é um sinal de erro dado pelas equacões: eq. (8) e eq. (9).

$$
\begin{array}{ll}
\delta_{i}=F^{\prime}\left(\text { net }_{i}(t)\right) \cdot\left(d_{i}-o_{i}\right) & \text { (camada de saída) } \\
\delta_{i}=F^{\prime}\left(\text { net }_{i}(t)\right) \cdot \sum_{j=1}^{n} w_{i j} \cdot \delta_{j} & \text { (camadas intermediárias) }
\end{array}
$$


Substituindo as derivadas da eq. (6), na eq. (8) e na eq. (9), temos as equações: eq. (10) e eq.(11).

$$
\begin{array}{ll}
\delta_{i}=o_{i}\left(1-o_{i}\right) \cdot\left(d_{i}-o_{i}\right) & \text { (camada de saída) } \\
\delta_{i}=o_{i}\left(1-o_{i}\right) \cdot \sum_{j=1}^{n} w_{i j} \cdot \delta_{j} & \text { (camadas intermediárias) }
\end{array}
$$

Essencialmente a determinação do sinal de erro $\delta$ é um processo recursivo que se inicia nas unidades da camada de saída e vai até as unidades da primeira camada intermediária. Para as unidades da camada de saída, o sinal de erro é similar ao da regra delta padrão, vide eq. (10). Para as unidades das camadas intermediárias, para as quais não existem saídas desejadas, o sinal de erro é determinado recursivamente em termos dos sinais de erros das $j$ unidades diretamente conectadas a elas e dos pesos destas conexões, vide eq. (11).

O algoritmo backpropagation fornece uma aproximação para a trajetória do espaço de pesos, calculada pelo gradiente descendente. A taxa de aprendizado $\eta$ é uma constante de proporcionalidade no intervalo [0,1], pois este procedimento de aprendizado requer apenas que a mudança no peso seja proporcional à $\eta$. Entretanto, o verdadeiro gradiente descendente requer que sejam tomados passos infinitesimais. HAYKIN (1994) observa que, quanto menor for essa constante, menor serão as mudanças nos pesos das conexões a cada iteração e mais suave será a trajetória de pesos. No entanto, se essa constante for pequena, o tempo de treinamento pode ser muito alto. Da mesma forma, quanto maior for essa constante, maior será a mudança nos pesos, aumentando a velocidade do aprendizado, o que pode levar a uma oscilação do modelo na superfície de erro. O ideal seria utilizar a maior taxa de aprendizado possível que não levasse a uma oscilação, resultando em um aprendizado mais rápido.

O treinamento das redes MLP com backpropagation pode demandar muitos passos no conjunto de treinamento, resultando um tempo de treinamento consideravelmente longo. Se for encontrado um mínimo local, o erro para o conjunto de treinamento pára de diminuir e estaciona em um valor maior que o aceitável. RUMELHART et. al. (1986) sugerem uma maneira de aumentar a taxa de aprendizado sem levar à oscilação, modificando a regra delta generalizada para incluir o termo momentum, uma constante que determina o efeito das mudanças passadas dos pesos na direção atual do movimento no espaço de pesos.

Isto é feito alterando a eq. (7) da seguinte forma:

$$
\Delta w_{i j}(\mathrm{n}+1)=\eta\left(\delta_{i} o_{i}\right)+\mu \Delta w_{i j}(\mathrm{n})
$$

nos quais:

$$
\begin{aligned}
& \eta \text { - taxa de aprendizado } \\
& \mu \text { - termo momentum }
\end{aligned}
$$

O termo momentum torna-se útil em espaços de erro que contenham longas gargantas, com curvas acentuadas ou vales com descidas suaves, como apresentado na FIGURA 8. 


\subsubsection{Utilização da Rede MLP}

Depois que a rede estiver treinada e o erro estiver em um nível satisfatório, a rede poderá ser utilizada como uma ferramenta para classificação de novos dados. Para isto, a rede deverá ser utilizada apenas no modo progressivo (feed-forward), como ilustra a FIGURA 11. Nesta fase, novas entradas são apresentadas à camada de entrada, são processadas nas camadas intermediárias e os resultados são apresentados na camada de saída, como no treinamento, mas sem a retropropagação do erro. A saída apresentada é o modelo dos dados na interpretação da rede.

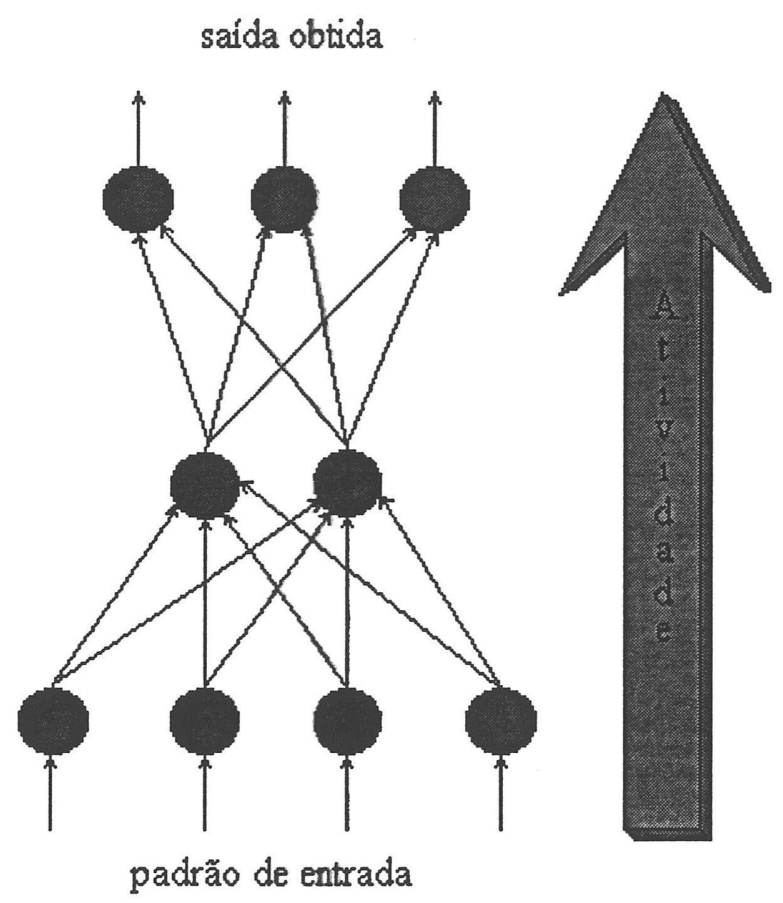

FIGURA 11 - Utilização da rede MLP.

\subsubsection{Limitações}

As Redes Neurais que utilizam backpropagation, assim como muitos outros tipos de Redes Neurais Artificiais, podem ser vistas como "caixas pretas", nas quais quase não se sabe porque a rede chega a um determinado resultado, uma vez que os modelos não apresentam justificativas para suas respostas. Neste sentido, muitas pesquisas vêm sendo realizadas visando à extração de conhecimento de Redes Neurais Artificiais e à criação de procedimentos explicativos, onde se tenta justificar o comportamento das redes em determinadas situações. Vide GALLANT (1988); FU (1994); BARON (1995).

Uma outra limitação refere-se ao tempo de treinamento de Redes Neurais utilizando backpropagation, que tende a ser muito longo. Algumas vezes são necessários milhares de ciclos para se chegar a níveis de erros aceitáveis, o que pode demandar um longo período de 
tempo. Este problema é ainda mais crítico se as redes estiverem sendo simuladas em computadores seriais, pois a CPU deve calcular as funções para cada unidade e suas conexões separadamente, o que pode ser problemático em redes muito grandes ou com grande quantidade de dados. Muitos estudos estão sendo realizados para implementação de Redes Neurais em computadores paralelos, como o apresentado por YOON et. al (1990), além de construção de chips neurais, como o Intel 80170NX Eletronically Trainable ANN, vide INTEL (1991), ou placas aceleradoras, como BrainMaker Accelerator Board - CNAPS, desenvolvida por MCCARTOR (1991).

Uma terceira limitação é a dificuldade de definir a arquitetura ideal da rede de forma que ela seja tão grande quanto o necessário para conseguir obter as representações internas necessárias e, ao mesmo tempo, pequena o suficiente para apresentar um treinamento rápido. Não existem regras claras para a definição de quantas unidades devem existir nas camadas intermediárias, quantas camadas, ou como devem ser as conexões entre essas unidades. Para contornar essa dificuldade, Algoritmos Genéticos podem ser utilizados para encontrar automaticamente boas arquiteturas de Redes Neurais.

\subsection{Desenvolvimento de Aplicações}

Nesta seção, será apresentada uma metodologia de desenvolvimento de aplicações que utilizam Redes Neurais de forma a criar um modelo mais preciso, consistente e robusto possível. Essa metodologia pode ser dividida em 7 passos principais:

\section{Coleta de Dados}

\section{Pré-Processamento dos Dados}

\section{Separação em Conjuntos de Dados}

\section{Definição da Configuração da Rede}

\section{Treinamento da Rede}

\section{Teste da Rede}

\section{Integração da Rede ao Sistema e Manutenção}

A seguir, serão discutidos alguns detalhes sobre cada uma dessas fases:

1. O primeiro passo do processo de implementação sistemas neurais é a coleta de dados relativos ao problema. $\mathrm{O}$ tipo de dados a serem coletados depende principalmente da natureza do problema a ser tratado e do algoritmo de aprendizado a ser utilizado. Geralmente, deve ser coletado o maior número de dados possível, dentro dos limites práticos e dos recursos disponíveis. Mas, como defendem BAILEY \& THOMPSON (1990), deve haver maior preocupação com a qualidade dos dados do que com o seu volume. 
Esta tarefa também requer uma análise cuidadosa sobre o problema para minimizar ambiguidades e erros nos dados. Além disso, os dados coletados devem ser significativos e cobrir amplamente o domínio do problema; não devem cobrir apenas as operações normais ou rotineiras, mas também as exceções e as condições nos limites do domínio do problema. Portanto, o auxílio de especialistas no domínio do problema pode ser de grande ajuda.

Depois de um grupo de dados ter sido selecionado, é uma boa prática determinar quais são as variáveis mais significativas ao processo a ser modelado, assim o espaço do problema pode ser reduzido. Várias ferramentas estatísticas podem ser utilizadas para auxiliar essa tarefa.

2. O segundo passo é o pré-processameto dos dados. Primeiramente, estes dados devem ser analisados para identificar as características das variáveis envolvidas e determinar o tipo de préprocessamento apropriado. Segundo STEIN (1993), uma boa técnica para este tipo de análise é a utilização de histogramas para visualizar a distribuição de cada variável. Assim, cada tipo de variável deve ser pré-processada diferentemente, dependendo do seu comportamento. De maneira geral, as varíaveis podem ser de dois tipos: variáveis nominais e variáveis numéricas.

As variáveis nominais geralmente se referem a classes com categorias mutuamente exclusivas e podem ser pré-processadas utilizando um vetor binário, em que cada posição do vetor representa uma categoria. Assim, a categoria a ser representada leva o valor 1 em sua respectiva posição do vetor e as outras posições devem ter o valor 0 . No caso de uma classe (ex. sexo) com apenas duas categorias, pode ser usado um vetor com apenas uma posição (ex. valor 1 para masculino e valor 0 para feminino).

As variáveis numéricas devem ser cuidadosamente analisadas, pois algumas vezes elas podem não se comportar como números, mas como códigos numéricos (ex. códigos postais, identificadores) e devem ser tratadas como variáveis nominais. Outro caso especial são os números ordinais, que representam uma ordenação. Estes devem ser tratados convertendo a ordenação em porcentagem e dividindo por 100, para obter valores entre 0 e 1 . As variáveis númericas, sejam números inteiros ou reais, devem ser escalonadas no intervalo entre 0 e 1 , utilizando normalização Euclidiana ou logarítmica.

Outro problema a ser enfrentado neste passo é a falta de valores em certas variáveis. A técnica convencional para o tratamento deste problema é a reposição dos valores que estiverem faltando pela melhor suposição possível, geralmente usando um valor esperado ou um valor da média dos valores dos dados, ou, em caso de dados consecutivos, a média de seus vizinhos. CROOKS (1992) observa que algumas vezes a falta de um valor pode ter um significado que pode ser interpretado (ex. para pergunta: Há quanto tempo é cliente do banco X? Se a resposta estiver faltando, isso pode ser interpretado como: não é cliente do banco X). Estes casos devem ser tratados e as causas deste tipo de problema também.

3. Separação em Conjuntos. Normalmente, os dados coletados são separados em duas categorias: dados de treinamento, que serão utilizados durante o processo de aprendizado da rede, e dados de teste, que serão utilizados para verificar o desempenho do modelo sob condições reais 
de utilização. Por isso o conjunto de teste deve ser tão grande quanto possível. Além dessa divisão, pode-se usar também uma subdivisão do conjunto de treinamento, criando um conjunto de validação, que pode ser utilizado para verificar a eficiência da rede quanto a sua capacidade de generalização durante o treinamento, podendo ser empregado como critério de parada do treinamento. Cada um destes conjuntos também deve cobrir extensivamente o domínio do problema. Depois de determinados estes conjuntos, eles são, geralmente, colocados em ordem aleatória para prevenção de tendências associadas à ordem de apresentação dos dados.

Além disso, quando a escolha dos dados for feita de forma aleatória, é uma boa prática gerar vários $(N)$ grupos de conjuntos e utilizar uma estratégia de $N$-validações cruzadas.

4. O quarto passo é a definição da configuração da rede, que pode ser dividida em três etapas:

a) Seleção do paradigma neural apropriado à aplicação.

b) Determinação da topologia da rede a ser utilizada: o número de camadas, o número de unidades em cada camada, etc.

c) Determinação de parâmetros do algoritmo de treinamento e funções de ativação.

Este passo tem um grande impacto na performance do sistema resultante. Existem metodologias, "dicas e truques" na condução destas tarefas, como os mostrados por CAUDIL (1991). Normalmente, estas escolhas são feitas de forma empírica, treinando algumas variações de arquiteturas (topologia e parâmetros) e testando cada uma delas. A definição da configuração de Redes Neurais é ainda considerada uma arte que requer grande experiência dos projetistas. Foram as dificuldades encontradas neste passo que motivaram o interese pelo projeto evolucionário de arquiteturas neurais.

5. O quinto passo é o treinamento da rede. Nesta fase, seguindo o algoritmo de treinamento escolhido, são ajustados os pesos das conexões da rede. É importante considerar, nesta fase, alguns aspectos, tais como a inicialização da rede, o modo de treinamento e o tempo de treinamento.

Uma boa escolha dos valores iniciais dos pesos da rede pode diminuir o tempo necessário para o treinamento. Normalmente, os valores iniciais dos pesos da rede são números aleatórios uniformemente distribuídos em um intervalo definido. A escolha errada destes pesos pode levar a uma saturação prematura, podendo ser necessária uma nova inicialização. NGUEYN \& WIDROW (1990) apresentam uma função que pode ser utilizada para determinar valores iniciais melhores que valores puramente aleatórios. No entanto, a discusão sobre o funcionamento desta função está fora do escopo deste trabalho.

Quanto ao modo de treinamento, na prática é mais utilizado o modo padrão, devido ao menor armazenamento de dados, além de ser menos suscetível ao problema de mínimos locais devido à pesquisa de natureza estocástica que realiza. Por outro lado, no modo batch se tem uma 
melhor estimativa do vetor gradiente, o que torna o treinamento mais estável. A eficiência relativa dos dois modos de treinamento depende do problema a ser tratado.

Quanto ao tempo de treinamento, vários fatores podem influenciar a sua duração, porém sempre será necessário utilizar algum critério de parada. $\mathrm{O}$ critério de parada do algoritmo backpropagation não é bem definido. Geralmente é utilizado um número máximo de ciclos, ou até que se tenha um erro menor que um erro mínimo esperado. Mas, devem ser consideradas a variação da taxa de erro médio por ciclo e a capacidade de generalização da rede. Pode ocorrer que em um determinado instante do treinamento a generalização comece a degenerar, causando o problema de over-training, ou seja, a rede se especializa no conjunto de dados do treinamento e perde a capacidade de generalização. $\mathbf{O}$ treinamento deve ser interrompido quando a rede apresentar uma boa capacidade de generalização e quando a taxa de erro for suficientemente pequena, ou seja, menor que um erro admissível. Assim, deve-se encontrar um ponto ótimo de parada com erro mínimo e capacidade de generalização máxima. Pode-se, ainda, utilizar uma estratégia de treinamento que armazene o estado da rede em momentos interessantes do treinamento, nos quais se apresentem a maior capacidade de generalização, a menor taxa de erro no treinamento ou uma combinação destes fatores.

6. O sexto passo é o teste da rede. Durante este passo o conjunto de teste é usado para determinar o desempenho da rede com dados que não foram previamente utilizados. $O$ desempenho da rede, medido nesta fase através de um conjunto de dados de teste significativo, é uma boa indicação de seu desempenho futuro.

Devem ser considerados ainda outros testes, como a análise do desempenho da rede com cada classe das saídas desejadas (para os problemas de classificação de padrões), análise do comportamento da rede utilizando entradas especiais e análise dos pesos atuais da rede, pois, segundo BAILEY \& THOMPSON (1990), se existirem valores muito pequenos, as conexões associadas podem ser consideradas insignificantes e, assim, ser eliminadas através de alguma técnica de prunning. De modo inverso, valores substantivamente maiores que os outros poderiam indicar que houve over-training da rede.

7. Finalmente, com a rede treinada e avaliada, ela pode ser integrada aos sistemas do ambiente da aplicação (novos ou previamente existentes). São possíveis várias categorias de integração, dependendo da utilização desejada. Para maior eficiência da solução, pode ser utilizada mais de uma rede integrada ao sistema, ou, ainda, em conjunção com outros métodos.

Este sistema deverá conter facilidades de utilização, como interface conveniente, e facilidades de aquisição de dados através de planilhas eletrônicas, interfaces com unidades de processamento de sinais ou arquivos padronizados. Uma boa documentação do sistema e o treinamento de usuários são necessários para o sucesso do mesmo. Além disso, o sistema deve periodicamente monitorar sua performance e fazer a manutenção da rede quando for necessário ou indicar aos projetistas a necessidade de um novo treinamento. Outras melhorias poderão ainda ser sugeridas quando os usuários forem se tornando mais familiarizados com o sistema. Estas sugestões poderão ser muito úteis em novas versões ou em novos produtos. 


\subsection{Considerações Finais}

Neste capítulo, foi mostrado que as Redes Neurais Artificiais são modelos matemáticos inspirados no funcionamento do sistema nervoso. Foram apresentadas as principais características destes modelos: a maneira como eles funcionam, a forma como as unidades e as conexões destes modelos podem ser organizadas (topologia), a maneira como eles podem se relacionar e aprender com seu ambiente (paradigmas e algoritmos de aprendizado). Foi apresentado o modelo Perceptron e seu algoritmo de aprendizado, a Regra Delta.

Foram analisadas detalhadamente as características do modelo Perceptron Multicamadas (MLP) e do algoritmo Backpropagation que serão utilizados neste trabalho. Foram analisadas também suas limitações e as principais fases do desenvolvimento de aplicações utilizando este modelo.

No capítulo seguinte, serão apresentadas as principais características dos Algoritmos Genéticos. Serão discutidos os aspectos mais atraentes desta ferramenta de busca e otimização para a solução de diferentes tipos de problemas. 


\section{Algoritmos Genéticos}

\subsection{Introdução}

Neste capítulo, serão analisados os principais aspectos e características da Computação Evolucionária e dos Algoritmos Genéticos. Estes aspectos os tornam extremamente atraentes como ferramenta de busca e otimização para a solução dos mais diferentes tipos de problemas.

Toda tarefa de busca ou otimização possui dois componentes principais:

Espaço de Busca - onde são consideradas todas as possibilidades de solução de um determinado problema;

Função de Avaliação (ou Função de Custo) - uma maneira de avaliar os membros do espaço de busca.

Como pode ser visto em WINSTON (1992), as técnicas de busca e otimização tradicionais iniciam-se com um único candidato que, iterativamente, é manipulado utilizando algumas heurísticas, normalmente estáticas, diretamente associadas ao problema a ser solucionado. Geralmente, estes processos heurísticos não são algorítmicos e sua simulação em computadores pode ser muito complexa. Apesar destes métodos não serem suficientemente robustos, isto não implica que eles sejam inúteis. Na prática, eles são amplamente utilizados, com sucesso, em inúmeras aplicações.

Por outro lado, as técnicas de computação evolucionária operam sobre uma população de candidatos em paralelo. Assim, elas podem realizar a busca em diferentes áreas do espaço de solução, alocando um número de membros apropriado para a busca simultânea em várias regiões. Segundo GOLDBERG (1989) os Algoritmos Genéticos diferem dos métodos tradicionais de busca e otimização, principalmente, em quatro aspectos:

1. Trabalham com uma codificação do conjunto de parâmetros e não com os próprios parâmetros.

2. Trabalham com uma população e não com um único ponto.

3. Utilizam informações de custo ou recompensa e não derivadas ou outro conhecimento auxiliar.

4. Utilizam regras de transição probabilísticas e não determinísticas. 
Como esclarece BAUER (1994), os pesquisadores costumam referir-se a "algoritmos genéticos" ou a "um algoritmo genético" e não ao "algoritmo genético", pois estes algoritmos são uma classe de procedimentos com muitos passos separados e cada um destes passos possui muitas variações possíveis.

Algoritmos Genéticos são muito eficientes para busca de soluções ótimas, ou aproximadamente ótimas em uma grande variedade de problemas, pois não impõem muitas das limitações encontradas nos métodos de busca tradicionais. Segundo HOLLAND (1975), além de ser uma estratégia de gerar e testar muito elegante, por serem baseados na evolução biológica, os Algoritmos Genéticos são capazes de identificar e explorar fatores ambientais e convergir para soluções ótimas, ou aproximadaménte ótimas, em níveis globais.

"Quanto melhor um indivíduo se adaptar ao seu meio ambiente, maior será sua chance de sobreviver e gerar descendentes": este é o conceito básico da seleção natural proposto por DARWIN (1859), mecanismo da evolução genética biológica. A área biológica mais proximamente ligada aos Algoritmos Genéticos é a Genética Populacional.

Antes de prosseguir com a análise das características destes algoritmos, alguns conceitos básicos são necessários. Estes conceitos podem ser naturalmente expostos explicando o funcionamento básico destes algoritmos. Inicialmente, é gerada uma população formada por um conjunto aleatório de indivíduos que podem ser vistos como possíveis soluções do problema. Durante o processo evolutivo, esta população é avaliada: para cada indivíduo é dada uma nota, ou índice, refletindo sua habilidade de adaptação a determinado ambiente. Uma porcentagem dos mais adaptados são mantidos, enquanto os outros são descartados (darwinismo). Os membros mantidos pela seleção podem sofrer modificações em suas características fundamentais através de mutações e cruzamento ou recombinação genética, gerando descendentes para a próxima geração. Este processo, chamado de reprodução, é repetido até que uma solução satisfatória seja encontrada.

Como defende GOLDBERG (1989), embora possam parecer simplistas do ponto de vista biológico, estes algoritmos são suficientemente complexos para fornecer mecanismos poderosos e robustos de busca adaptativa.

\subsection{Um Breve Histórico}

Até meados do século 19, a humanidade acreditava que cada espécie havia sido criada separadamente por um ser supremo ou através de geração espontânea. $O$ trabalho do naturalista Carolus Linnaeus sobre a classificação biológica de organismos despertou o interesse pela similaridade entre certas espécies, levando a acreditar na existência de uma certa relação entre elas. Outros trabalhos influenciaram os naturalistas em direção à teoria da seleção natural, tais como os de Jean Baptiste Lamark, que propôs uma teoria evolucionária no "uso e desuso" de órgãos, e o de Thomas Robert Malthus, que sugeriu que fatores ambientais, tais como doenças e carência de alimentos, limitavam o crescimento de uma população. 
Depois de mais de 20 anos de observações e experimentos, Charles Darwin apresentou, em 1858, sua teoria de evolução através de seleção natural, simultaneamente com outro naturalista inglês, Alfred Russel Wallace. No ano seguinte, Darwin publica o seu livro On the Origin of Species by Means of Natural Selection com a sua teoria completa, sustentada por muitas evidências colhidas durante suas viagens a bordo do navio Beagle, DARWIN (1859). Segundo FUTUYAMA (1992), este trabalho exerceu forte influência em trabalhos futuros da Biologia, Botânica e Zoologia, além de afetar o pensamento religioso, filosófico, político e econômico.

A teoria da evolução e a computação nasceram praticamente na mesma época: Charles Babbage, um dos fundadores da computação moderna e amigo pessoal de Darwin, desenvolveu sua máquina analítica em 1833. Ambos provavelmente estariam surpresos e orgulhosos com a ligação entre estas duas áreas.

Por volta de 1900, o trabalho de Gregor Mendel, desenvolvido em 1865, sobre os princípios básicos de herança genética, foi redescoberto pelos cientistas da época e teve grande influência nos futuros trabalhos relacionados à evolução.

A moderna teoria da evolução combina a genética e as idéias de Darwin e Wallace sobre a seleção natural, criando o princípio básico de Genética Populacional: "a variabilidade entre indivíduos em uma população de organismos que se reproduzem sexualmente é produzida pela mutação e pela recombinação genética". Este princípio foi desenvolvido, durante os anos $30 \mathrm{e}$ 40 , por biólogos e matemáticos de importantes centros de pesquisa.

Nos anos 50 e 60, muitos biólogos começaram a desenvolver simulações computacionais de sistemas genéticos. Entretanto, foi John Holland quem começou, seriamente, a desenvolver as primeiras pesquisas no tema. Holland foi gradualmente refinando suas idéias e, em 1975, publicou o seu livro Adaptation in Natural and Artificial Systems, HOLLAND (1979), hoje considerado a bíblia de Algoritmos Genéticos. Desde então, estes algoritmos vêm sendo aplicados com sucesso nos mais diversos problemas de otimização e aprendizado de máquina.

\subsection{Características Gerais}

Algoritmos Genéticos são algoritmos de otimização global, baseados nos mecanismos de seleção natural e da genética. Eles empregam uma estratégia de busca paralela e estruturada, mas aleatória, que é voltada em direção ao reforço da busca de pontos de "alta aptidão", ou seja, pontos nos quais a função a ser minimizada (ou maximizada) tem valores relativamente baixos (ou altos). Apesar de aleatórios, eles não são caminhadas aleatórias não direcionadas, pois exploram informações históricas para encontrar novos pontos de busca, onde são esperados melhores desempenhos.

Isto é realizado através de processos iterativos, onde cada iteração é chamada de geração. Durante cada iteração, os princípios de seleção e reprodução são aplicados a uma população de candidatos que pode variar de tamanho, dependendo da complexidade do problema e dos 
recursos computacionais disponíveis. Através da seleção, determinam-se quais indivíduos conseguirão se reproduzir, gerando um número determinado de descendentes para a próxima geração, com uma probabilidade determinada pelo seu índice de aptidão. Em outras palavras, os indivíduos com maior adaptação relativa têm maiores chances de se reproduzir.

O ponto de partida para a utilização de Algoritmos Genéticos como ferramenta para solução de problemas é a representação destes problemas de maneira que estes algoritmos possam trabalhar adequadamente sobre eles. A maioria das representações são genotípicas, utilizam vetores de tamanho finito em um alfabeto também finito.

Tradicionalmente, os indivíduos são representados por vetores binários, onde cada elemento de um vetor denota a presença (1) ou ausência (0) de uma determinada característica. Através de uma representação tem-se o genótipo de um indivíduo. Os elementos de um genótipo podem ser combinados formando as características reais do indivíduo, ou seja, o seu fenótipo. Como explicam SPEARS et. al. (1993), teoricamente, a representação binária é independente do problema, pois, uma vez encontrada a representação em vetores binários, as operações padrão podem ser utilizadas, facilitando o seu emprego em diferentes classes de problemas.

A utilização de representações em níveis de abstração mais altos tem sido investigada. Como estas representações são mais fenotípicas, facilitariam sua utilização em determinados ambientes, onde essa transformação "fenótipo - genótipo" é muito complexa. Neste caso, precisam ser criados os operadores específicos para utilizar estas representações.

O princípio básico do funcionamento dos Algoritmos Genéticos é que um critério de seleção vai fazer com que, depois de várias gerações, o conjunto inicial de indivíduos produza indivíduos mais aptos. A maioria dos métodos de seleção são projetados para escolher preferencialmente indivíduos com maiores notas de aptidão, embora não exclusivamente, a fim de manter a diversidade da população.

Um método de seleção muito utilizado é o Método da Roleta, onde indivíduos de uma geração são escolhidos para fazer parte da próxima geração através de um sorteio de roleta. Neste método, cada indivíduo da população é representado na roleta proporcionalmente ao seu índice de aptidão. Assim, aos indivíduos com alta aptidão é dada uma porção maior da roleta, enquanto aos de aptidão mais baixa é dada uma porção relativamente menor da roleta. A FIGURA 12 ilustra a criação desta roleta. Finalmente, a roleta é girada um determinado número de vezes, dependendo do tamanho da população, e são escolhidos, como indivíduos que participarão da próxima geração, aqueles sorteados na roleta.

Existem algumas variações deste método que não são baseadas na aptidão relativa, mas na classificação (ranking) dos candidatos, WHITLEY (1989) apresenta vários casos nos quais esta alternativa é melhor. 


\begin{tabular}{ccc}
$\begin{array}{c}\text { Indivíduo } \\
\mathbf{S}_{\mathrm{i}}\end{array}$ & $\begin{array}{c}\text { Aptidão } \\
f\left(\mathrm{~S}_{\mathrm{i}}\right)\end{array}$ & $\begin{array}{c}\text { Aptidão } \\
\text { Relativa }\end{array}$ \\
\hline $\mathrm{S}_{1} 10110$ & 2.23 & 0.14 \\
$\mathrm{~S}_{2} 11000$ & 7.27 & 0.47 \\
$\mathrm{~S}_{3} 11110$ & 1.05 & 0.07 \\
$\mathrm{~S}_{4} 01001$ & 3.35 & 0.21 \\
$\mathrm{~S}_{5} 00110$ & 1.69 & 0.11
\end{tabular}

FIGURA 12 - Indivíduos de uma população e a sua correspondente roleta de seleção.

Um conjunto de operações é necessário para que, dada uma população, consiga-se gerar populações sucessivas que (espera-se) melhorem sua aptidão com o tempo. Estes operadores são: cruzamento e mutação. Eles são utilizados para assegurar que a nova geração seja totalmente nova, mas que de alguma forma possua características de seus pais, ou seja, a população se diversifica e mantém características de adaptação adquiridas pelas gerações anteriores. Para prevenir que os melhores não desapareçam da população pela manipulação dos operadores genéticos, estes indivíduos podem ser automaticamente colocados na próxima geração através de uma política elitista.

Esse ciclo é repetido um determinado número de vezes, dependendo dos recursos disponíveis, ou até que uma solução adequada seja encontrada. Durante esse processo, os melhores indivíduos, assim como alguns dados estatísticos, podem ser coletados e armazenados para avaliação. Na FIGURA 13 é mostrado um exemplo de algoritmo genético.

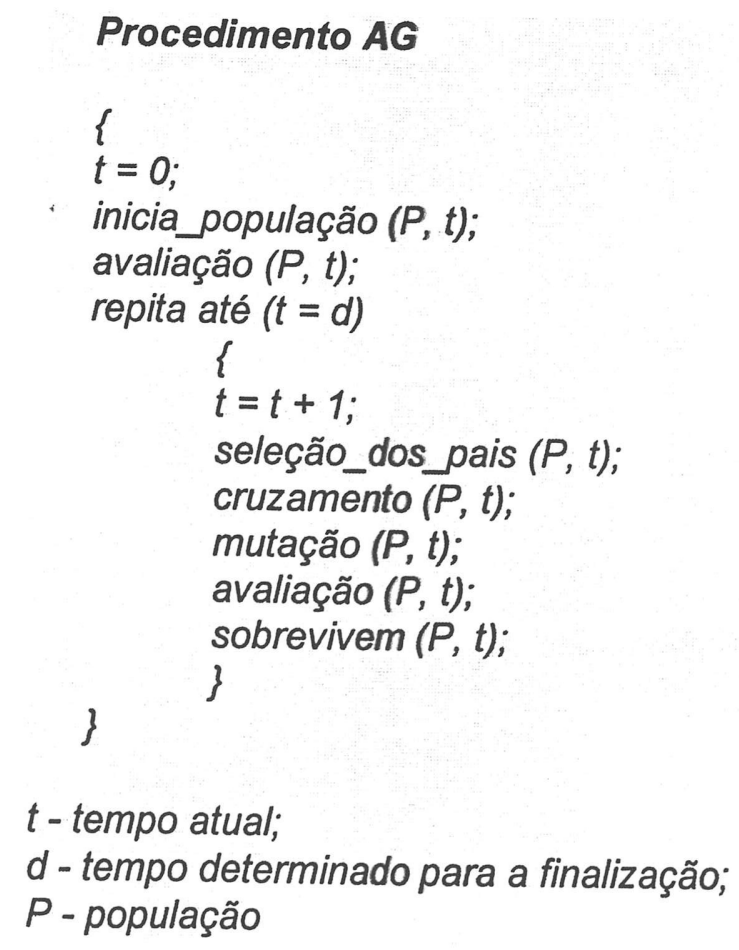

FIGURA 13 - Um algoritmo genético. 
Segundo GOLDBERG (1989), estes algoritmos, apesar de serem computacionalmente muito simples, são bastante poderosos. Além disso, eles não são limitados por suposições sobre o espaço de busca, relativas a continuidade, existência de derivadas, etc. Os espaços de busca em problemas reais são repletos de descontinuidades, ruídos e outros problemas. Métodos que dependam fortemente de restrições de continuidade e existência de derivadas são adequados apenas para problemas em um domínio limitado.

Na próxima seção, serão apresentados os mecanismos dos operadores genéticos.

\subsection{Operadores Genéticos}

O princípio básico dos operadores genéticos é o de transformar uma população através de sucessivas gerações, estendendo a busca até chegar a um resultado satisfatório. Os operadores genéticos são necessários para que a população se diversifique e mantenha características adequadas adquiridas pelas gerações anteriores.

O operador de mutação é responsável pela introdução e manutenção da diversidade genética da população, alterando arbitrariamente um ou mais componentes de uma estrutura escolhida, como é ilustrado na FIGURA 14. Desta forma, este operador fornece meios para introdução de novos elementos na população. A mutação assegura que a probabilidade de se chegar a qualquer ponto do espaço de busca nunca será zero, além de contornar o problema de mínimos locais, pois, com este mecanismo, altera-se levemente a direção da busca. O operador de mutação é aplicado aos indivíduos com uma probabilidade dada pela taxa de mutação $(0 \leq \mathrm{Pm} \leq 1)$; geralmente, utiliza-se uma taxa de mutação pequena $(0.001 \leq \mathrm{Pm} \leq 0.1)$, pois este é um operador genético secundário.

\section{Antes da Mutação: 11100 \\ Depois da Mutação: 11000}

FIGURA 14 - Exemplo de mutação.

O cruzamento, ou crossover, é o operador responsável pela recombinação de características dos pais durante a reprodução, permitindo que as próximas gerações herdem essas características. Ele é considerado o operador genético predominante, por isso é aplicado com probabilidade dada pela taxa de cruzamento $\left(0 \leq \mathrm{Pc}_{1} \leq 1\right)$, que deve ser maior que a taxa de mutação. Esta taxa é usualmente $0.6 \leq \mathrm{Pc}_{1} \leq 0.99$. Este operador pode ser utilizado de várias maneiras. As mais utilizadas são:

- um-ponto: um ponto de cruzamento é escolhido e, a partir deste ponto, as informações genéticas dos pais são trocadas. As informações anteriores a este ponto em um dos pais 
são ligadas às informações posteriores a este ponto no outro pai e vice versa. Este processo é mostrado no exemplo da FIGURA 15.

- multipontos: é uma generalização desta idéia de troca de material genético através de pontos, onde muitos pontos de cruzamento podem ser utilizados.

- uniforme: não utiliza pontos de cruzamento, mas determina, através de um parâmetro global, qual a probabilidade de cada variável ser trocada entre os pais.

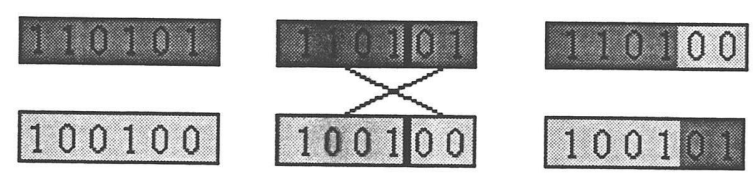

(a)

(b)

(c)

FIGURA 15 - Um exemplo de cruzamento de um ponto.

(a) dois indivíduos são escolhidos.

(b) um ponto (4) de cruzamento é escolhido.

(c) são recombinadas as características, gerando dois novos indivíduos.

$\mathrm{Na}$ próxima seção, serão analisados alguns parâmetros que podem ser utilizados por Algoritmos Genéticos e de que maneira estes parâmetros influem no seu comportamento.

\subsection{Parâmetros Genéticos}

É importante também, analisar de que maneira alguns parâmetros que podem ser utilizados influem no comportamento dos Algoritmos Genéticos para que se possa estabelecê-los conforme as necessidades do problema e dos recursos disponíveis. Segundo DE JONG (1980), os principais parâmetros e suas influências são os seguintes:

- Tamanho da População. O tamanho da população afeta o desempenho global e a eficiência dos Algoritmos Genéticos. Com uma população pequena, o desempenho pode cair, pois deste modo a população fornece uma pequena cobertura do espaço de busca do problema. Uma grande população geralmente fornece uma cobertura representativa do domínio do problema, além de prevenir convergências prematuras para soluções locais ao invés de globais. No entanto, para se trabalhar com grandes populações, são necessários maiores recursos computacionais, ou que o algoritmo trabalhe por um período de tempo muito maior.

- Taxa de Cruzamento. Quanto maior for esta taxa, mais rapidamente novas estruturas serão introduzidas na população. Mas, se esta for muito alta, estruturas com boas aptidões poderão ser retiradas a uma velocidade que supere a capacidade da reprodução em criar melhores estruturas. Se esta taxa for muito baixa, a busca pode estagnar. 
- Taxa de Mutação. Uma baixa taxa de mutação previne que uma dada posição fique estagnada em um valor, além de possibilitar que se chegue em qualquer ponto do espaço de busca. Com uma taxa muito alta, a busca se torna essencialmente aleatória.

- Intervalo de Geração. Controla a porcentagem da população que será substituída durante a próxima geração. Com um valor alto, a maior parte da população será substituída, mas com valores muito altos pode ocorrer perda de estruturas de alta aptidão. Com um valor baixo, o algoritmo pode se tornar muito lento, pois o número de gerações necessárias pode ser muito grande.

\subsection{Aplicações}

Um sistema que necessite de bom desempenho em um ambiente dinâmico geralmente exige soluções adaptativas ou evolutivas. Sistemas evolutivos tentam resolver problemas acumulando conhecimento sobre o problema e utilizando estas informações para gerar soluções aceitáveis. Como mostrado por AUSTIN (1990), estes problemas, tipicamente, encontram-se nas áreas de configuração de sistemas complexos, alocação de tarefas, seleção de rotas e outros problemas de otimização e aprendizado de máquina.

Seguem-se alguns exemplos de sistemas que utilizam Algoritmos Genéticos:

- Controle de sistemas dinâmicos - GOLDBERG (1989).

- Indução e otimização de bases de regras - HOLLAND (1975).

- Definição de arquiteturas conexionistas - HARP et. al. (1991):

- Projeto evolucionário de arquiteturas de Redes Neurais Artificiais.

- Modelagem de estruturas neurais biológicas.

- Simulação de modelos biológicos - HOLLAND (1975):

- Comportamento.

- Evolução.

- Evolução interativa de imagens - CALDWELL \& JOHNSTON (1991) e SIMS (1993).

- Composição musical - HORNER \& GOLDBERG (1989). 


\subsection{Considerações Finais}

Neste capítulo, foram vistas as principais diferenças entre os métodos tradicionais de busca e os Algoritmos Genéticos, algoritmos inspirados nos mecanismos biológicos de genética e seleção natural. Foram analisadas as principais características destes algoritmos e seus princípios básicos de funcionamento.

Como mostrado, estes algoritmos trabalham com uma população de candidatos a soluções de um problema. Durante o processo evolutivo, esta população é avaliada e uma parcela dos mais adaptados são mantidos. Os candidatos mantidos podem sofrer modificações em suas características através de mutações e cruzamento, gerando descendentes e uma nova população.

Foi apresentado um método de seleção, conhecido como Método da Roleta e foram discutidos os mecanismos de funcionamento dos operadores genéticos de mutação e cruzamento. Foram também analisadas as influências do tamanho da população, das taxas de cruzamento e mutação e do intervalo de geração.

Finalmente, foram apresentados alguns exemplos de sistemas evolutivos.

No próximo capítulo, será analisada a abordagem evolucionária de projeto de Redes Neurais, ou seja, a utilização de Algoritmos Genéticos para a busca de arquiteturas de Redes Neurais Artificiais adequadas para a solução de problemas particulares. Serão mostrados os principais aspectos dos processos de codificação, avaliação de desempenho e reprodução. 


\section{Evolução em Redes Neurais}

\subsection{Introdução}

Os sistemas baseados em Redes Neurais Perceptron Multicamadas (MLP) dependem fortemente da topologia destas redes (tamanho, estrutura e conexões), assim como dos parâmetros de seu algoritmo de aprendizado (taxa de aprendizado, termo momentum). Como resultado, a determinação da arquitetura da rede (topologia e parâmetros) afeta muito o seu desempenho, isto é, velocidade de aprendizado, precisão do aprendizado, tolerância a ruídos e capacidade de generalização.

É grande a dificuldade de se projetarem Redes Neurais eficientes. $\mathrm{O}$ espaço de busca entre as Redes Neurais válidas é muito grande. Além disso, ele é deceptivo e multimodal, como mostram MILLER et. al. (1989). Deceptivo, pois duas arquiteturas similares podem apresentar desempenhos muito diferentes. E multimodal, porque duas arquiteturas muito distintas podem ter desempenhos semelhantes.

Existem algumas técnicas que utilizam conhecimentos empíricos que podem ajudar em alguns casos particulares, como mostra CAUDIL (1991). BAILEY \& THOMPSON (1990) sugerem uma abordagem muito utilizada na prática, que é a construção de redes a partir de arquiteturas padronizadas ou baseadas em outras redes previamente utilizadas; então, é realizado um teste dessa rede para a função desejada e altera-se a arquitetura da rede até que seja obtida uma arquitetura razoavelmente adequada para a aplicação. Entretanto, esse tipo de abordagem demanda muito tempo, tem um custo muito elevado e não apresenta resultados muito confiáveis. Além disso, não é possível garantir a otimização da solução, pois o critério de desempenho é baseado em uma combinação complexa de fatores. Este é um típico problema de otimização "multicriterial".

Visando resolver este problema, várias técnicas para automação do projeto de arquiteturas neurais para classes particulares de problemas vêm sendo pesquisadas. Uma destas técnicas envolve a utilização de abordagens evolucionárias, como heurística de busca de arquiteturas aproximadamente ótimas.

MURRAY (1994) defende que os Algoritmos Genéticos proporcionam a abordagem mais natural para a solução deste problema, especialmente porque o cérebro humano também é resultado da evolução biológica. Segundo o pesquisador Gerald Edelman, prêmio Nobel de 1972, 
em entrevista ao jornal Folha de São Paulo, DE SÁ (1995), a mente humana é resultado direto da seleção natural. Ele sugere que o aparecimento de sulcos cerebrais cada vez mais acentuados levou a um aumento significativo na área total do cérebro, o que, em outras palavras, significa um maior número de neurônios em um mesmo espaço físico. Além disso, EDELMAN (1988) sugere que a organização dos neurônios e as suas conexões não foram pré-determinadas, mas foram evoluindo para competir com as circunstâncias impostas pelo ambiente.

A arquitetura do cérebro foi, durante milhões de anos de evolução, astuciosamente modelada através da genética e da seleção natural. Assim, neste trabalho, deseja-se utilizar uma abordagem artificialmente equivalente para resolver este problema para "seres" também artificiais, que neste caso seriam Redes Neurais Artificiais.

Existem, ainda, outras possibilidades de utilização da abordagem evolucionária em Redes Neurais Artificiais, tais como a sua utilização como algoritmo de treinamento, como mostrado por MONTANA \& DAVIS (1989); PORTO (1995) e para encontrar regras de aprendizado eficientes para Redes Perceptron sem camadas intermediárias, apresentado por CHALMERS (1991). Além disso, existem outras possibilidades muito promissoras a serem exploradas, tais como na escolha inicial de pesos da rede; na determinação de conjuntos de dados de treinamento, validação e teste ou dos atributos a serem utilizados nestes conjuntos; ou, ainda, na determinação de janelas de dados de séries temporais a serem utilizadas no treinamento de redes para previsões. Neste primeiro trabalho, foi analisada apenas sua utilização para definição de arquiteturas de redes MLP feed-forward inteiramente conectadas, treinadas com backpropagation.

Neste capítulo, serão discutidos alguns aspectos do projeto evolucionário de arquiteturas neurais, abordagens de representação, critérios de avaliação de desempenho, estratégias de reprodução, mecanismos de seleção e funcionamento dos operadores genéticos.

\subsection{Projeto Evolucionário de Arquiteturas Neurais}

Para a aplicação de Algoritmos Genéticos, visando à resolução de problemas específicos, como o projeto de arquiteturas neurais, é necessário fornecer algumas informações a respeito do problema, tais como:

- Representação: estes algoritmos necessitam de uma representação apropriada (genótipo) das possíveis soluções, normalmente na forma de vetores. Assim, deve-se fornecer uma representação adequada da arquitetura destas redes e uma função que transforme esta representação genotípica, utilizada por estes algoritmos, em soluções fenotípicas: arquiteturas de redes. 
- Desempenho: é preciso que seja fornecida uma função que associe um valor a cada solução, isto é, ao desempenho de cada uma das redes da população. Este valor deve refletir a aptidão destas redes na solução do problema considerado.

- Reprodução: devem-se especificar os operadores de cruzamento e mutação que permitam a criação de novas gerações de arquiteturas de redes, a partir de seus pais. A especificação destes operadores depende fortemente da representação utilizada. Em alguns casos, pode ser necessária a satisfação de restrições para assegurar que as novas redes geradas sejam soluções válidas.

Estes aspectos serão analisados em maiores detalhes nas próximas seções. A seguir, serão vistos os principais processos desta abordagem, que são ilustrados graficamente na FIGURA 16 e envolvem:

- Decodificação (Gerador);

- Treinamento (Simulador);

- Avaliação de Desempenho;

- Seleção (AG);

- Reprodução (AG).

No projeto de evolucionário de arquiteturas neurais, cada indivíduo pode ser visto como um ponto ou estado do espaço de possíveis arquiteturas de redes. Iniciando o processo com uma população de representações genotípicas de redes válidas, geradas aleatoriamente, um gerador reconstrói essas redes (fenótipos) a partir de sua representação (genótipos), de acordo com a função de transformação utilizada.

Em seguida, um simulador treina todas as redes com um mesmo conjunto de dados de treinamento e seus desempenhos são avaliados. Com isso, são obtidos alguns dados para avaliar o atual estado da população e determinar uma nota de aptidão para cada rede, de acordo com o seu desempenho em relação a todas as outras redes.

Através de um método como o da roleta, são selecionadas as redes, de acordo com uma probabilidade relativa proporcional às suas notas de aptidão. Isto é feito até preencher o espaço de candidatos, que serão colocados para reprodução regida pelos operadores genéticos de cruzamento e mutação. Através destes operadores, é construída uma nova geração de arquiteturas neurais. Para evitar que as melhores redes desapareçam rapidamente da população, pode ser utilizada uma política elitista, que faz com que estas redes estejam presentes na próxima geração.

Esse ciclo é repetido e, com a passagem de novas gerações, a população vai gradativamente evoluindo rumo a genótipos que correspondam a fenótipos de melhores desempenhos. Isto é feito um determinado número de vezes, até que o algoritmo encontre soluções adequadas ao problema ou, em casos extremos, até convergir para uma única solução. Durante este processo, as melhores redes, assim como alguns dados estatísticos, podem ser coletados e armazenados para uma análise posterior sobre $\mathrm{o}$ andamento do processo evolutivo. 


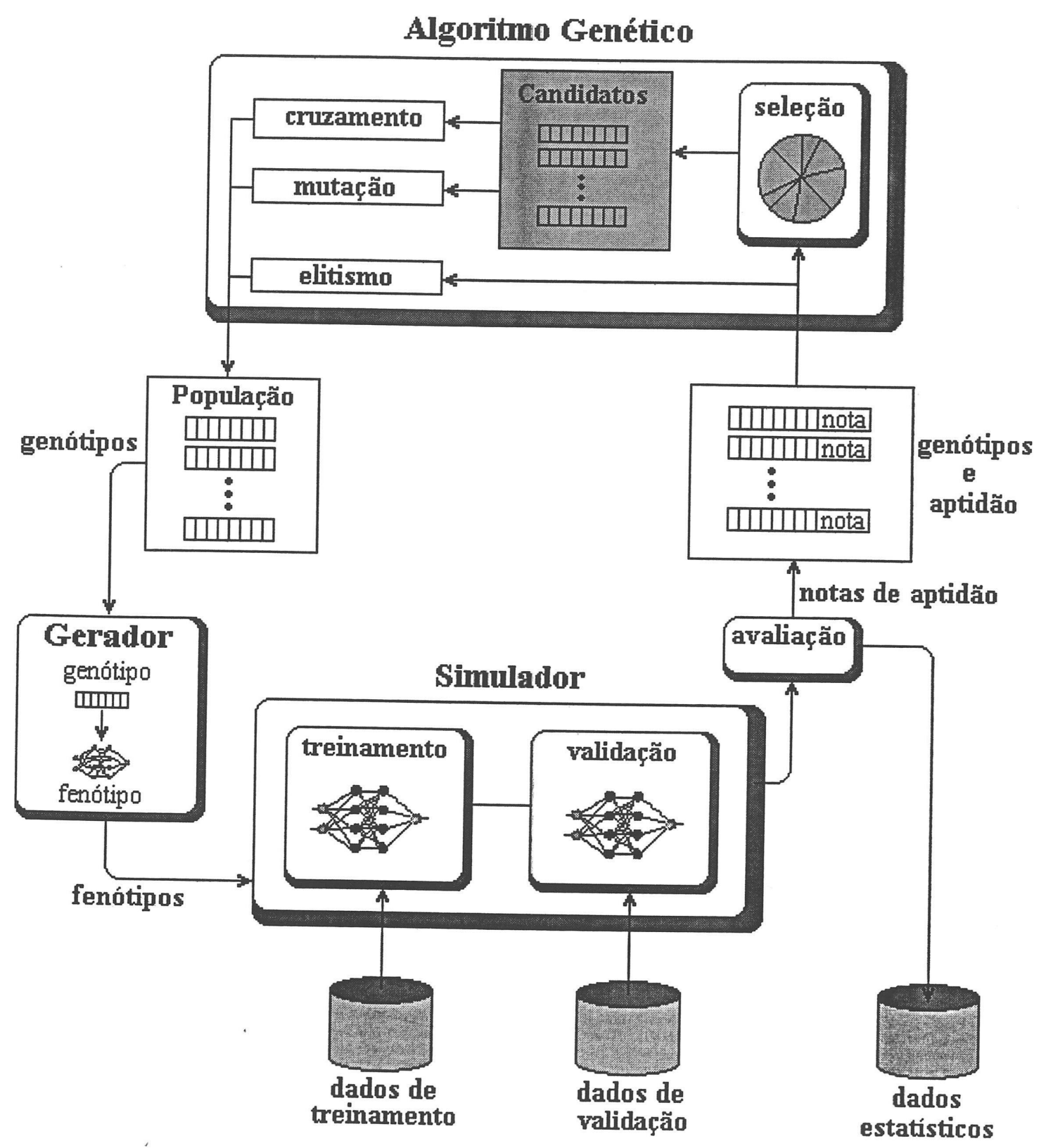

FIGURA 16 - Processos da abordagem evolucionária para projeto de arquiteturas neurais.

\subsection{Abordagens de Representação}

A questão de como uma arquitetura neural é representada genotipicamente é crítica no projeto de um sistema evolucionário. BALAKRISHNAN \& HONAVAR (1995) afirmam que a representação ou codificação utilizada determina não apenas as classes de arquiteturas neurais que podem ser geradas, mas também o funcionamento do processo de decodificação e dos operadores de reprodução. 
A representação da estrutura de uma rede neural não é uma tarefa tão direta. Vários fatores devem ser considerados para a escolha da representação: se a representação permite que soluções ótimas ou proximamente ótimas sejam representadas; como estruturas inválidas podem ser excluídas; como devem atuar os operadores de reprodução, de forma que a nova geração possua somente Redes Neurais válidas; e como a representação suporta o crescimento em tamanho das arquiteturas neurais. BRANKE (1995) sugere que o ideal seria que o espaço genético das Redes Neurais não contivesse genótipos de redes inviáveis e que pudesse expandir este espaço a todos os genótipos de redes potencialmente úteis.

Segundo WEI $\beta$ (1990). existem dois paradigmas principais de representação de Redes Neurais: a representação direta, ou de baixo-nível, e a representação indireta, ou de alto-nível. Existe uma clara distinção entre estes dois paradigmas. A seguir, serão apresentadas as principais características dos métodos existentes de representação, baseados nestes dois paradigmas, e o método de codificação utilizado neste trabalho.

\subsubsection{Representações Diretas}

Uma representação direta especifica exatamente cada parâmetro da rede e requer pouco esforço de decodificação, pois a transformação de genótipos em fenótipos é trivial. Um exemplo é a codificação em uma matriz de conexões, que especifica de maneira direta e precisa as conexões de uma Rede Neural. Contudo, este tipo de codificação pode deixar o espaço de busca muito grande, levando à necessidade de um maior número de iterações, sendo, assim, útil apenas para topologias neurais relativamente pequenas.

Um método de representação direta muito utilizado foi apresentado por MILLER et. al. (1989). Neste método, para a codificação genotípica de topologias neurais com $N$ unidades, são mapeadas estruturas na forma de matrizes de conexões binárias $N \mathrm{x}(N+1)$, onde cada elemento $\mathrm{C}_{\mathrm{ij}}$ da matriz determina a existência ou não de uma conexão entre as unidades $j$ e $i$. E, na coluna $N+1$, é representada a existência de thresholds ou bias. Este método é ilustrado na FIGURA 17.

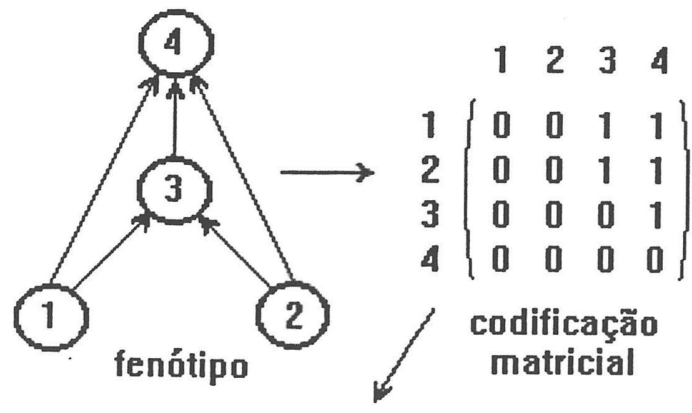

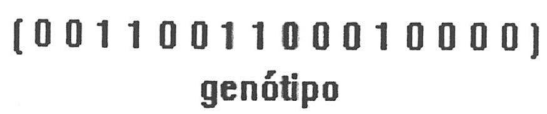

FIGURA 17 - Exemplo de representação direta. 
Este método é obviamente voltado para a escolha das conexões, visto que outros parâmetros da topologia neural devem ser previamente estabelecidos. Os problemas principais dessa abordagem são o tamanho dos códigos e a geração de estruturas incorretas Pois, são necessários códigos muito grandes para a codificação de redes com grandes números de camadas e conexões e, trabalhando com redes feedforward, podem ser geradas conexões com realimentação (feedback). O problema de geração de estruturas incorretas foi tratado eliminando as estruturas incorretas, mas quando este tipo de problema apresentar grande ocorrência, irá afetar de maneira significativa o desempenho do Algoritmo Genético.

Os problemas tratados em MILLER et. al. (1989), utilizando este método, eram problemas simples como: XOR, 4-Quadrantes e Cópia de Padrões. Seu desempenho em problemas mais complexos ainda não havia sido testado. Este método foi um dos primeiros apresentados na literatura e outros métodos foram propostos baseados neste tipo de representação. WHITLEY et. al.(1990) incluiram os valores dos pesos das conexões, tornando-o um algoritmo de treinamento ou de escolha inicial de pesos. E SHIFFMANN et. al. (1991) codificam as redes através de listas de unidades e de conexões.

\subsubsection{Representações Indiretas}

Algumas abordagens de representação não codificam diretamente as arquiteturas neurais em genótipos, mas utilizam descrições abstratas para a caracterização das redes ou, ainda, codificações gramaticais. As abordagens que utilizam representações indiretas podem exigir um esforço considerável para a decodificação na construção de fenótipos. No entanto, as redes podem ser pré-estruturadas utilizando restrições para excluir algumas arquiteturas indesejáveis, o que faz com que o espaço de busca seja muito menor. Desse modo, as buscas podem ser focalizadas na procura das melhores redes.

Uma das primeiras abordagens de representação indireta foi proposta por KITANO (1990), que codifica topologias neurais através de regras em uma gramática livre de contexto. Neste método, são utilizados símbolos não-terminais que devem ser substituídos por matrizes $2 \times 2$ de símbolos terminais e os símbolos terminais devem ser substituídos por matrizes $2 \times 2$ de binários. Nos problemas utilizados, este método apresentou um desempenho superior ao obtido através de um método de codificação direta, pois encontrou as topologias mais rapidamente e com menores taxas de erro. A diferença entre os dois métodos se acentuava a favor do método de codificação indireta quando o número de unidades intermediárias das redes aumentava. No entanto, este método também é voltado para a escolha das conexões e, como utiliza matrizes de conectividade, também necessita de códigos grandes para a representação de grandes topologias.

Alguns métodos sofisticados apresentados por HARP et. al. (1991) e MANDISHER (1993) trabalham com representações indiretas através de descrições de redes em termos de vários parâmetros, como: número de camadas, tamanho das camadas e conexões entre camadas, possibilitando a colocação de restrições na arquitetura das redes e reduzindo o número de estruturas incorretas. Com isso, o número de estruturas a serem treinadas e avaliadas, assim como o número de ciclos evolucionários necessários para se chegar a boas redes, é drasticamente reduzido. 
O método proposto por MANDISHER (1993), basicamente um aperfeiçoamento do método apresentado por HARP et. al. (1991), é voltado para a escolha da arquitetura e das conexões e utiliza uma representação que descreve os componentes principais das redes, que podem ser divididos em duas áreas: área de parâmetros e área de camadas.

Neste método, a área de parâmetros especifica a taxa de aprendizado e o termo momentum para todas as conexões da rede. Cada camada tem sua própria área de camada, especificando o número de unidades na camada e as conexões às outras camadas. As conexões são separadas em projetivas (conexões com camadas posteriores) e receptivas (conexões com camadas anteriores), e são especificadas através dos parâmetros raio e densidade. O parâmetro raio especifica o raio de conexão para cada unidade e é dado pela porcentagem relativa ao tamanho da camada de destino. Já o parâmetro densidade especifica a densidade de conexões de uma unidade receptiva e é dado pela porcentagem de unidades que estão conectadas a esta unidade, como ilustra a FIGURA 18.

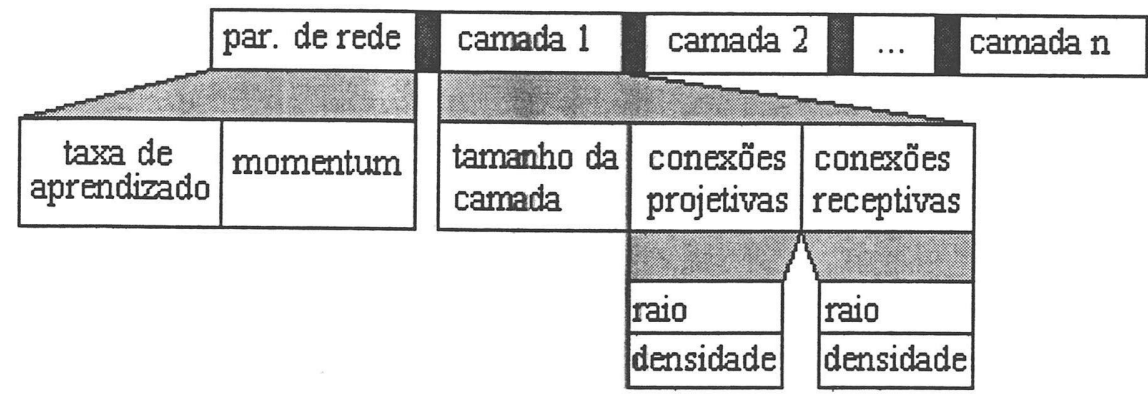

FIGURA 18 - Exemplo de representação indireta.

Um problema apresentado neste método é que sua decodificação é inexata. Os parâmetros raio e densidade são definidos como porcentagens relativas ao tamanho das unidades a serem conectadas. Durante a decodificação, as conexões são estabelecidas aleatoriamente, seguindo estes parâmetros. Assim, um mesmo código pode produzir diferentes topologias.

\subsubsection{Representação Utilizada}

O interesse deste trabalho é apenas pela escolha da arquitetura. As conexões são determinadas pelo próprio algoritmo de treinamento, fazendo com que o espaço de busca para o Algoritmo Genético seja muito menor. Assim, as redes são inicialmente inteiramente conectadas, e estritamente "em camadas" (strictly layred), ou seja, só podem existir conexões entre duas camadas consecutivas. $\mathrm{O}$ algoritmo de treinamento estabelece os pesos das conexões e estas podem ser podadas, através de um algoritmo de prunning, quando se mostrarem irrelevantes.

Por esse motivo, e devido aos recursos computacionais disponíveis, foi decidido criar uma representação que não se preocupasse com as conexões e que fosse mais direta, utilizando uma simplificação da representação proposta por MANDISHER (1993), de forma a diminuir o tamanho do espaço de busca. Com os recentes sucessos de implementações de Algoritmos Genéticos que utilizam representações com números reais e inteiros, foi decido pela sua 
utilização, como na representação de Mandisher, ao invés das representações binárias tradicionais.

Esta representação também descreve os componentes em área de parâmetros e área de camadas. A área de parâmetros especifica a taxa de aprendizado e o termo momentum para todas as conexões da rede. A área de camadas especifica o número de unidades em cada camada, podendo ser utilizadas até três camadas. Como ilustra o exemplo da FIGURA 19, esta representação requer um menor esforço de decodificação, devido a sua simplicidade e, por ser direta e exata, diferentemente das representação de Harp e Mandisher, a decodificação gera apenas uma arquitetura.

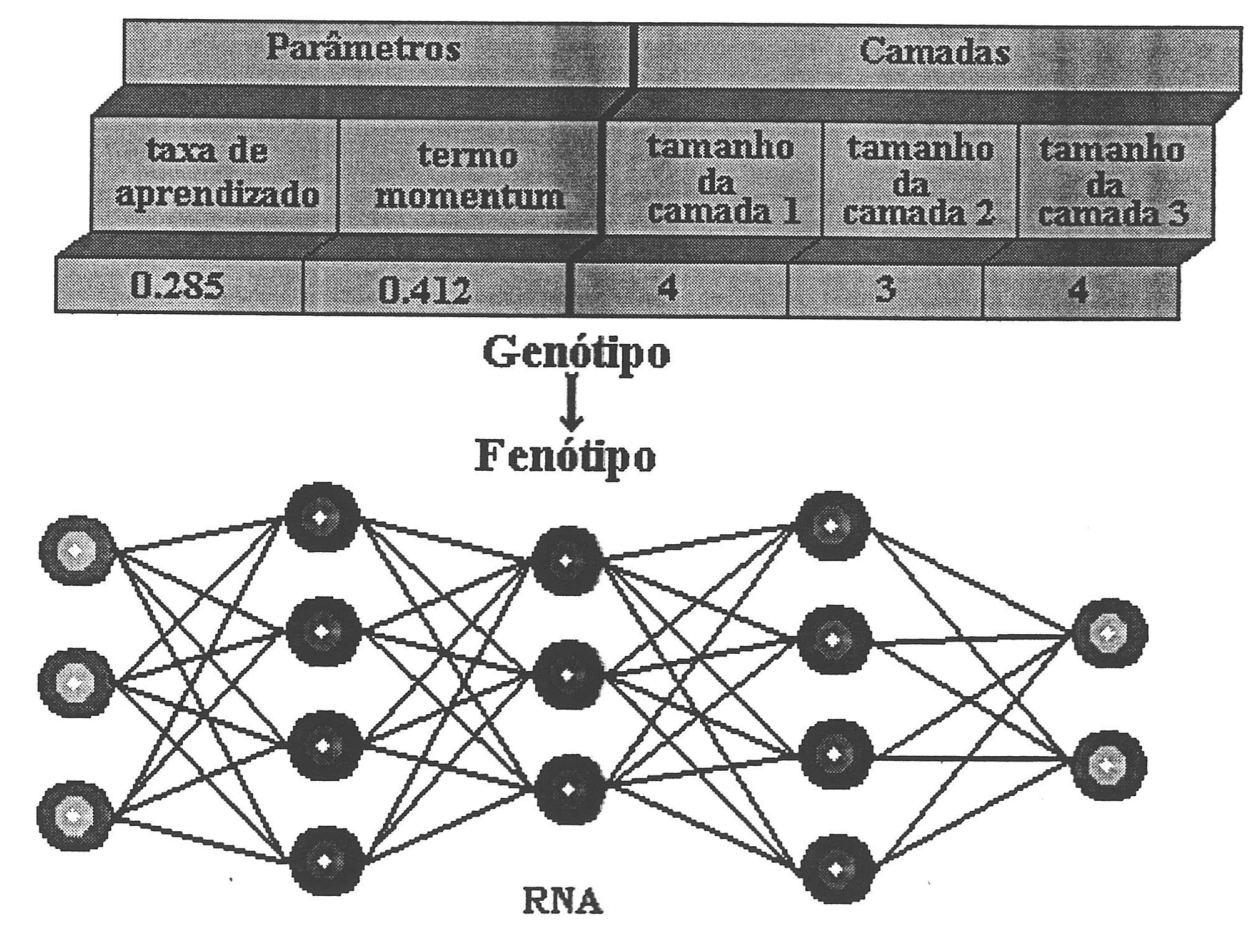

FIGURA 19 - Exemplo da representação utilizada.

Nesta representação, é necessário especificar apenas o número de unidades de entrada e saída, além do número máximo de unidades nas camadas intermediárias. Com isso, torna-se possível a representação de soluções ótimas ou proximamente ótimas. Estruturas inválidas poderiam ser geradas em apenas um caso: quando não houver unidades na segunda camada intermediária e houver na terceira. No entanto, este caso é facilmente detectável e estruturas inválidas não são geradas na fase de inicialização.

Os operadores genéticos de reprodução e mutação capazes de trabalhar com números reais e inteiros podem ser utilizados, havendo apenas alguns casos especiais a serem tratados de forma bastante simples, como será apresentado em seção posterior. 


\subsection{Avaliação de Desempenho}

Não é possível avaliar o desempenho das redes de modo direto. Só depois de terem sido treinadas, as redes poderão ser avaliadas. Os resultados obtidos durante o treinamento serão utilizados para estimar a qualidade das arquiteturas neurais. As redes devem ser treinadas por um número determinado de ciclos, utilizando os mesmos conjuntos de dados de treinamento e validação. Os resultados de treinamento e validação podem ser utilizados para determinar o desempenho destas redes e, se houver a disponibilidade, um segundo conjunto de testes deve ser utilizado para determinar o desempenho destas redes com dados não previamente vistos, que serviria como validação ao Algoritmo Genético.

Para a criação de uma função que associe uma nota de aptidão para cada uma das redes, podem ser utilizadas algumas heurísticas. Essas heurísticas podem levar em conta aspectos como: erro quadrático médio, ou número de padrões erradamente classificados nos conjuntos de treinamento e validação; integral do erro sobre o número de ciclos; tempo de treinamento; capacidade de generalização; tamanho das redes, entre outros. Tais heurísticas devem ponderar estes aspectos, levando em consideração o comportamento desejado para a aplicação. Para determinadas aplicações, a característica mais desejável poderá ser uma maior capacidade de generalização e, para outras, poderá ser uma menor taxa de erro ou, ainda, uma menor arquitetura.

Em algumas aplicações como avaliação de crédito e previsões financeiras, nas quais o sistema criado foi utilizado, foi possível especificar heurísticas de avaliação de desempenho que levassem em consideração os custos dos erros cometidos pela rede, através de uma matriz de custos, ou do cálculo dos prejuízos causados pela rede em cada transação. Com isto, as avaliações podem ser mais específicas e precisas e as notas dadas mais representativas da real de aptidão das redes na solução destes problemas. No problema de avaliação de crédito, uma função de desempenho pode ser calculada pela eq. (13).

Aptidão = Custo Máximo - (Custo no Treinamento + 2 . Custo na Validação $)$

Nos quais:

Custo Máximo = $($ Custo Máximo no Treinamento +2 . Custo Máximo na Validação $)$

Custo Máximo no Treinamento $=(\mathrm{C} 1$. NPTC1 + C2. NPTC2 $)$

Custo Máximo na Validação $=(\mathrm{C} 1$. NPVC1 $+\mathrm{C} 2$. NPVC2 $)$

Custo no Treinamento $=(\mathrm{C} 1$. NPTEC1 + C2. NPTEC2 $)$

Custo na Validação $=(\mathrm{C} 1$. NPVEC1 + C2. NPVEC2 $)$

$\mathrm{Cn}=$ Custo de um erro de classificação nos padrões da classe $n$

NPTC $n=$ Numero de padrões de treinamento da classe $n$

NPVCn $=$ Numero de padrões de validação da classe $n$

NPTECn $=$ Numero de padrões de treinamento erradamente classificados da classe $n$

NPTECn $=$ Numero de padrões de validação erradamente classificados da classe $n$ 
Como a avaliação das arquiteturas neurais envolve treinamentos e testes, o custo computacional é muito elevado. No entanto, devido às características inerentemente paralelas dos algoritmos envolvidos, sua utilização em ambientes distribuídos ou em implementações paralelas, como as apresentadas por HUNG \& ADELI (1994) pode reduzir estes custos.

\subsection{Reprodução}

A estratégia de reprodução é o ponto mais importante de um Algoritmo Genético. A definição desta estratégia deve levar em consideração as características da representação a ser utilizada, as necessidades do problema e os recursos computacionais disponíveis. Na definição da estratégia de reprodução, devem ser especificados os mecanismos de seleção, as políticas elitistas, os operadores de cruzamento e mutação e suas respectivas taxas de ocorrência. Estes aspectos serão analisados nas próximas subseções.

\subsubsection{Mecanismo de Seleção}

Neste trabalho, foi utilizado o método da roleta baseado em aptidão relativa, mecanismo clássico de seleção, pois o interesse era na escolha das melhores arquiteturas, mas mantendo a diversidade da população. Uma variante deste método, baseada em ranking, favorece muito os indivíduos de maior aptidão e, com isso diminui ainda mais a diversidade. No entanto, como mostrado por WHITLEY (1989), esta variante pode funcionar melhor que o método clássico quando os valores de aptidão forem muito próximos.

No método baseado em aptidão relativa, com $n$ indivíduos da população, são dadas notas de aptidão $A$ para cada indivíduo $i$ e, através da eq. (14), são calculadas as notas de aptidão relativa $R$ dos $n$ indivíduos. Para a escolha de $k$ candidatos, a roleta é girada por $k$ vezes, determinando cada candidato $c$. Isto é feito através da escolha de um número aleatório $x$ que indica o indivíduo $i$ a ser colocado no conjunto $S$ de candidatos, como mostra a eq. (15). Os indivíduos do conjunto de candidatos poderão ser manipulados pelos operadores genéticos de cruzamento e mutação.

$$
\begin{gathered}
R_{i}=\frac{A_{i}}{\sum_{j=1}^{n} A_{j}} \\
S_{c}=i \quad \text { se } \sum_{j=1}^{i-1} R_{j}<x \leq \sum_{j=1}^{i} R_{j} \quad i=1,2, \ldots, n
\end{gathered}
$$

Através deste método, são selecionadas, preferencialmente, as redes de maior aptidão, como ilustra a FIGURA 20, com uma população de 5 indivíduos e um conjunto de 5 candidatos. 


\begin{tabular}{|c|c|c|}
\hline Individuo & Nota & Nota Relativa \\
\hline 1 & 506 & 0,1105 \\
\hline 2 & 1147 & 0,2505 \\
\hline 3 & 1268 & 0,2769 \\
\hline 4 & 1373 & 0,2998 \\
\hline 5 & 285 & 0,0622 \\
\hline
\end{tabular}

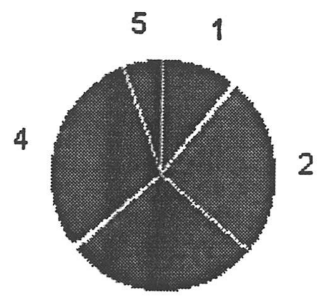

3

\begin{tabular}{|c|c|}
\hline Roleta $(k)$ & Candidato Escolhido \\
\hline 0,3186 & 2 \\
\hline 0,7845 & 4 \\
\hline 0,5124 & 3 \\
\hline 0,8604 & 4 \\
\hline 0,1056 & 1 \\
\hline
\end{tabular}

FIGURA 20 - Um exemplo de seleção pelo método da roleta.

\subsubsection{Elitismo}

De forma a evitar que a arquitetura com maior nota de aptidão desapareça da população pela manipulação dos operadores genéticos, foi utilizada uma política elitista. Ou seja, a arquitetura com a maior nota de aptidão é automaticamente colocada na próxima geração. Pode ocorrer o fato de várias arquiteturas terem a (mesma) maior nota. Neste caso, o critério de desempate escolhido é o tamanho da topologia, favorecendo, assim, a rede com o menor número de unidades.

\subsubsection{Operadores Genéticos}

Os operadores genéticos são utilizados para transformar a população de arquiteturas neurais através das gerações, diversificando esta população e mantendo as características desejáveis adquiridas pelas gerações anteriores. Neste trabalho, estas características podem ser: taxa de aprendizado, termo momentum e número de unidades nas camadas intermediárias. Eles são especificados de acordo com a representação utilizada. Podem ser utilizadas funções que limitem suas transformações, heurísticas de transformação de acordo com a funcionalidade desejada, além de funções que assegurem a validade das arquiteturas neurais geradas.

O operador genético de cruzamento, operador predominante, é responsável pela recombinação de características das redes durante a reprodução, permitindo que as próximas gerações herdem características desejáveis. 0 cruzamento pode ser utilizado de várias maneiras, mas neste trabalho foi utilizado apenas o cruzamento de um-ponto.

Este operador pode fazer uma troca de características entre duas arquiteturas, que são selecionadas com probabilidade dada pela taxa de cruzamento $\mathrm{P}_{c},\left(0 \leq \mathrm{P}_{\mathrm{c}} \leq 1\right)$. O operador de cruzamento tradicional foi modificado de forma a trabalhar com números reais e inteiros. Através de um número escolhido aleatoriamente, este operador especifica o ponto de cruzamento no qual as características das duas arquiteturas serão trocadas, como ilustra a FIGURA 21. 


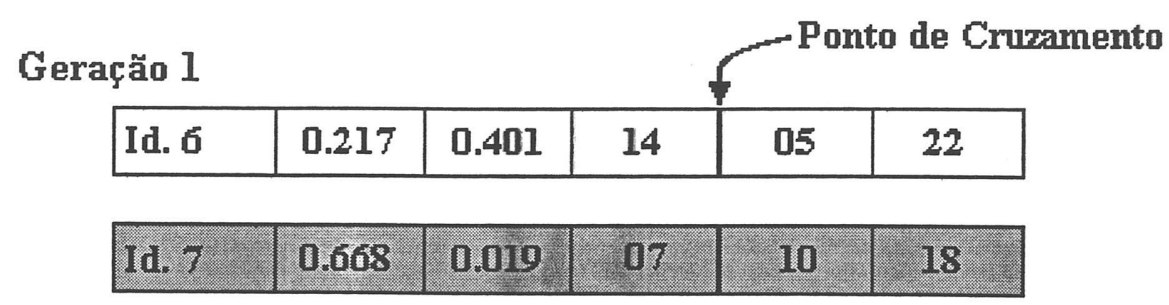

Geração 2

\begin{tabular}{|c|c|c|c|c|c|}
\hline Id. 21 & 0.217 & 0.401 & 14 & 10 & 18 \\
\hline Id. 22 & 0.668 & 0.019 & 07 & 05 & 22 \\
\hline
\end{tabular}

FIGURA 21 - Exemplo do operador de cruzamento utilizado.

$\mathrm{Na}$ especificação deste operador, utilizando diferentes abordagens de representação, há sempre uma grande preocupação com a validade das arquiteturas geradas. Utilizando a representação proposta, existe apenas um caso em que é gerada uma arquitetura inválida: quando uma das arquiteturas apresentar zero unidade na segunda e na terceira camada intermediária; a outra apresentar um número qualquer de unidades na segunda e terceira camadas; e o ponto de cruzamento for o ponto entre estas duas camadas, como ilustra a FIGURA 22. Neste caso, o operador irá gerar uma rede com zero unidade na segunda camada intermediária e $N$ unidades na terceira. No entanto, este caso especial é facilmente identificado e tratado, excluindo a arquitetura inválida da população. Assim, somente arquiteturas corretas de redes participam do processo de evolução.

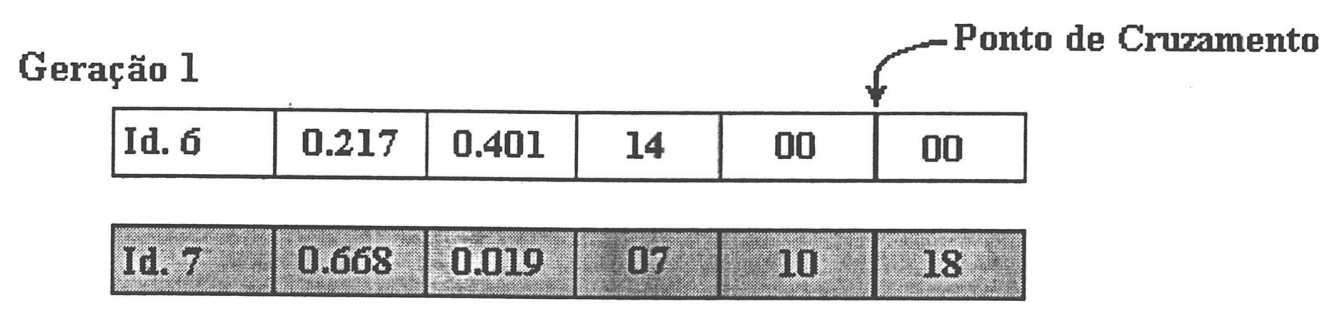

Geração 2

\begin{tabular}{|l|l|l|l|l|l|}
\hline Id. 21 & 0.217 & 0.401 & 14 & 00 & 18 \\
\hline Id. 22 & 0.668 & 0.019 & 07 & 10 & 00 \\
\hline
\end{tabular}

FIGURA 22 - Caso especial de cruzamento que pode gerar uma arquitetura inválida. 
A atuação do operador genético de mutação, operador secundário, deve causar apenas pequenas mudanças qualitativas nas características das arquiteturas das redes durante a reprodução, permitindo que as próximas gerações possam se diversificar mais.

Uma arquitetura é escolhida para mutação com probabilidade dada pela taxa de mutação $\mathrm{P}_{\mathrm{m}}$ $\left(0 \leq \mathrm{P}_{\mathrm{m}} \leq 1\right)$, geralmente muito menor que a taxa de cruzamento. Com isso, uma das características da arquitetura é alterada. O operador de mutação tradicional também foi modificado de forma a trabalhar com números reais e inteiros. Neste caso, a taxa de mutação deve ser um pouco maior que esta taxa no operador tradicional.

Assim, através de um número escolhido aleatoriamente, é especificado o ponto de mutação no qual a característica da arquitetura é alterada para um valor também escolhido aleatoriamente, seguindo limites máximos e mínimos definidos para cada característica, como ilustra a FIGURA 23.

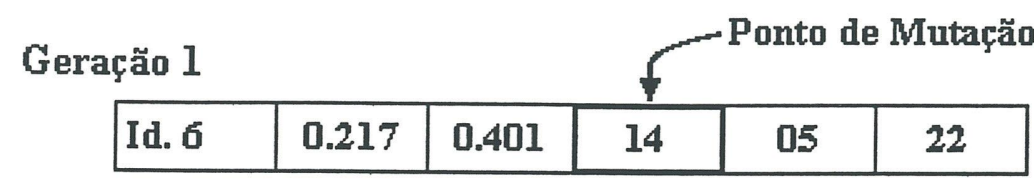

Geração 2

\begin{tabular}{|l|l|l|l|l|l|}
\hline Id. 25 & 0.217 & 0.401 & 10 & 05 & 22 \\
\hline
\end{tabular}

FIGURA 23 - Exemplo do operador de mutação utilizado.

$\mathrm{Na}$ especificação deste operador, também existe a preocupação com a validade das arquiteturas geradas. Utilizando a representação proposta, existe apenas um caso em que é gerada uma arquitetura inválida: quando a arquitetura apresentar zero unidade na segunda e terceira camadas intermediárias e o ponto escolhido para mutação for o ponto da terceira camada, como ilustra a FIGURA 24. Este caso especial, de ocorrência ainda mais rara que o caso especial de cruzamento, também é facilmente identificado. Ele é tratado, excluindo a arquitetura inválida da população.

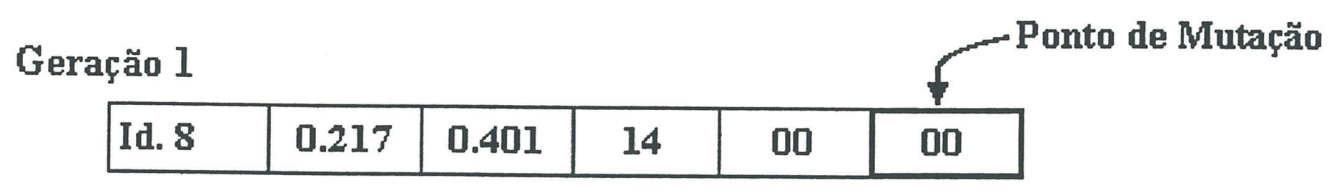

Geração 2

\begin{tabular}{|l|l|l|l|l|l|}
\hline Id. 27 & 0.217 & 0.401 & 10 & 00 & 04 \\
\hline
\end{tabular}

FIGURA 24 - Caso especial de mutação que pode gerar uma arquitetura inválida. 


\subsection{Considerações Finais}

Neste capítulo, foi mostrado que o projeto de arquiteturas de Redes Neurais MLP pode ser automatizado utilizando Algoritmos Genéticos para a busca de arquiteturas aproximadamente ótimas. Foram mostrados os principais aspectos dos processos de codificação, avaliação de desempenho e reprodução. Foram analisados os principais métodos de codificação existentes para representação direta e indireta de arquiteturas neurais e foi apresentado um método de codificação adequado às necessidades particulares envolvidas neste trabalho. Uma função para associação de notas de aptidão para os problemas de avaliação de crédito foi apresentada. Foram também mostrados os mecanismos de seleção e o funcionamento dos operadores genéticos de mutação e cruzamento.

Os modelos existentes analisados tratavam eficientemente problemas simples como XOR e alguns outros. A utilização destes métodos em problemas complexos não foi encontrada na literatura. Devido à necessidade de grandes códigos, ao tamanho do espaço de busca e do tempo necessário para a avaliação das arquiteturas neurais, a utilização destes métodos em problemas reais pode ser impraticável. No método proposto, foram colocadas algumas restrições, fazendo com que a codificação seja pequena e de tamanho fixo, de forma a tornar menor o espaço de busca, visto que, neste trabalho, os problemas tratados são problemas complexos do mundo real.

No capítulo seguinte, será apresentado o problema de avaliação de crédito financeiro, serão analisadas as abordagens existentes e será proposto um sistema neural para o seu modelamento. 


\section{Avaliação de Crédito}

\subsection{Introdução}

O mercado financeiro é afetado por um grande número de fatores econômicos, políticos e psicológicos, fortemente relacionados e que interagem entre si de uma maneira bastante complexa. Além disso, a maior parte destas relações parecem ser probabilísticas e não-lineares. Portanto, estas relações dificilmente poderiam ser expressas através de regras.

SIMON (1960) classifica as decisões gerenciais financeiras em um intervalo contínuo, variando entre altamente estruturadas e altamente não-estruturadas. Nas decisões altamente estruturadas, os processos para a obtenção de uma solução (razoavelmente) boa são bem conhecidos de antemão e existem inúmeras ferramentas computacionais para o auxílio a estes tipos de decisões. Já para as decisões não-estruturadas, somente a intuição e a experiência de gerentes são utilizadas. Estes gerentes podem contar até com auxílio de especialistas em determinadas áreas, mas as decisões finais tomadas pelos gerentes geralmente envolvem substanciais elementos subjetivos. HAWLEY et. al. (1996) afirmam que problemas altamente não-estruturados não são facilmente adaptáveis aos métodos convencionais de análise auxiliada por computador ou sistemas de suporte a decisões.

Sistemas de suporte a decisões financeiras devem transformar grandes quantidades de dados em classificações inteligíveis, reconhecendo tendências e padrões em conjuntos de dados utilizados. No setor de serviços financeiros, sistemas inteligentes de suporte a decisões, baseados em Redes Neurais, vêm sendo amplamente empregados em uma grande gama de tarefas, incluindo projeção de autorização de crédito, CARTER \& CATLETT (1987); avaliação de risco de falência LEE \& KIM (1994); previsão econômica e financeira WHITE (1988), entre outras.

Recentemente, alguns bancos como o Citibank e o Chase Manhattan, além de empresas de investimento como a Morgan Stanley Inc., vêm utilizando sistemas neurais para previsões financeiras e suporte a decisões, em substituição a métodos estatísticos, como regressão linear e análise discriminante.

$\mathrm{Na}$ área de avaliação de crédito, um dos sistemas especialistas de maior sucesso é o American Express Credit Autorizer's Assistant, utilizado para tomada de decisão sobre autorização de compras realizadas por clientes. Como este tipo de cartão não tem limite fixo, cada transação é uma nova requisição de crédito. Atualmente, este sistema é utilizado em bases 
de atendimento por telefone 24 horas e tem ajudado a reduzir o tempo gasto nestas transações em 20\%. Como mostram TRELEAVEN \& GONNATILAKE (1992), a qualidade das decisões tomadas por este sistema são em média $50 \%$ melhores que decisões tomadas pelo pessoal de autorização de crédito.

Outras empresas provedoras de cartões de crédito, como Mastercard e Visa, já dispõem de projetos para a construção de sistemas semelhantes ao da American Express, utilizando Redes Neurais Artificiais. Estes sistemas serão empregados para avaliação de propostas de novos clientes, detecção de fraudes na utilização dos cartões, além de avaliação sobre autorização de compra. VISA (1995). O Falcon, um sistema neural da HNC para detecção de fraudes na utilização de cartões de crédito, é apontado como o maior processador de cartões de crédito dos Estados Unidos. Testes mostraram que os modelos neurais são melhores que os modelos convencionais e de avaliação humana na detecção de fraudes. Em nota na revista AI EXPERT JUNE 1994, a HNC alega que seu sistema tenha economizado 50 milhões de dólares em prejuízos com fraudes.

$\mathrm{Na}$ maioria dos ambientes de avaliação de crédito, os gerentes financeiros trabalham com uma enorme variedade de informações vindas das mais diversas fontes. Muitas destas informações podem ser incompletas, ambíguas, parcialmente incorretas ou de relevância dúbia. Além disso, estes ambientes são dinâmicos, com constantes alterações, nos quais as decisões devem ser tomadas rapidamente. Devido a estes aspectos, estes ambientes podem ser classificados como altamente não-estruturados. Os gerentes analisam estas informações de maneira muito subjetiva e, muitas vezes, não conseguem explicar os processos de tomada de decisões, embora consigam apontar os fatores que influenciam suas decisões, o que também dificulta o processo de aquisição de conhecimento para o desenvolvimento de sistemas especialistas tradicionais.

Os sistemas que utilizam Redes Neurais Artificiais estão se tornando uma técnica muito atrativa para estas aplicações, pois oferecem uma alternativa mais eficiente para tratar informações dessa natureza.

As seções seguintes apresentam uma análise dos principais aspectos relacionados aos problemas de avaliação de crédito, as abordagens mais utilizadas, as características das Redes Neurais Artificias que justificam sua adequação para a solução de problemas de avaliação de crédito e uma proposta de um sistema baseado em Redes Neurais Artificiais para a solução deste problema.

\subsection{Avaliação de Crédito}

O crédito a pessoas físicas, nas diversas modalidades financeiras de cartão de crédito, crédito direto ao consumidor e cheque especial, tem sido tratado empiricamente ou por sistemas de credit score baseados em análise discriminante ou de regressão logística. No entanto, nos últimos anos, em razão do crescimento do mercado de crédito ao varejo (crédito massificado ao 
consumidor), esta atividade passou a merecer maior atenção e preocupação, notadamente em razão da forte elevação das taxas de inadimplência.

O crédito massificado ao consumidor caracteriza-se por: transações de baixo ou médio valor em grande quantidade; por estar fundamentada em enorme quantidade de dados sobre a clientela; e por mutações no perfil de comportamento dos tomadores de crédito, decorrentes de mudanças nas variáveis econômicas: quem não seria inadimplente sob condições normais, poderá vir a sê-lo sob redução da liquidez da economia. Portanto, exige baixo custo operacional e risco controlado. Os prejuízos causados aos doadores de recursos são enormes e qualquer redução do risco poderá implicar em grandes benefícios.

No método empírico de avaliação de crédito, também chamado de Análise Casuística, os dados de um cliente são analisados por gerentes que decidem quanto à aceitação ou rejeição da aplicação, baseados em informações sobre o cliente, em sua experiência gerencial e em relatórios de departamentos administrativos ou agências de crédito. Esta é uma tarefa muito trabalhosa, demorada e que tem um impacto significativo nos lucros das empresas. Como se isto não bastasse, as decisões devem ser muito criteriosas, pois decisões erradas podem provocar não apenas prejuízos financeiros à instituição de crédito, mas também prejuízos financeiros e morais aos seus clientes.

Este método de avaliação apresenta os seguintes problemas:

- Baixa Eficiência. Consome muito tempo e necessita de pessoal altamente especializado realizando tarefas numerosas e repetitivas.

- Baixo Desempenho. A experiência de grande parte dos gerentes não é suficientemente abrangente para produzir avaliações muito meticulosas.

- Pouca Flexibilidade. Uma grande experiência é necessária antes que os gerentes possam realizar esta tarefa. Este método reage muito vagarosamente a mudanças.

- Inconsistência. Diferentes gerentes utilizam diferentes critérios de avaliação.

Com níveis de inadimplência elevado nas aplicações de crédito ao varejo, as instituições financeiras foram em busca de sistemas mais apurados para a gerência de risco. Inicialmente, técnicas estatísticas, como análise discriminante, foram largamente utilizadas em sistemas automatizados de Credit Score para auxílio de avaliações. Entre alguns destes sistemas pode-se citar o Apprise(tm) Financials Accounts Receivable para plataformas AS-400 e o SAS Financial Solutions for Credit Analysis.

Estes sistemas melhoraram os processos de avaliação, pois apresentam maior flexibilidade, consistência e eficiência, principalmente devido à utilização de técnicas de gerenciamento de dados. Mas como explicam CARTER \& CATLETT (1987), alguns fatores destas técnicas, como a modelagem linear, não são muito apropriados para estes problemas e podem comprometer o desempenho destes modelos. Em razão disto, novas abordagens ao problema tornaram-se necessárias. Entre as mais proeminentes das novas técnicas apresentadas, estão os sistemas especialistas e, como já mencionado, os sistemas neurais. 
A primeira, tradicionalmente, utiliza sistemas baseados em regras, onde o conhecimento de especialistas na área é adquirido através de entrevistas e outros métodos. Esta abordagem modela o processo de avaliação através de regras obtidas de especialistas humanos e não através de registros anteriores das aplicações de crédito. Entre os sistemas especialistas existentes de maior sucesso pode-se citar o American Express Credit Autorizer's Assistant e o Credit Analysis Advisor da Financial Proformas. Embora esta abordagem evite os problemas de consistência e eficiência, não evita o problema de desempenho e aumenta o problema de flexibilidade, visto que o processo de extração de conhecimento pode ser muito demorado e o tempo de vida do modelo muito curto, já que estes ambientes são dinâmicos e apresentam constantes mutações de comportamento.

Os sistemas de aprendizado baseado em exemplos, como os sistemas neurais, oferecem uma abordagem mais adequada para o tratamento de problemas deste tipo. Uma Rede Neural pode ser treinada utilizando grandes quantidades de exemplos significativos, o que contribui para a obtenção de um desempenho mais elevado. Ou seja, a avaliação é modelada através de exemplos de aplicações bem ou mal sucedidas, encontrados nos históricos dos clientes e não através de modelos objetivos ou quantificáveis da operação de avaliação. Como realiza uma modelagem não-linear, a rede é capaz de encontrar relações entre as diversas informações e incorporar os aspectos subjetivos do processo de avaliação da empresa.

Estes sistemas são mais flexíveis pois, quando mudanças são necessárias devido a aspectos políticos, econômicos ou regionais, pode-se alterar apenas o conjunto de exemplos de treinamento e alguns parâmetros da rede, o que não requer grandes mudanças estruturais no sistema. Estes sistemas podem, até mesmo, se auto monitorar e, detectando esta necessidade, realizar as mudanças necessárias e realizar um novo treinamento automaticamente. Também são considerados consistentes e eficientes, pois um mesmo sistema pode ser utilizado nos diferentes postos de atendimento, ser operado por pessoal sem experiência gerencial e realizar avaliações mais rapidamente.

Segundo ALMEIDA \& DUMONTIER (1996), devido a estas qualidades, os sistemas neurais permitem às empresas explorar seu ambiente de maneira privilegiada e assegurar sua perenidade, transformando dados em informações úteis à tomada de decisão, aumentando o valor agregado dos seus produtos e serviços.

Alguns exemplos de sistemas neurais para avaliação de crédito existentes são o BrainMaker Credit Scoring da California Scientific Software e o Capstone da HNC, que é um sistema híbrido de redes neurais e estatística. Muitos outros sistemas de avaliação de crédito vêm sendo produzidos pelas empresas, geralmente utilizando pacotes ou simuladores comerciais de Redes Neurais, como o Predict da Neuralware, o BrainMaker da California Scientific Software, o MATLAB Neural Network Toolbox da MathWorks, o NeuroForecaster da Accel Infotech, entre outros. Muitos destes pacotes apresentam limitações no treinamento ou arquiteturas de redes padronizadas e, algumas vezes, são manipulados por pessoal sem qualquer experiência com Redes Neurais, podendo produzir modelos limitados. Contudo, quando utilizados apropriadamente, podem produzir boas soluções. 


\subsection{Sistema Neural para Avaliação de Crédito}

Nesta seção, serão apresentados os módulos do NeurAval, um sistema neural para avaliação de crédito, e as fases do treinamento e utilização da rede através do Módulo Neural do NeurAval. O sistema pode ser dividido, como ilustra a FIGURA 25, em dois módulos principais:

1. Módulo de Aplicação. Constituído de um submódulo Gerenciador de Banco de Dados e de um submódulo de Interface.

O Gerenciador é responsável pela manutenção dos dados dos clientes, dos quais é possível extrair um histórico das aplicações negadas ou concedidas e/ou bem ou mal sucedidas, de modo que se tenha uma classificação destas aplicações em níveis, de acordo com o interesse da empresa por estes clientes. Esta classificação será utilizada durante o treinamento da rede como saída desejada e, durante a avaliação, os clientes serão classificados de acordo com estes níveis. O Gerenciador também é responsável pela reunião dos dados potencialmente úteis à tarefa de avaliação.

A Interface é responsável pela integração do Sistema de Aplicação com o Operador, com o Gerenciador e com o Módulo Neural e deve conter facilidades de operação e boa documentação, adequando o sistema ao ambiente de operações da empresa.

2. Módulo Neural. Constituído pelo submódulo de Desenvolvimento e pelo submódulo de Avaliação.

O submódulo de Avaliação é constituído de um Pré-processador, responsável pela transformação de dados para utilização na rede, e pela própria Rede Neural.

O submódulo de Desenvolvimento é constituído por: um Gerador de Conjuntos que irá determinar os conjuntos de dados utilizados nas diferentes fases do treinamento da rede e pelos processos de Treinamento e Teste da rede. 


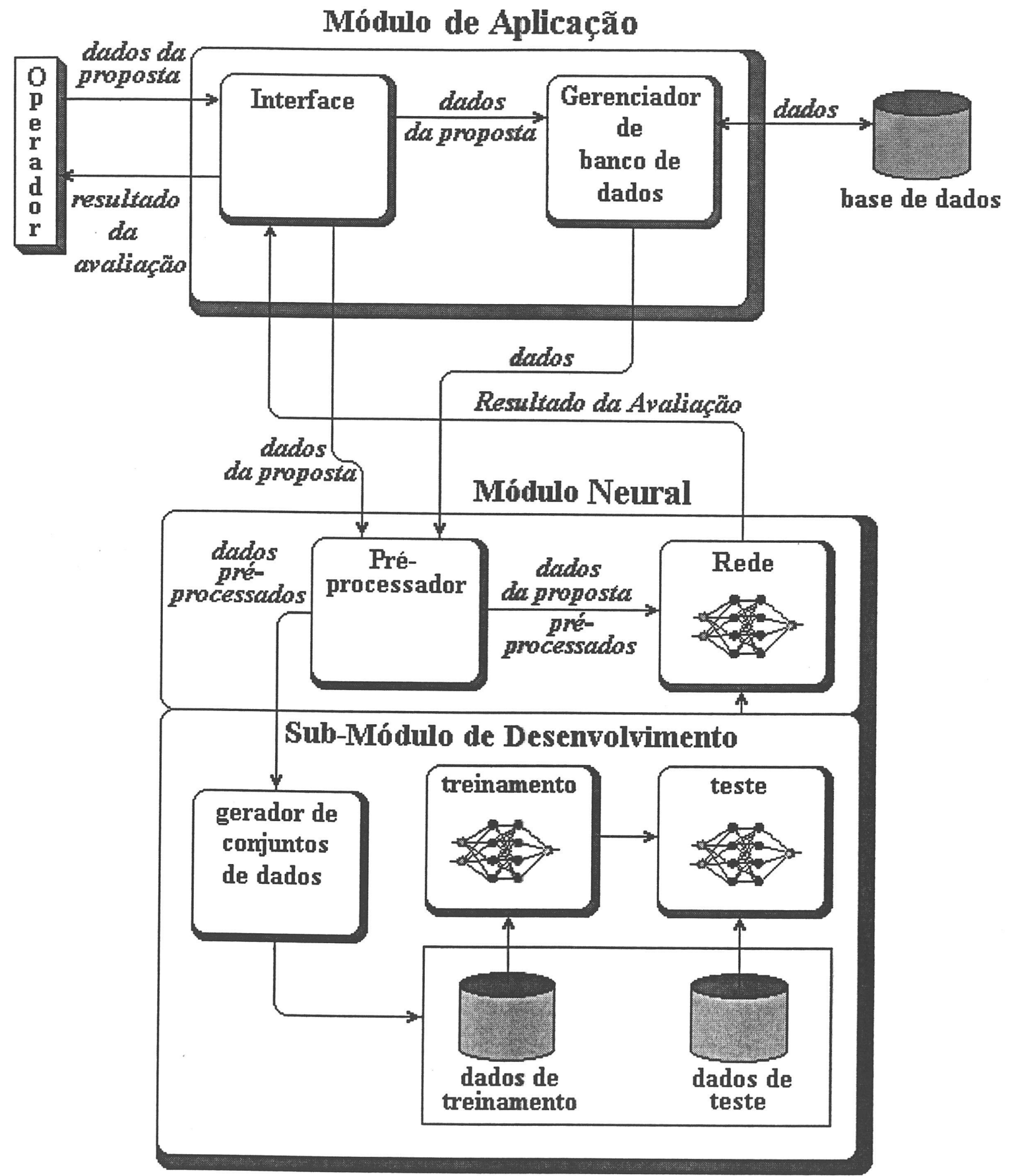

FIGURA 25 - Modelo de integração de módulos do NeurAval. 
A seguir, será apresentado o processo de desenvolvimento da rede no NeurAval, que pode ser dividido nas seguintes fases:

A. Coleta de Dados. Nesta primeira fase, são reunidos todos os dados pertinentes e potencialmente úteis à tarefa. Estes estão contidos nas bases de dados da empresa, facilitando este processo, e serão passados ao Módulo Neural pelo Gerenciador de banco de dados. Dados como nomes e endereços de clientes podem ser descartados do conjunto que será utilizado pela rede. Outros dados podem ser transformados em formas mais simples ou adequadas ao sistema de avaliação.

B. Pré-processamento dos Dados. Dados simbólicos são transformados em dados numéricos, mais adequados para utilização pela rede. Estas transformações incluem normalização, escalonamento e outras conversões, feitas automaticamente pelo sistema. As funções de pré-processamento dos dados, que serão utilizados durante o treinamento, deverão ser incluídas no sistema do ambiente da aplicação, para o pré-processamento dos dados durante sua utilização pela rede.

C. Separação dos Conjuntos de Dados. Os dados coletados são separados, pelo Gerador de Conjuntos, em conjuntos de treinamento, validação e teste, para serem utilizados em cada uma das fases do desenvolvimento da rede. Estes conjuntos são cuidadosamente escolhidos para cobrir extensivamente o domínio do problema. Além disso, eles devem ser colocados em ordem aleatória dentro dos conjuntos, para prevenir quanto à influência da ordenação natural. Segundo as regras do PROBEN1 apresentadas por PRECHELT (1994), estes conjuntos devem conter $50 \%, 25 \%, 25 \%$ de todos os dados, respectivamente. Um outro método utilizado por KLIMASAUSKAS (1991) leva em consideração a distribuição das classes nos conjuntos. Neste método, os conjuntos de teste e validação devem conter a mesma proporção de classes apresentadas no conjunto integral e, o conjunto de treinamento, um mesmo número de padrões de cada classe.

D. Seleção da Arquitetura, Treinamento e Teste da Rede. Como já mencionado, a escolha da arquitetura adequada da rede tem um impacto substancial no desempenho do sistema. Nesta fase, é utilizado o sistema proposto para o projeto evolucionário de arquiteturas neurais. Através deste sistema, é escolhida uma arquitetura adequada à aplicação. $\mathrm{O}$ treinamento é realizado com o algoritmo backpropagation e, em seguida, são realizados os testes. Com os testes obtêm-se as medidas de desempenho da rede. Essas medidas são obtidas através de várias simulações, de modo a representarem, da forma mais fiel possível, o comportamento futuro da rede.

E. Integração da Rede Neural ao Sistema. Uma vez treinada, a rede pode ser integrada ao sistema de avaliação. De forma a obter uma maior eficiência da solução, várias redes são integradas ao sistema, formando um comitê de avaliação. 


\subsection{Considerações Finais}

Neste capítulo, foram mostradas as motivações para a utilização de Redes Neurais em sistemas para auxílio a decisões da área financeira. Através da analise das características do problema de gestão de crédito massificado, foi mostrado que este é um problema bastante complexo e que envolve decisões altamente não-estruturadas. Foram analisadas as principais abordagens para o tratamento deste problema: Análise Casuística; técnicas estatísticas de Credit Scoring; Sistemas Especialistas e Redes Neurais.

A abordagem empírica de avaliação de crédito, ou Análise Casuística, foi analisada e foram apontadas as maiores deficiências dessa abordagem: baixa eficiência; desempenho insatisfatório; pouca flexibilidade e inconsistência.

As abordagens de Credit Score baseadas em técnicas estatísticas para avaliação de crédito melhoraram os processos de avaliação devido principalmente à automação do processo e à utilização de técnicas de gerenciamento de dados. No entanto, estas abordagens podem apresentar problemas de desempenho, devido à modelagem linear.

As abordagens que utilizam Sistemas Baseados em Regras podem ser atrativas em alguns casos mais estruturados, mas também apresentam baixa eficiência e desempenho.

Foram mostradas as principais características que contribuem para que as abordagens que utilizam Redes Neurais ofereçam o tratamento mais adequado a este tipo de problema, como: aprendizado baseado em exemplos; modelagem não-linear; rapidez de processamento, facilidade de modificação.

Foram também citados alguns exemplos de sistemas existentes que utilizam cada uma destas abordagens.

Finalmente, foi proposto um sistema neural para avaliação de crédito, o NeurAval. Foram apresentados cada um dos módulos e submódulos desse sistema e foram analisadas todas as fases do processo de desenvolvimento da rede utilizando este sistema.

No capítulo seguinte, serão mostradas as metodologias utilizadas em cada parte deste trabalho, os experimentos realizados e os resultados obtidos. 


\section{Metodologia, Resultados e Discussões}

Neste capítulo, serão apresentadas as metodologias utilizadas na construção dos protótipos do sistema de avaliação de crédito, NeurAval, e do sistema de projeto evolucionário de arquiteturas neurais, NeurEvol. Serão apresentados e discutidos os experimentos realizados com os protótipos desenvolvidos e análisados os resultados obtidos.

\subsection{NeurAval}

Durante o desenvolvimento deste trabalho, foi criado, utilizando a linguagem Delphi, um protótipo de sistema de avaliação de crédito, o NeurAval, MENDES \& CARVALHO (1996). O protótipo criado consiste de: um módulo gerenciador de banco de dados; um módulo para a criação de conjuntos de dados, pré-processamento dos dados e conversão de tipos; e um módulo que utiliza a rede para a avaliação.

Neste protótipo não foram incluídos os submódulos de treinamento e teste. Durante este projeto, todo o desenvolvimento, treinamento e teste das redes foram feitos através do simulador SNNS - Stuttgart Neural Network Simulator, ZELL et. al. (1995); DINIZ et. al (1997), que oferece um ambiente eficiente e flexível para pesquisa e aplicação de Redes Neurais. O componente XGUI - Graphical User Interface, deste simulador, foi utilizado para a criação das redes e avaliação preliminar das arquiteturas geradas, e o componente Batchman - Batch Simulator, que fornece um interpretador com uma sintaxe muito adequada à simulação de Redes Neurais, foi utilizado através de programas que permitiam a construção de esquemas de treinamento mais elaborados e a análise mais aprofundada dos desempenhos obtidos pelas redes.

Nestes programas Batchman, foram definidos os conjuntos de dados a serem utilizados em cada fase, as redes, a função de treinamento, os parâmetros de aprendizado, intervalo de validação, número de ciclos de treinamento e critério de parada a serem utilizados, além dos testes a serem realizados. Com a execução destes programas, são gerados arquivos de resultados com relatórios sobre o andamento do treinamento e resultados dos testes.

A seguir serão apresentados os experimentos realizados através do NeurAval. Serão também mostrados e analisados os resultados obtidos nestes experimentos. 


\subsubsection{Experimento 1}

Este experimento foi realizado no início deste projeto para avaliar comportamento das redes MLP como técnica para análise de crédito financeiro. Neste primeiro experimento, foi utilizado um conjunto de dados para benchmark de algoritmos de aprendizado, compostos de aplicações reais para cartões de crédito junto com a decisão tomada pela instituição bancária (ou instituição semelhante), obtidos do conjunto de bases de dados para aprendizado de máquina da UCI, University of California, Irvine organizados por MURPHY \& AHA (1994). Para a validação dos experimentos, foram seguidas as regras de avaliação do Proben1, PRECHELT (1994). Este documento define um conjunto de regras de condução de experimentos e documentação de avaliações em Redes Neurais Artificiais.

Neste primeiro experimento, o NeurAval foi utilizado apenas para a transformação dos conjuntos de dados para o formato do simulador, visto que estes dados já estavam préprocessados e separados em conjuntos de treinamento, validação e teste.

O objetivo do modelo criado era o de imitar o processo de avaliação humana na avaliação de propostas de adesão de cartões de crédito. A seguir, serão apresentadas as metodologias utilizadas em cada fase do desenvolvimento do experimento.

Como estes dados já estavam pré-processados e separados, não foi possível verificar como estes processos foram feitos. Além disso, o significado dos atributos não é esclarecido, por se tratarem de dados confidenciais. No entanto, de forma a ilustrar e discutir alguns aspectos do desenvolvimento, será apresentado um exemplo, que pode não ser exatamente o mesmo utilizado pela equipe que pré-processou e selecionou os conjuntos de dados.

Uma proposta de adesão, como a ilustrada na FIGURA 26, é preenchida pelos clientes e entregue à empresa provedora do cartão. Esta é incluída à base de dados da empresa e é avaliada, para determinar qual o risco da transação. 
Tipo de Cartão:

(Nacional / Internacional)

Dados Pessoais

Nome:

$\mathrm{CPF}$ :

Data de Nascimento: __ _ I

Sexo: ___ (Masculino / Feminino)

Estado Civil: ___ (Solteiro / Casado / Viúvo / Divorciado)

Número de Dependentes:

Tipo de Residência:

Dados Residenciais

(Própria / Alugada / Família)

Dados Profissionais

Função:

Tempo na Empresa:

(Anos)

Salário Atual: R\$

Rendimentos

Outras Fontes: $\mathrm{R} \$$

Bens Possuídos

Tipo: (Imóveis, Veículos)

Valor Atual: R\$

\section{Outros Cartões Que Possui}

Sistema: _ $(\mathrm{A}, \mathrm{B}, \mathrm{C}, \mathrm{D}, \mathrm{E}, \mathrm{F})$

FIGURA 26 - Um modelo básico de proposta de cartão de crédito.

As bases de dados devem conter os dados e históricos dos clientes, de modo que se tenha uma classificação em níveis, de acordo com o interesse da empresa por estes clientes. Estas classificações serão utilizadas durante o treinamento da rede, como saídas desejadas. Durante a avaliação, os clientes que enviarem propostas serão classificados pelo sistema neural, também de acordo com estes níveis. Neste experimento, eles são classificados em: baixo risco (muito interesse) e alto risco (pouco ou nenhum interesse).

Para se adequarem ao sistema neural, estes dados devem ser transformados ou codificados em formas padronizadas, de acordo com a política de avaliação. Alguns exemplos: datas de nascimento podem ser transformadas em faixas etárias $(1 \leftarrow[21,29] ; 2 \leftarrow[30,39] ; 3 \leftarrow[40,50]$; $4 \leftarrow[50$...] ); podem ser utilizados códigos de função de acordo com tabelas pré-definidas, de modo a agrupar as diversas funções profissionais em categorias; o CPF pode ser verificado em serviços de proteção ao crédito, podendo ser transformado em (Cadastrado/ Não-Cadastrado); dados como sexo, estado civil, tipo de residência, etc., podem ser naturalmente transformados em números de acordo com a sua classe. Todas estas transformações podem ser feitas automaticamente pelo sistema durante a sua inclusão à base de dados. Feito o pré-processamento, estes dados poderão ser utilizados para o treinamento da rede. Este mesmo pré-processamento será necessário durante a avaliação de novas propostas utilizando o sistema. 
Antes de iniciar a fase de seleção da arquitetura neural e treinamento da rede, os dados devem ser cuidadosamente separados em conjuntos de treinamento, validação e teste. Estes conjuntos devem conter os dados mais representativos do problema como um todo e os níveis de classificação devem estar bem distribuídos entre os conjuntos. Segundo as regras do Proben1, estes conjuntos devem conter $50 \%, 25 \%, 25 \%$ de todos os dados, respectivamente.

No conjunto de dados que foi utilizado neste primeiro experimento, existem dados de 690 clientes, classificados em Baixo Risco e Alto Risco. Os conjuntos foram divididos, como ilustra a TABELA 1.

TABELA 1 - Separação dos dados em conjuntos - Experimento 1.

\begin{tabular}{|l|c|c|c|c|}
\hline \multicolumn{1}{|c|}{ Categoria } & $\begin{array}{c}\text { Dados } \\
\text { Originais }\end{array}$ & $\begin{array}{c}\text { Conjunto de } \\
\text { Treinamento }\end{array}$ & $\begin{array}{c}\text { Conjunto de } \\
\text { Validação }\end{array}$ & $\begin{array}{c}\text { Conjunto de } \\
\text { Teste }\end{array}$ \\
\hline Baixo Risco & 307 & 154 & 76 & 77 \\
\hline Alto Risco & 383 & 191 & 96 & 96 \\
\hline Total: & 690 & 345 & 172 & 173 \\
\hline
\end{tabular}

Neste experimento, a arquitetura foi escolhida empiricamente. O número de unidades da camada de entrada e de saída é dado pelas características dos registros. Uma vez que cada registro destes dados continha 51 atributos de entrada e a saída é dada em duas classes, foram necessárias 51 unidades na camada de entrada e 2 unidades na camada de saída.

A arquitetura que apresentou melhor desempenho foi: 51-10-6-2 (inteiramente conectada). A rede foi inicializada com pesos aleatórios no intervalo $[-1,1]$, com taxa de aprendizado de 0.002 , e termo momentum de 0.002 , o treinamento foi realizado durante 1000 ciclos e utilizou o algoritmo backpropagation com termo momentum.

Os erros quadráticos médios (EQM) e porcentagem de padrões corretamente classificados (PPCC) nos conjuntos são mostrados na TABELA 2. O gráfico do erro dos conjuntos de treinamento e validação durante os 1000 ciclos de treinamento é apresentado na FIGURA 27.

TABELA 2 - Resultados nos conjuntos de dados.

\begin{tabular}{|lcc|}
\hline \multicolumn{1}{|c}{ Fase } & EQM & PPCC \\
\hline Treinamento: & 0.14025 & $87.83 \%$ \\
\hline Validação: & 0.13016 & $89.02 \%$ \\
\hline Teste: & 0.15462 & $88.37 \%$ \\
\hline
\end{tabular}




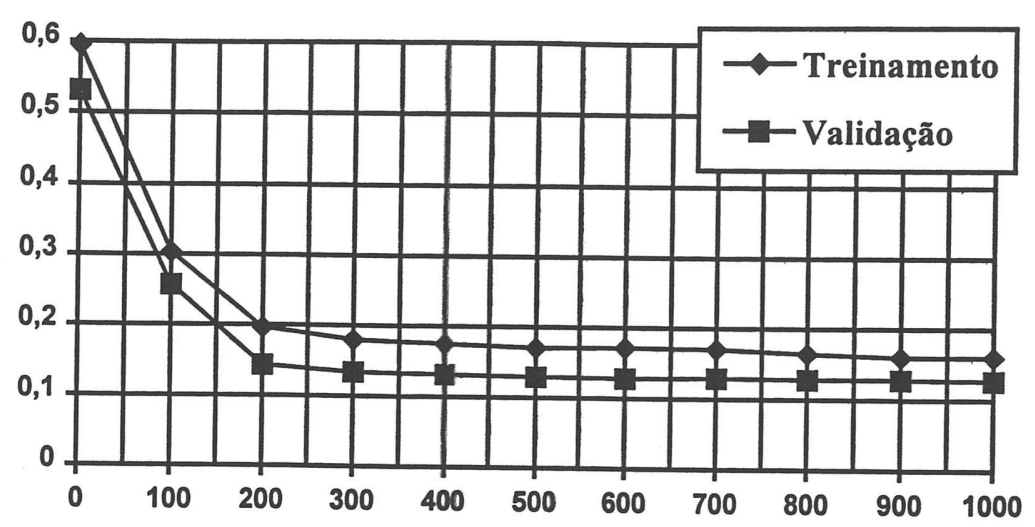

FIGURA 27 - Gráfico de erro de treinamento e validação.

Os resultados obtidos confirmaram a eficiência do modelo para a solução deste tipo de problema, quando comparados aos resultados obtidos através de outros modelos existentes, utilizando os mesmos dados. Estes resultados são apresentados por CARTER \& CATLETT (1987). A TABELA 3, ilustra os resultados obtidos pelos diferentes modelos.

TABELA 3 - Resultados dos Modelos.

\begin{tabular}{|c|c|}
\hline Método & PPCC \\
\hline Existente & $78,4 \%$ \\
\hline ID3 & $80,4 \%$ \\
\hline C4 & $85,5 \%$ \\
\hline RNA & $88,3 \%$ \\
\hline
\end{tabular}

O pequeno número de dados dificultou a criação de modelos mais adequados. Além disso, estes dados levaram em consideração apenas as informações presentes nas propostas dos clientes e seus respectivos resultados da avaliação humana, que podem não ser corretas. Estes fatores contribuem para que estes dados sejam utilizados somente para a comparação de desempenho entre modelos de aprendizagem, mas estão longe de representar a real complexidade deste tipo de problema.

Aplicações financeiras de avaliação de propostas de cartões de crédito imitando o comportamento de um avaliador humano, representa apenas uma classe de problemas no qual modelos de Redes Neurais podem ser utilizados. 


\subsubsection{Experimento 2}

Devido aos resultados satisfatórios obtidos com o primeiro experimento, foi decido buscar um conjunto de dados de crédito relativo a algum problema brasileiro, preferivelmente contendo históricos de clientes e aplicações, de forma a não limitar o modelamento a avaliações humanas, mas criar um modelo a partir de exemplos de aplicações bem ou mal sucedidas.

Após alguns contatos com empresas e instituições de pesquisa, foi obtido, junto ao Centro de Pesquisas em Crédito e Banking da Faculdade de Economia e Administração da Universidade de São Paulo, um conjunto de dados contendo aplicações de crédito bancário do Banestado, Banco do Estado do Paraná.

Durante este experimento, apresentado também em MENDES et. al. (1996), foram construídos os principais submódulos do protótipo do NeurAval, que foi utilizado para o préprocessamento dos dados, separação dos conjuntos e transformação dos conjuntos de dados para o formato do simulador.

O objetivo do modelo criado era o de avaliar o risco de novas aplicações de crédito baseado em informações sobre o cliente e sobre a aplicação. A metodologia utilizada nas diferentes fases deste experimento incluiu várias estratégias para tratamento das informações das bases de dados, seleção, treinamento e testes das redes, como será discutido a seguir.

Em uma fase inicial, foram reunidos todos os dados pertinentes e potencialmente úteis à tarefa. Estes estavam contidos nas bases de dados fornecidas, no formato dbase (.dbf), o que facilitou o processo de coleta e criação do Módulo Gerenciador destas bases de dados do NeurAval. Os dados coletados incluíam informações pessoais dos clientes, informações sobre a aplicação de crédito solicitada e um histórico sobre a adimplência destes clientes, o que permitiu sua classificação em duas classes: Adimplentes e Inadimplentes.

A FIGURA 28 apresenta uma tela do Gerenciador contendo as informações reunidas de uma transação de crédito. 


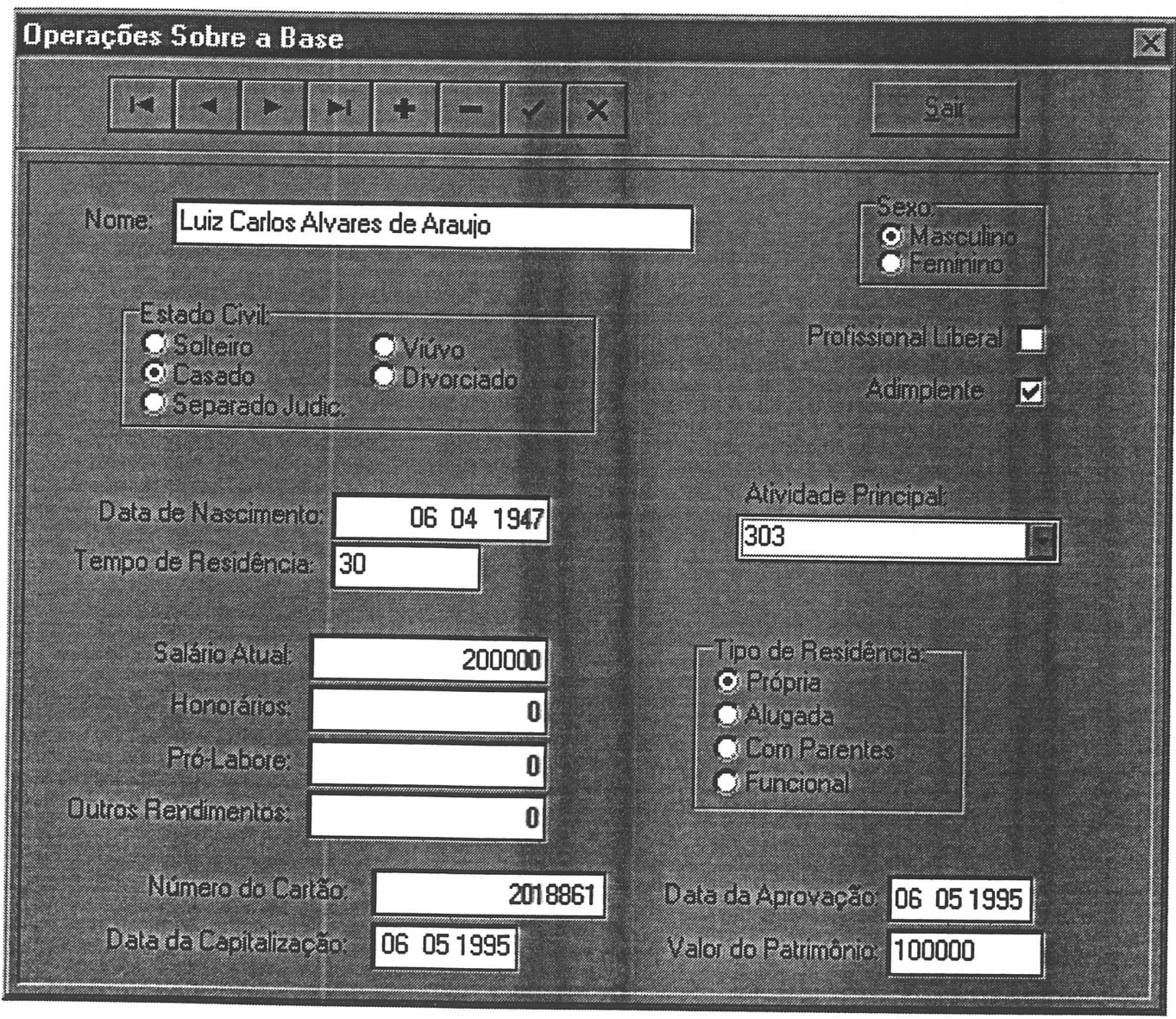

FIGURA 28 - Informações sobre uma transação de crédito.

$\mathrm{Na}$ fase de pré-processamento, os dados simbólicos como Sexo, Estado Civil, Tipo de Residência, entre outros, foram transformados em classes numéricas, mais adequadas para a utilização pela rede. Dados numéricos como Salário Atual, Valor do Patrimônio, entre outros, foram normalizados para o intervalo $[0,1]$.

Todos os dados das transações foram pré-processados, agrupados em vetores numéricos e arranjados de forma aleatória em arquivos no formato padrão do simulador. Estas operações foram feitas através do submódulo de pré-processamento do protótipo criado.

A FIGURA 29 mostra o padrão pré-processado, resultante das informações da transação ilustrada na FIGURA 28.

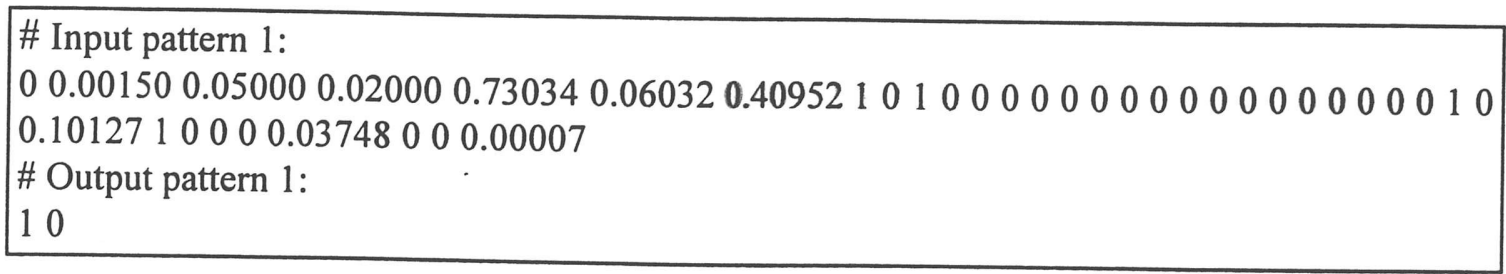

FIGURA 29 - Exemplo de um padrão resultante do pré-processamento. 
Os dados coletados, 5635 registros, foram divididos em duas classes: Adimplentes, 5414 registros (96.07\%) e Inadimplentes, 221 registros (03.93\%). Eles foram separados em conjuntos de treinamento, validação e teste, para serem utilizados em cada uma das fases do desenvolvimento da rede. Estes conjuntos foram cuidadosamente divididos, seguindo uma metodologia semelhante à sugerida por KLIMASAUKAS (1991), como mostra a TABELA 4.

O conjunto de validação foi composto por uma porcentagem, neste caso $10 \%$, dos registros originais, escolhidos aleatoriamente e mantendo a mesma proporção de classes presentes nos dados originais. $\mathrm{O}$ conjunto de teste foi criado desta mesma forma.

O conjunto utilizado no treinamento foi composto pelos registros da classe com o menor número de registros (Inadimplentes) que não entraram no conjunto de validação e teste e o mesmo número de registros da outra classe, escolhidos aleatoriamente.

TABELA 4 - Separação dos dados em conjuntos - Experimento 2.

\begin{tabular}{|c|c|c|c|c|}
\hline Classe & $\begin{array}{c}\text { Dados } \\
\text { Originais }\end{array}$ & $\begin{array}{c}\text { Conj. de } \\
\text { Treinamento }\end{array}$ & $\begin{array}{c}\text { Conj. de } \\
\text { Validação }\end{array}$ & $\begin{array}{c}\text { Conj. de } \\
\text { Teste }\end{array}$ \\
\hline Adimplente & 5414 & 177 & 541 & 541 \\
\hline Inadimplente & 221 & 177 & 22 & 22 \\
\hline Total & 5635 & 354 & 563 & 563 \\
\hline
\end{tabular}

Esta metodologia para separação dos conjuntos de dados favorece o desenvolvimento de modelos para classificação, visto que, no treinamento com um número igual de padrões de cada classe, o modelo se concentra na caracterização dos aspectos mais relevantes de cada classe. Já na validação e teste com uma distribuição de classes proporcional ao encontrado nos dados originais, consegue-se uma visão mais realista do desempenho dos modelos. Alguns outros conjuntos de teste também foram criados. Maiores detalhes sobre estes conjuntos serão vistos posteriormente.

A escolha da configuração adequada da rede teve impacto substancial no desempenho do modelo. Neste experimento, essa tarefa foi feita de forma empírica: foram analisados preliminarmente várias arquiteturas e parâmetros diferentes utilizando a XGUI do simulador e foram dadas pontuações às redes analisadas de acordo com suas características de aprendizado e capacidade de generalização.

A FIGURA 30 mostra alguns resultados preliminares, obtidos durante 300 ciclos de treinamento, onde podem-se perceber os efeitos do parâmetro de aprendizado $\eta$, termo momentum $\mu$ e topologias. As três topologias escolhidas foram: 38-5-2, 38-20-8-2 e 38-20-10-2. Estas redes foram as que apresentaram aprendizado mais estável e maior capacidade de generalização. As outras topologias apresentaram desempenhos abaixo do nível mínimo satisfatório $(96.07 \%$ = porcentagem de registros de adimplentes) com alguns parâmetros. 


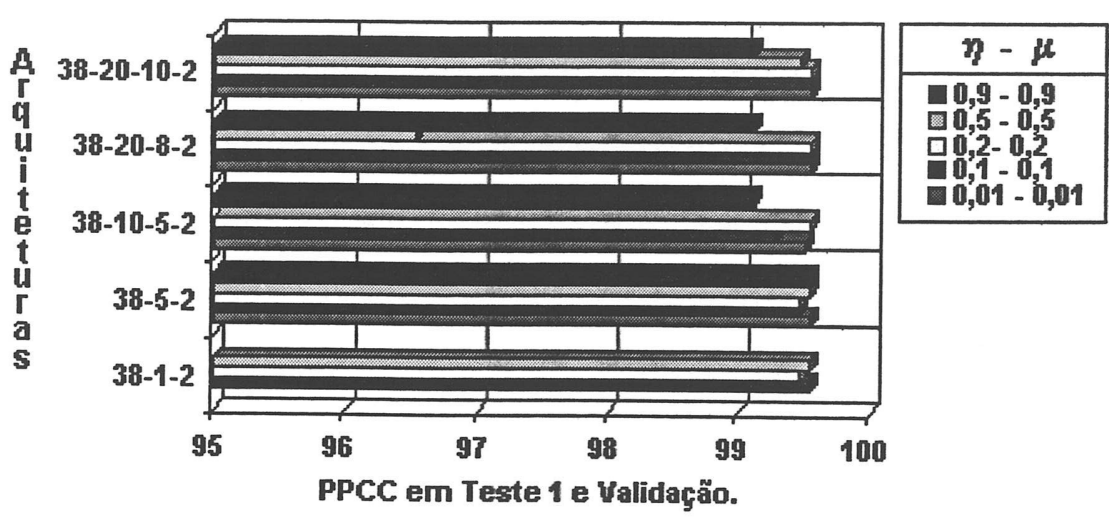

FIGURA 30 - Efeito dos parâmetros e da arquitetura.

O treinamento foi realizado utilizando o algoritmo backpropagation com termo momentum durante 1000 ciclos e o estado das redes foi gravado em arquivos nos ciclos em que foram apresentadas as menores taxas de erro no conjunto de validação.

O gráfico de erros quadráticos médios nos conjuntos de treinamento e validação durante os 1000 ciclos de treinamento da rede 38-20-8-2, com $\eta$ : 0,025 e $\mu$ : 0,025, é apresentado na FIGURA 31. O ponto grifado foi o ciclo 127 , que foi o ciclo de melhor validação neste treinamento (EQM Validação = 0,0088 - EQM Treinamento =0,0689).

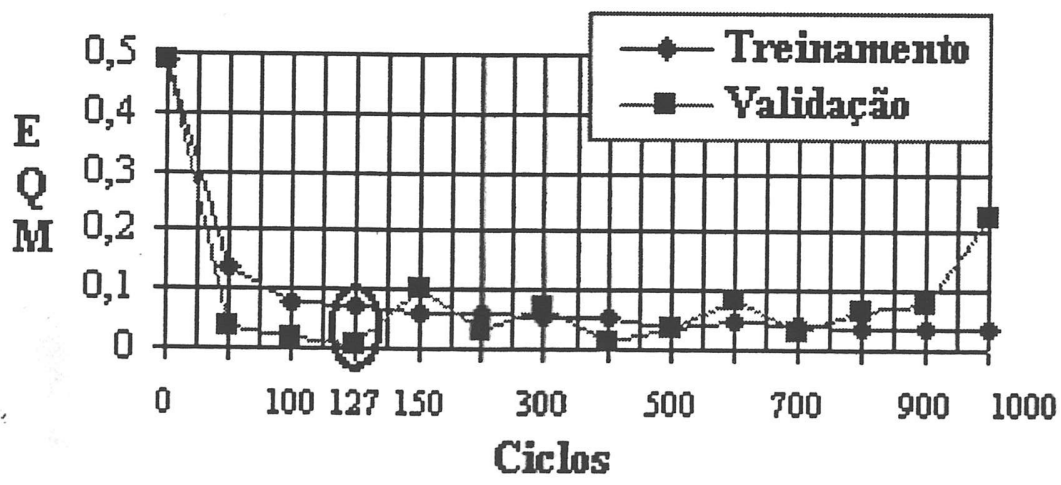

FIGURA 31 - Gráfico de erro (EQM) de treinamento e validação.

Foram realizados dois testes para analisar o desempenho das arquiteturas neurais escolhidas, utilizando diferentes amostras: uma amostra contendo 10\% dos padrões originais escolhidos aleatoriamente, mantendo a mesma proporção de classes da base (Teste1) e uma amostra com todos os padrões da base (Teste2). Este segundo teste foi realizado para a comparação com os resultados obtidos através de um modelo estatístico anteriormente utilizado. Foram calculados os erros quadráticos médios (EQM) e as porcentagens de padrões corretamente classificados (PPCC). Os resultados apresentados na TABELA 5 mostram os desempenhos das redes escolhidas. 
TABELA 5 - Desempenho das redes nos testes.

\begin{tabular}{|c|c|c|c|c|}
\cline { 2 - 5 } \multicolumn{1}{c}{} & \multicolumn{2}{c}{ Testel } & \multicolumn{2}{c|}{ Teste2 } \\
\hline Arquiteturas & EQM & PPCC & EQM & PPCC \\
\hline $38-5-2$ & 0,0115 & $99,47 \%$ & 0,02169 & $99,69 \%$ \\
\hline $38-20-8-2$ & 0,0104 & $99,47 \%$ & 0,02363 & $99,71 \%$ \\
\hline $38-20-10-2$ & 0,0091 & $99,47 \%$ & 0,02214 & $99,69 \%$ \\
\hline
\end{tabular}

A arquitetura que apresentou melhores resultados foi: 38-20-8-2, com taxa de aprendizado $\eta=0.025$ e termo momentum $\mu=0.025$. A rede foi inicializada com pesos aleatórios no intervalo $[-0.5,0.5]$, o treinamento foi realizado durante 1000 ciclos e utilizou o algoritmo de aprendizado backpropagation com termo momentum. Os erros quadráticos médios (EQM), o número de padrões erradamente classificados (NPEC), o número de padrões classificados corretamente (NPCC) e a porcentagem de padrões classificados corretamente (PPCC) utilizando esta rede para todos os padrões contidos na base, divididos por classes, são mostrados na TABELA 6.

TABELA 6 - Resultados do Teste 2 separados por classes.

\begin{tabular}{|c|c|c|c|c|}
\hline & EQM & NPEC & NPCC & PPCC \\
\hline Adimplentes & 0.01923 & 4 & 5410 & $99,93 \%$ \\
\hline Inadimplentes & 0.13151 & 16 & 205 & $92,76 \%$ \\
\hline
\end{tabular}

É importante notar que o Teste 2, com todos os padrões da base, não fornce uma estimativa realista do desempenho futuro do modelo, uma estimativa mais realista é dada pelo Teste 1 . $O$ Teste 2 foi inicialmente idealizado para a comparação com os resultados obtidos através de um outro modelo. No entanto, este teste revelou-se util para a análise do comportamento do modelo com padrões que não foram vistos em nenhum dos outros conjuntos. Visto que, muitos padrões da classe Adimplentes não foram utilizados nem no treinamento, nem na validação, nem no Teste1. Como pode ser observado, o modelo classificou erradamente apenas 4 padrões da classe Adimplentes, dos 5414 padrões desta classe.

Foi observado que alguns padrões da classe Inadimplentes dificilmente são classificados corretamente pelas redes. Um estudo preliminar revelou que estes padrões eram considerados exceções, realmente difíceis de serem avaliadas e que estas poderiam não estar bem representadas no conjunto de treinamento.

Foi utilizada uma matriz de custos para classificar o desempenho da rede na solução do problema. Esta matriz, apresentada na TABELA 7, indica que é pior classificar um cliente como adimplente quando ele é inadimplente (custo: 3), do que classificar como inadimplente quando ele é adimplente (custo: 1). Os padrões erradamente classificados são multiplicados pelos pesos dados nesta matriz e são somados. A rede escolhida 38-20-8-2 foi a que apresentou a menor taxa de custo. 
TABELA 7 - Matriz de custos de padrões classificados erradamente.

\begin{tabular}{|c|c|c|}
\hline & $\begin{array}{l}\text { Classificado como } \\
\text { Adimplente }\end{array}$ & $\begin{array}{l}\text { Classificado como } \\
\text { Inadimplente }\end{array}$ \\
\hline Padrão Adimplente & 0 & 1 \\
\hline Padrão Inadimplente & 3 & 0 \\
\hline
\end{tabular}

A TABELA 8 mostra uma comparação entre os resultados obtidos neste experimento, e os resultados do modelo estatístico anteriormente utilizado. Observação: Este modelo estatístico foi considerado inapropriado, pois sua taxa de acerto (PPCC total $=95,19)$ estava abaixo do nível mínimo satisfatório $(96.07 \%$ = porcentagem de registros de adimplentes).

TABELA 8 - Resultados do Experimento $2 \times$ Análise Discriminante.

\begin{tabular}{|c|c|c|c|}
\cline { 2 - 4 } \multicolumn{1}{c|}{} & NPEC - C1 & NPEC - C2 & Custo \\
\hline Rede Neural & 4 & 16 & 52 \\
\hline Análise Discriminante & 52 & 219 & 709 \\
\hline
\end{tabular}

Os resultados obtidos confirmam a eficiência do modelo e da metodologia utilizada para a solução deste tipo de problema. A rede selecionada foi inserida no módulo de avaliação do sistema, para então ser utilizada para previsão do risco de inadimplência de outros clientes. $\mathrm{O}$ protótipo construído revelou-se uma ferramenta muito útil para auxílio à gestão de crédito financeiro massificado.

Os dados utilizados apresentavam históricos com poucos exemplos de clientes inadimplentes, o que dificultou o processo de treinamento. Este pequeno número de exemplos se deve ao fato de ser utilizada, pelo banco, uma avaliação preliminar de novos clientes, préscreening, a cargo de seus gerentes e analistas. Assim a rede gerada neste experimento será eficiente apenas para análise de casos que passem por esta primeira avaliação. 


\subsection{NeurEvol}

Durante o desenvolvimento deste trabalho, também foi criado um protótipo de sistema para o projeto evolucionário de arquiteturas neurais, o NeurEvol, utilizando a linguagem $A N S I C$, de forma a facilitar sua migração para as diferentes plataformas em que o simulador SNNS pode ser utilizado. O protótipo criado consiste de dois módulos principais: o Módulo Evolucionário e o Módulo Neural.

O Módulo Evolucionário consiste de um Algoritmo Genético, como o discutido no Capítulo 4, que possui submódulos de avaliação e reprodução. O Módulo Neural utiliza, através de trocas de arquivos, o simulador SNNS para o treinamento e teste das redes, e consiste de um submódulo gerador de redes, um submódulo gerador de programas batchman e um submódulo para a leitura dos resultados gerados pelo simulador.

Este protótipo funciona, resumidamente, da seguinte maneira. É gerada, inicialmente, uma população de representações de arquiteturas neurais de forma aleatória. As representações são passadas, uma a uma, ao Módulo Neural, que gera arquivos de redes, com as especificações destas redes, no formato do simulador e arquivos de programas batchman. Estes programas são processados através do simulador, que faz o treinamento e o teste destas redes e gera arquivos com os resultados. Estes arquivos de resultados são lidos e os dados de desempenho são passados ao submódulo de avaliação, que dá as notas de aptidão relativas a cada uma das representações. As representações e suas notas são passadas ao submódulo de reprodução, que utiliza os mecanismos de seleção e os operadores genéticos para a criação de uma nova geração da população, que é novamente avaliada. Este processo é repetido até um determinado número de gerações, como ilustra o esquema da FIGURA 32. 


\section{Módulo Evolucionário}

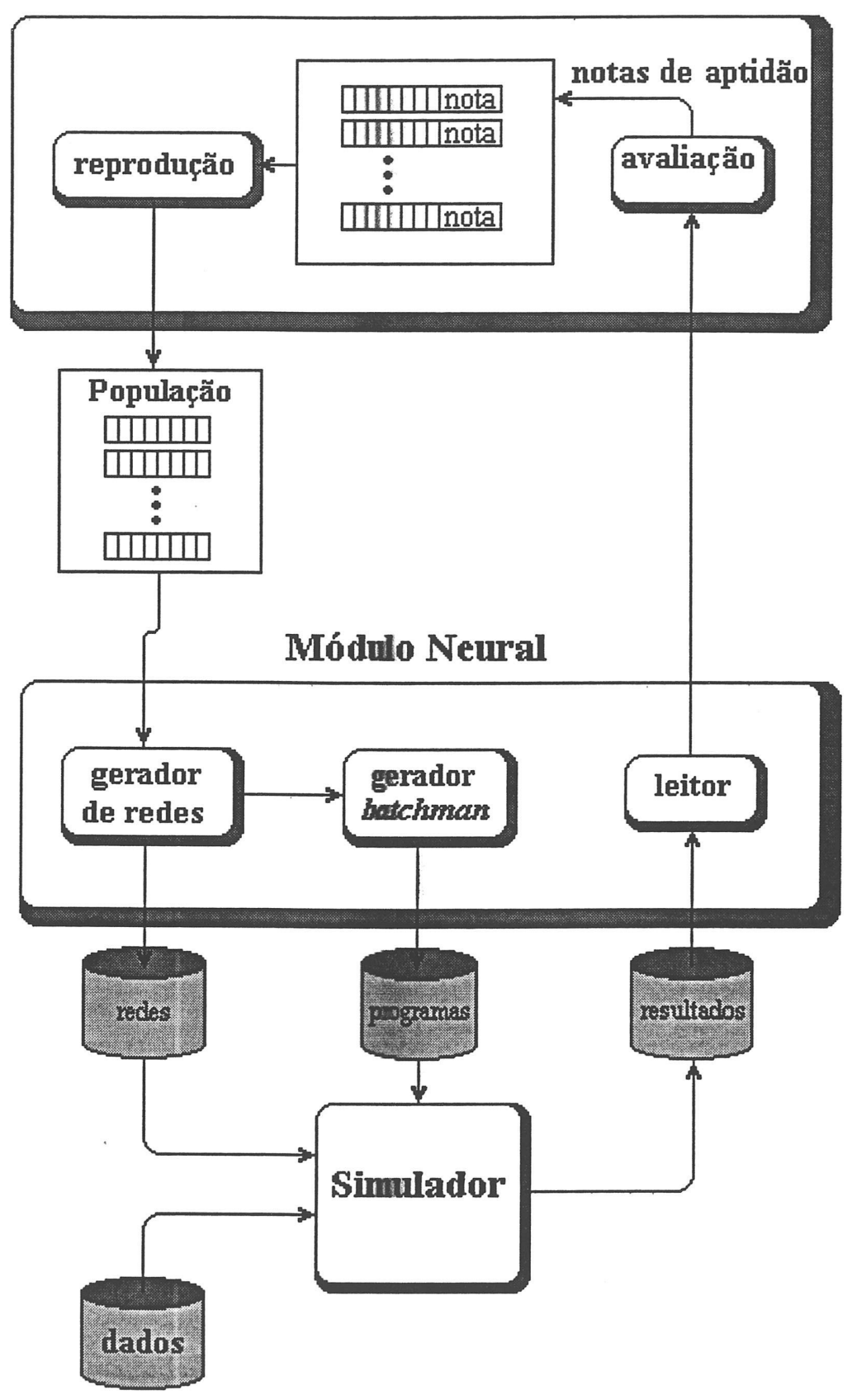

FIGURA 32 - Esquema de funcionamento e módulos do NeurEvol.

No início do processo podem ser especificados, conforme as necessidades do projeto e as limitações dos recursos disponíveis, o número de indivíduos da população, o número de máximo de gerações, as funções de custo para a avaliação de desempenho, as taxas de cruzamento e mutação, os conjuntos de dados a serem utilizados, o número máximo de unidades nas camadas intermediárias, o número de ciclos de treinamento e o critério de parada para o treinamento. 
Nos experimentos realizados, o NeurEvol foi utilizado com uma população de 20 indivíduos, durante 10 gerações, com taxa de cruzamento de $70 \%$ e taxa de mutação de $20 \%$. Durante o treinamento das redes, foi utilizado como critério de parada o menor valor da soma dos erros quadráticos médios nos conjuntos de treinamento e validação. Foi especificado um número máximo de 20 unidades nas camadas intermediárias e o treinamento foi realizado durante 800 ciclos. Além disso, foi utilizado um esquema de cross-validation com três grupos de dados, ou seja, cada arquitetura foi treinada e testada três vezes, utilizando três diferentes permutações dos conjuntos de dados. Sua nota de aptidão refletia a média dos três resultados de treinamento e validação.

A seguir serão apresentados os experimentos realizados através do NeurEvol. E serão mostrados e analisados os resultados obtidos nestes experimentos.

\subsubsection{Experimento 1}

O primeiro experimento realizado com o NeurEvol foi o projeto evolucionário das arquiteturas neurais do Experimento 1 do NeurAval, utilizando o conjunto de dados de aplicações reais para cartões de crédito para benchmark de algoritmos de aprendizado.

A FIGURA 33 apresenta as notas de aptidão do melhor indivíduo da população em cada geração e FIGURA 34 apresenta a média das notas de aptidão da população. Pode ser observado que a nota do melhor indivíduo apresentou melhorias nas gerações 2 , e 5, depois desta geração não foi encontrado nenhum indíviduo com maior nota de aptidão. A média da população foi rapidamente evoluindo nas primeiras gerações, apresentou oscilações a partir da geração 3 e conseguiu o melhor resultado na geração 10 , na qual várias boas arquiteturas foram obtidas.

\section{Melhor Indivíduo}

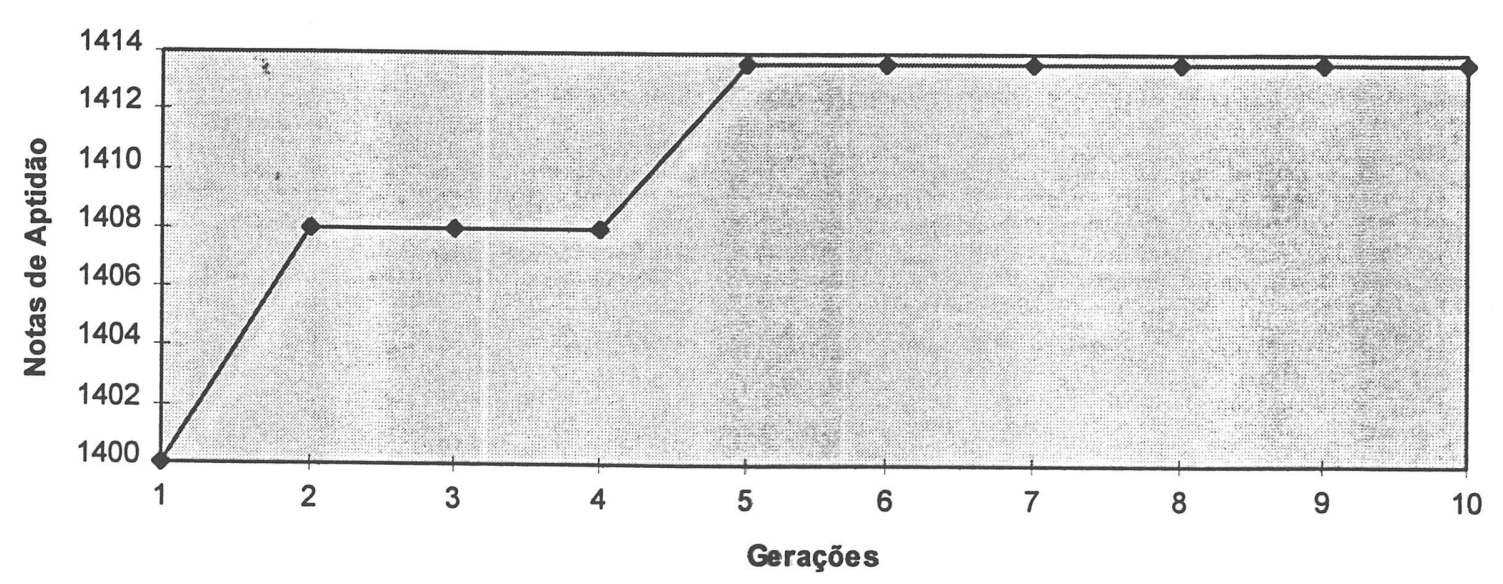

FIGURA 33 - Evolução do melhor indivíduo durante as 10 gerações do Experimento 1. 
Média da População

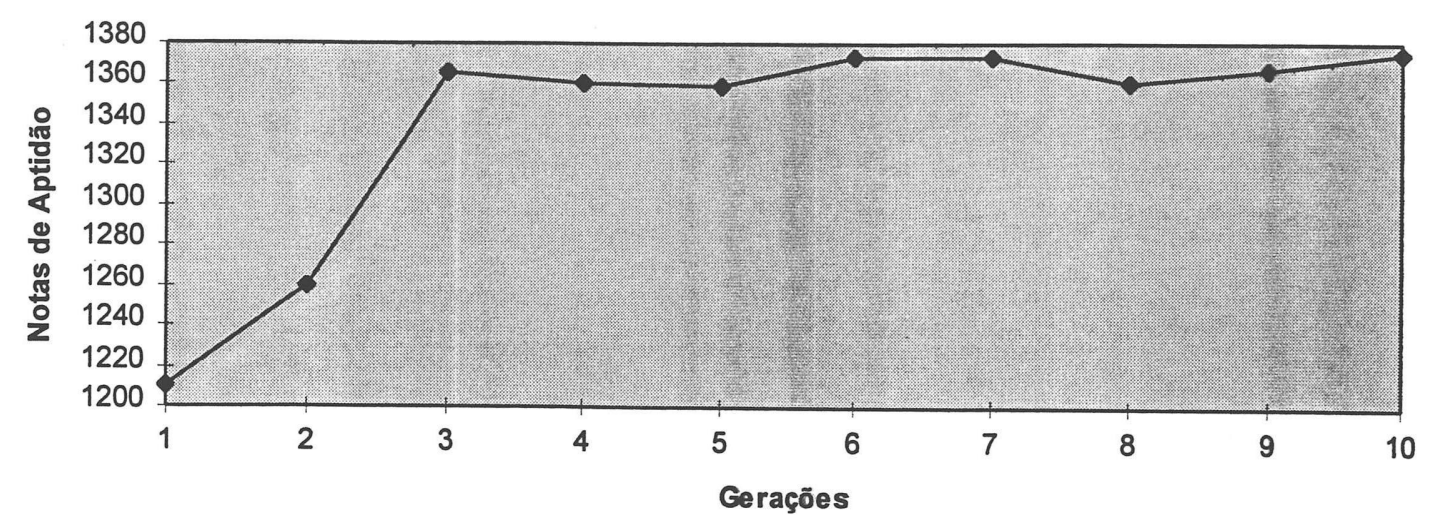

FIGURA 34 - Evolução da média da população durante as 10 gerações do Experimento 1.

A melhor arquitetura encontrada foi: $51-13-4-4-2$, com $\eta=0,078720$ e $\mu=0,334010$. Os resultados obtidos com a rede encontrada através deste experimento foram comparados aos resultados obtidos através da rede escolhida empiricamente. A TABELA 9 apresenta a média da porcentagem de padrões erradamente classificados (MPPEC) em cada conjunto de dados e a TABELA 10 apresenta o custo destes erros em cada conjunto de dados, calculado através da matriz de custos da TABELA 7.

TABELA 9 - Resultados (MPPEC) nos conjuntos de dados do Experimento 1.

\begin{tabular}{|c|c|c|c|}
\hline & \multicolumn{3}{|c|}{ MPPEC } \\
\hline Método & Treinamento & Validaçăo & Teste \\
\hline Empírico & $2,02 \%$ & $11,22 \%$ & $21,39 \%$ \\
\hline
\end{tabular}

TABELA 10 - Resultados (Custos) nos conjuntos de dados do Experimento 1.

\begin{tabular}{|c|c|c|c|}
\hline & \multicolumn{3}{|c|}{ Custos } \\
\hline Método & Treinamento & Validaçã̃o & Teste \\
\hline EeurEvol & 15,6 & 39,3 & 73 \\
\hline
\end{tabular}

Como pode ser observado, os resultados obtidos foram muito semelhantes, com uma pequena desvantagem para a rede encontrada pelo NeurEvol apenas no conjunto de teste. Este fato se deve por dois aspectos: O critério de desempenho adotado no NeurEvol não utiliza o desempenho nos testes, já na escolha empírica este é um fator determinante. Além disso, estes resultados refletem a média do número de padrões erradamente classificados nos 3 grupos de 
dados usados no esquema $N$-cross-validation. Em um destes grupos o erro de teste foi mais alto que nos outros, fazendo com que a média fosse mais alta.

A rede encontrada pelo sistema evolutivo apresentou menores taxas de erro no treinamento e validação. Ou seja, através da abordagem evolucionária foi encontrada uma solução melhor dentro do critério adotado: melhor desempenho de treinamento e validação. Portanto, o problema parece estar nos conjuntos de dados. Pode ser que os padrões dos conjuntos de treinamento e validação não sejam muito representativos do problema, ocorrendo vários erros no conjunto de teste. Entretanto, a diferença entre o desempenho das redes encontradas através das duas abordagens não é muito significativa.

Outro fato interessante a ser notado é que nas últimas gerações o Algoritmo Genético vinha convergindo para 3 arquiteturas principais: 51-13-4-4-2, 51-20-2-4-2 e 51-20-4-4-2 com $\eta$ e $\mu$ variando bastante. Todas as arquiteturas da última geração apresentavam 4 unidades na última camada intermediária, ou seja, o algoritmo pode ter encontrado um número ideal de unidades para esta camada.

\subsubsection{Experimento 2}

Este experimento visava o projeto evolucionário das arquiteturas neurais do Experimento 2 do NeurAval, utilizando o conjunto de dados de aplicações de crédito do banco Banestado.

A FIGURA 35 apresenta as notas de aptidão do melhor indivíduo da população em cada geração e a FIGURA 36 apresenta a média das notas de aptidão da população. Pode ser observado que a nota do melhor indivíduo apresentou uma grande melhoria na geração 2 , e uma pequena melhoria na geração 7. Já a média da população apresentou oscilações nas primeiras gerações, devido principalmente a atuação do operador de mutação, mas foi gradativamente evoluindo. Estes resultados também mostram que várias boas arquiteturas podem ser obtidas em poucas gerações, visto que a média da população apresenta boas notas na última geração. 


\section{Evolução do Melhor Indivíduo}

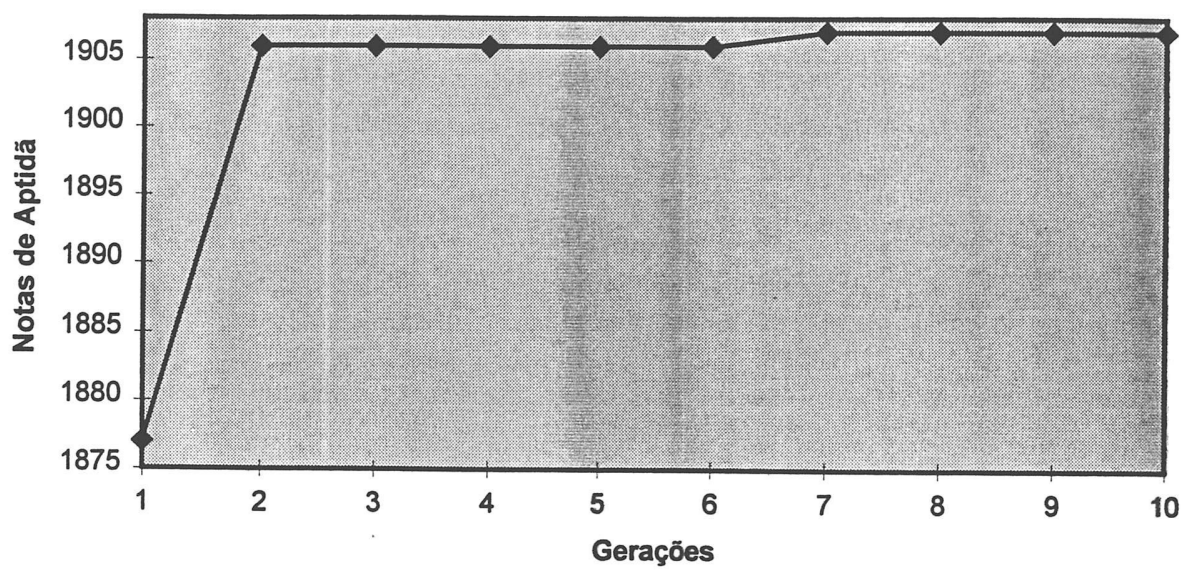

FIGURA 35 - Evolução do melhor indivíduo durante as 10 gerações do Experimento 2.

\section{Evolução da Média da População}

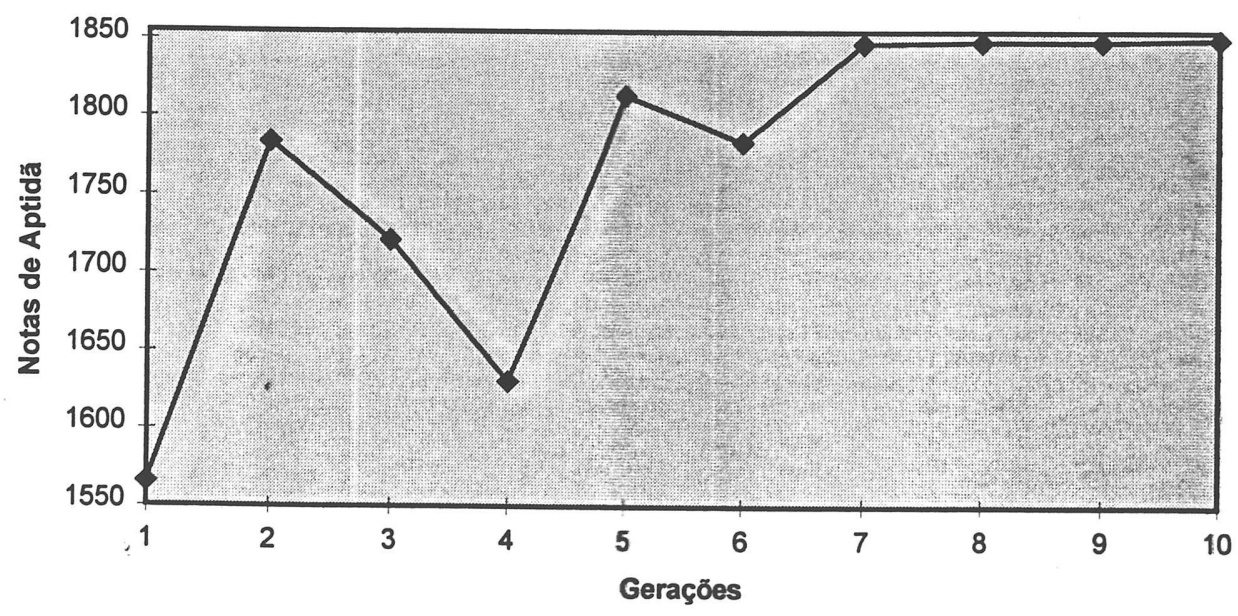

FIGURA 36 - Evolução da média da população durante as 10 gerações do Experimento 2.

A melhor arquitetura encontrada foi: 38-13-9-19-2, com $\eta=0,56538$ e $\mu=0,0394$. Os resultados obtidos com a rede encontrada através deste experimento foram comparados aos resultados obtidos através da rede escolhida empiricamente. A TABELA 11 apresenta a média da porcentagem de padrões erradamente classificados (MPPEC) em cada conjunto de dados e a TABELA 12 apresenta o custo destes erros em cada conjunto de dados, calculado através da matriz de custos da TABELA 7. 
TABELA 11 - Resultados (MPPEC) nos conjuntos de dados do Experimento 2.

\begin{tabular}{|c|c|c|c|c|}
\cline { 2 - 5 } & \multicolumn{4}{c|}{ MPPEC } \\
\hline NeurEvol & Treinamento & Validação & Teste 1 & Teste 2 \\
\hline Empírico & $3,26 \%$ & $0,35 \%$ & $0,53 \%$ & $0,27 \%$ \\
\hline
\end{tabular}

TABELA 12 - Resultados (Custos) nos conjuntos de dados do Experimento 2.

\begin{tabular}{|c|c|c|c|c|}
\cline { 2 - 5 } \multicolumn{1}{c|}{ Método } & Treinamento & Validação & Teste 1 & Teste 2 \\
\hline NeurEvol & 24 & 6 & 9 & 47 \\
\hline Empírico & 38 & 6 & 9 & 52 \\
\hline
\end{tabular}

Como pode ser observado, os resultados obtidos foram muito semelhantes, com uma pequena vantagem para a rede encontrada pelo NeurEvol apenas no treinamento e Teste 2, com todos os padrões da base. Estes fatos podem ser interpretados assim: embora as redes encontradas através das duas abordagens apresentem desempenhos semelhantes, a rede encontrada pelo sistema evolutivo apresenta treinamento mais consistente e capacidade de generalização um pouco mais elevada.

Outro fato interessante a ser notado é que nas últimas gerações o Algoritmo Genético vinha convergindo para 3 arquiteturas principais: 38-13-9-19-2, 38-13-9-2 e 38-13-5-2, com $\eta$ :0,56538 e $\mu: 0,0394$. Todas as arquiteturas da última geração apresentavam 13 unidades na primeira camada intermediária, ou seja, o algoritmo pode ter encontrado um número ideal de unidades para a primeira camada.

\subsection{Considerações Finais}

Neste capítulo foram apresentados os dois protótipos desenvolvidos durante este trabalho. $\mathrm{O}$ protótipo do sistema de avaliação de crédito, NeurAval, e o protótipo do sistema de projeto evolucionário de arquiteturas neurais, NeurEvol. Foram também discutidos os resultados obtidos através de diferentes experimentos realizados utilizando estes protótipos.

No próximo capítulo serão apresentadas as conclusões finais sobre os estudos aqui desenvolvidos e serão feitas sugestões para pesquisas que poderiam ser realizadas dando prosseguimento a este trabalho. 


\section{Conclusão}

\subsection{Considerações}

Neste trabalho foram investigadas as principais características que envolvem a construção de um sistema inteligente para avaliação de crédito financeiro. Foi fornecida uma visão geral de Redes Neurais Artificiais e Algoritmos Genéticos. Foram pesquisados os métodos de projeto evolucionário de arquiteturas neurais. Foram elucidados todos os passos da construção de um sistema de avaliação utilizando estas técnicas.

A abordagem evolucionária para 0 projeto de arquiteturas neurais é frequentemente apresentada na literatura para o tratamento de problemas simples. Neste trabalho, foi investigada a sua utilização em problemas reais, para tanto foram colocadas algumas restrições nas arquiteturas das redes de forma a diminuir o espaço de busca utilizado pelo Algoritmo Genético.

Os resultados apresentados mostraram que é possível automatizar o projeto de arquiteturas neurais utilizando a abordagem evolucionária. Foi mostrado que esta abordagem é capaz de aperfeiçoar as arquiteturas neurais em direção a arquiteturas otimizadas. Embora os resultados apresentados utilizando a abordagem evolucionária e utilizando uma abordagem empírica sejam semelhantes, deve ser notado que na abordagem empírica os dados de teste foram utilizados para na escolha da arquitetura, já a abordagem evolucionária foram utilizados apenas os dados de treinamento e validação. Um outro conjunto de teste, diferente do conjunto de teste final, deveria ser utilizado na função de avaliação desempenho para se ter uma melhor avaliação quanto a capacidade de generalização das redes. Isto não foi possível nos problemas aqui tratados, devido ao pequeno número de padrões exemplares disponíveis.

Além disso, escolha da arquitetura feita de forma empírica, foi realizada exaustivamente por pessoal com experiência na construção de modelos neurais e demandou em média de um mês para ser realizada. Utilizando o protótipo evolutivo construído a tarefa pôde ser realizada em média em cinco dias, em uma boa estação de trabalho. Ou seja, o esforço exigido é computacional e não dos projetistas.

A maior vantagem da utilização de uma ferramenta deste tipo é a automação dos processos envolvidos no projeto de arquiteturas neurais, além da facilidade de observação dos resultados. Isto ocorre porque, os processos de criação e treinamento das redes, o processo de seleção das 
redes com maior desempenho e a geração de novas redes baseadas nas redes de maior desempenho, são todos automatizados. A automação dos processos de seleção e geração de novas redes é o que justifica o uso da abordagem evolucionária.

Uma outra vantagem desta abordagem é que podem ser encontradas várias arquiteturas adequadas para a solução de um problema, visto que a média da população também evolui. Com isto torna-se possível a construção de sistemas que integrem várias redes formando um comitê de avaliação.

A idéia de utilizar sistemas computacionais para auxílio na avaliação de crédito financeiro é antiga. Como em todas as alternativas existentes, a construção e a utilização de modelos de Redes Neurais MLP para avaliação de crédito requer certos cuidados para que os objetivos destes sistemas sejam alcançados.

Longe de ser um substituto aos gerentes e analistas de crédito, ou uma ferramenta geral para o tratamento de todas as modalidades de avaliação de crédito, o protótipo construído deve ser considerado uma ferramenta auxiliar ao processo de decisão, específica do ambiente, modalidade e função para as quais foi concebida.

A utilização apropriada de uma ferramenta como esta pode possibilitar uma melhor gestão de crédito massificado (previsão de resultados, fixação de preços ou tarifas, definição de estratégias de gestão, facilidade de revisão e atualização); um crescimento da atividade (expansão de produtos ou carteiras de crédito); melhoria no atendimento (maior rapidez); e redução de custos (redução da inadimplência, redução de prejuízos e contas perdidas e redução de custos de mão-de-obra).

\subsection{Contribuiç̧̃es deste trabalho}

Este trabalho apresentou um estudo das áreas de pesquisa envolvidas e as metodologias utilizadas nas implementações de dois protótipos o NeurAval e o NeurEvol, embora estas duas ferramentas sejam independendes e atendam a interesses distintos, elas são complementares.

O NeurAval foi criado especificamente para a utilização de Redes Neurais MLP em problemas de avaliação de crédito, mas com pequenas mudanças pode ser utilizado em muitos outros problemas de classificação de padrões, ou previsões, utilizando quaisquer modelos de Redes Neurais, modelos estatísticos, sistemas baseados em conhecimento ou ainda integrando todas estas técnicas. Durante o desenvolvimento deste trabalho, foi observado que é grande o interesse por sistemas deste tipo, tanto na área comercial quanto de pesquisa.

O NeurEvol também foi criado especificamente para o projeto de arquiteturas de Redes Neurais MLP para problemas de classificação utilizando o simulador SNNS, mas já esta sendo utilizado em problemas de problemas de previsão. As mudanças necessárias foram facilmente realizadas. Para a sua utilização com outros modelos de Redes Neurais são necessárias 
modificações em alguns submódulos do protótipo, dependendo do modelo a ser utilizado. Para a maioria dos modelos de redes feed-forward estas mudanças são pequenas.

Foram criados vários subprodutos destes protótipos que podem ser utilizados independentemente e vêm despertando o interesse da comunidade acadêmica, como o préprocessador, o gerador de conjuntos de conjuntos de dados, os programas batchman, o analisador de resultados, o gerador de redes, o compilador snns2pas, e o continuador. Além do "SNNS Manual de Referência Rápida", DINIZ et. al. (1997), e de uma página $W W W$ sobre este simulador, escritos durante este trabalho. Todos estes sub produtos visavam facilitar o planejamento, a construção e o controle de experimentos com Redes Neurais no simulador utilizado. A seguir, serão discutidos cada um destes subprodutos.

O pré-processsador e o gerador de conjuntos de dados podem ser utilizados para a transformação de dados contidos em uma base de dados no formato dbase e criação de arquivos de conjuntos de treinamento, validação e teste no formato do simulador SNNS.

Os programas batchman foram cuidadosamente desenvolvidos e permitem utilizar um esquema de treinamento mais elaborado que o permitido através da interface gráfica $X G U I$ do SNNS. Além disso, com a utilização do analisador de resultados criado (o analyze.gawk) podem ser gerados arquivos de resultados com o desempenho das redes durante o treinamento e teste, o que facilita a observação dos experimentos. Um outro programa batchman criado gera arquivos que podem ser utilizados para a construção de gráficos dos erros de treinamento, através do gnuplot.

O gerador de redes pode ser utilizado para a criação de redes feed-forward, no formato do SNNS sem a necessidade da utilização da interface gráfica $X G U I$, facilitando a automação da geração de arquivos de redes.

O compilador snns2pas foi construído baseado no compilador $s n n s 2 c$ fornecido juntamente com o simulador. Esta ferramenta é utilizada para a transformação de redes no formato do SNNS para a linguagem Pascal e foi usada na integração da rede ao NeurAval, escrito na linguagem Delphi (similar ao Pascal).

O continuador foi desenvolvido para fazer com que o processo do NeurEvol, interrompido continuasse do ponto em que parou. Como o processo é muito longo (demorando alguns dias), e como são frequentes as falhas na rede de comunicações, falhas no sistema elétrico ou ainda a indolência de alguns usuários, o processo era interrompido muitas vezes. Assim, o continuador lia o arquivo gerado pelo NeurEvol até o ponto da interrupção e continuava o processo. No entanto, foi encontrada também, uma outra utilidade para esta ferramenta, com pequenas modificações ela pode ser utilizada para um desenvolvimento planejado de Redes Neurais. Para isso, basta que o projetista defina as arquiteturas que devem ser testadas (em um arquivo padronizado) e o sistema poderá fazer automaticamente a criação, o treinamento e o teste destas redes e gerar os arquivos de resultados. 


\subsection{Propostas para Trabalhos Futuros}

Algumas pesquisas que podem seguir em decorrência da complementação deste trabalho, além de sugestões para a utilização e aperfeiçoamento dos protótipos construídos, são apresentados nesta seção.

O protótipo de avaliação de crédito utiliza Redes Neurais geradas e treinadas, separadamente, por um simulador. Para a sua utilização em ambientes comerciais, deve ser considerado a inclusão de módulos de treinamento e projeto de Redes Neurais, além de um módulo para monitorar o desempenho da rede e indicar a necessidade de um novo treinamento ou projeto de novas redes.

Poderia ser feito um estudo da lucratividade e dos prejuízos em cada transação de crédito, formando assim um maior número de classes. Uma rede treinada utilizando várias classes poderia ser uma boa alternativa para a determinação de behavioral score, pontuação relativa ao comportamento de clientes. Seria interessante coletar também os dados das propostas rejeitadas no pré-screening, política inicial de avaliação. Uma rede treinada com todas estas informações poderia ser utilizada em uma ferramenta completa para análise todas as transações que envolvessem avaliação de crédito.

A utilização da abordagem evolucionária é muito atraente para a automatização do projeto de arquiteturas neurais, embora seja um processo demorado. De forma a viabilizar a sua utilização em maior escala, seria interessante a implementação deste protótipo em um ambiente distribuído.

Neste trabalho, as restrições empregadas nas arquiteturas das redes para a solução de problemas complexos, foram úteis para restringir o espaço de buscas do Algoritmo Genético que consome muito tempo de processamento. No entanto, com a utilização de máquinas mais rápidas ou em ambientes distribuídos estas algumas destas restrições poderão ser amenizadas, e poderiam ser utilizadas populações com um maior número de indivíduos, por um número maior de gerações.

Neste trabalho foi focalizado apenas o projeto evolucionário de arquiteturas de redes MLP treinadas com backpropagation, mas é importante notar que a abordagem é geral o suficiente para a sua aplicação utilizando diferentes modelos conexionistas ou diferentes algoritmos de treinamento. O protótipo do NeurEvol já esta sendo modificado para trabalhar com o QuickProp, FAHLMAN (1988), e o RProp, RIEDMILLER (1994), além de redes Radial Base Function, BROOMHEAD \& LOWE (1988).

O protótipo do NeurEvol, ainda carece de uma interface adequada para facilitar a sua utilização por usuários sem muita experiência com Redes Neurais, ou com a linguagem $C$.

Em trabalhos futuros poderão ser investigados os impactos das mudanças no tamanho da população e no número de gerações, além da remoção das restrições das arquiteturas, e utilização diferentes abordagens de representação e funções de avaliação de desempenho. 
Devem ser analizados também, os desempenhos dos protótipos criados em problemas reais de avaliação de crédito de outras empresas, em outros problemas da área financeira, como: abertura de crediário ou cheque especial, determinação de limites de crédito, previsão de falência, previsão de variáveis econômicas e em problemas de outras áreas como administração de empresas, Medicina, entre outras.

A utilização destas novas tecnologias poderá apresentar um grande impacto em muitas áreas do processamento de informações. Futuramente, muitas empresas poderão se beneficiar da utilização de sistemas inteligentes deste tipo para realizar grande parte de suas tarefas. 


\section{Referências Bibliográficas}

ALMEIDA, F.; DUMONTIER, P. (1996). O uso de redes neurais em avaliação de riscos de inadimplência. Revista de Administração, v. 31, n. 1, p. 52-63, mar.

ANGELINE, P.J. (1995). Evolution Revolution: An Introduction to the Special Track on Genetic and Evolutionary Programming. IEEE Expert, v. 10. , n. 3, p. 6-10, Jun.

APTÉ, C.; KASTNER, J.; eds. (1987). Financial Applications. Special Issue. IEEE Expert, v. 2, n.3, Fall Edition.

ARBIB, M. A. ed. (1995) The Handbook of Brain Theory and Neural Networks. Los Angeles, MIT Press.

AUSTIN, S. (1990). An Introduction to Genetic Algorithms. AI Expert. v. 5, n. 3, p.48-53, Mar.

BALAKRISHNAN, K.; HONAVAR, V. (1995). Evolutionary Design of Neural Architetures a Preliminary Taxonomy and Guide to Literature. Artificial Intelligence Research Group, Iowa State University. (Technical Report CS TR \#95-01) .

BARR, D.S.; MANI, G. (1994). Using Neural Nets to Manage Investments. AI Expert. v.9, n.2, p.16-21, Feb.

BARON, R. (1995). Knowledge Extraction From Neural Network: A Survey. (NeuroCOLT Technical Report Series).

BAUER, R.J.J. (1994) Genetic Algorithms and Investment Strategies. New York, John Wiley \& Sons Inc.

BAILEY, D.L.; THOMPSON, D.M. (1990). Developing Neural Network Applications. AI Expert,. v. 5, n. 9, p. 34-41, Sep.

BRANKE J. (1995). Evolutionary Algorithms for Network Design an Training. Institute AIFB, University of Karlsruhe. (Technical Report: 322/95).

BROOMHEAD D.S., LOWE, D.,(1988). Multivariable Functional Interpolation and Adaptive Networks. Complex Systems, vol 2, p. 321-355. 
CALDWELL, C.; JOHNSTON, S. (1991). Tracking a Criminal Suspect Through Face Space with a Genetic Algorithm. apud BAUER, R.J.J. (1994) Genetic Algorithms and Investment Strategies. New York, John Wiley \& Sons Inc. Cap. 8.

CARBONELL, J.G. (1989). Introduction: Paradigms for Machine Learning. Artificial Intelligence, v. 40, n. 1-3, p 1-9, Sep.

CARTER, C.; CATLETT, J. (1987). Assessing Credit Card Applications Using Machine Learning. IEEE Expert. vol. 2, n.3, p. 71-79, Fall Edition.

CAUDILL, M. (1991). Neural Network Training Tips and Techniques. AI Expert, v. 6, n. 1, p.56-61, Jan.

CHALMERS, D. J. (1991). The evolution of learning: An experiment in genetic connectionism. In: TOURETZKY, D.S.; ELMAN, J.L.; HINTON, G.E. (eds). Connectionist Models: Proceedings of the 1990 Summer School, p.81-90. Morgan Kauffman.

CROOKS, T. (1992). Care and feeding of Neural Network. AI Expert, v., n., p.36-41, Jul.

CYBENKO, G. (1988). Continuous Valued Neural Networks with Two Hidden Layers Are Sufficient. Department of Computer Science, Tufts University, Medford, Ma.. (Technical Report).

CYBENKO, G. (1989). Approximation by Superpositions of Sigmoidal Function. Mathematics of Control, Signals, and Systems. v. 2, p.303-314.

DARWIN, C. (1859). On the Origin of Species by Means of Natural Selection. London, John Murray.

DE JONG, K. (1980). Adaptative System Design: A Genetic Approach. IEEE Transactions on Systems, Man, and Cybernetics, v. SMC-10, n. 9, Sep.

DE SÁ, V. (1995). Mente humana é resultado da seleção natural. Folha de São Paulo. 20 ago. Caderno 5, p. 11.

DINIZ, H.; MENDES, E.; CARVALHO, A. (1997), SNNS - Manual de Referência Básica, ICMSC, Universidade de São Paulo, Brasil, (Relatórios Técnicos do ICMSC - n. 53).

EDELMAN, G. (1988). Neural Darwinism. New York. Basic Books.

EIMÁS, P.D.; GALABURDA, A.M. (1990). Neurobiology of Cognition. Cambridge, MA. MIT Press.

FAHLMAN, S.E. (1988). Faster-learning variations on back-propagation: An empirical study. In SEJNOWSKI, T. J. et. al. editors, 1988 Connectionist Models Summer School, San Mateo, Morgan Kauffman. 
FU, L.M. (1994). Rule Generation from Neural Networks. IEEE Transactions on Systems, Man, and Cybernetics, v. 24, n. 8, p. 1114-1124.

FUTUYAMA, D.J. (1992). Biologia Evolutiva. 2. ed. CNPq. São Paulo. Sociedade Brasileira de Genética.

GALLANT, I.S.R. (1988). Connectionist Expert Systems. Communications of the ACM, v. 31, n. 2, p. 152-169, Feb.

GINSBERG, M. (1993). Essentials of Artificial Intelligence. San Mateo, CA, Morgan Kaufmann.

GOLDBERG, D.E. (1989). Genetic Algorithms in Search Optimization and Machine Learning. Reading, MA., Addison Wesley.

HARP, S.A.; SAMAD, T.; GUHA A. (1991). Towards the genetic syntesis of neural networks. Proceedings of the Fouth International Conference on Genetic Algoritms, p. 360-369, Morgan Kaufmann.

HAWLEY, D.; JOHNSON, J.; RAINA, D. (1996). Artificial Neural Systems: A New Tool for Financial Dicision Making. In: TRIPPI, R.; TURBAN, E., eds. (1996). Neural Networks in Finance and Investing. Revised Edition. New York, Irwin. Cap. 2, p. 25-44.

HAYKIN, S. (1994). Neural networks: a comprehensive foundation. (Local), IEEE Press.

HEBB, D.O. (1949). The Organization of Behavior. New York, Wiley.

HOLLAND, J.H. (1975). Adaptation in Natural and Artificial Systems. Ann Arbor, MI, The University of Michigan Press.

HOPFIELD, J. (1982). Neural networks and physical systems with emergent collective computacional properties. Proceedings of the National Academy of Sciences. USA, n. 79, p.2554-2558.

HORNER, A.; GOLDBERG, D.E. (1989). Genetic Algorithms and Computer Assisted Music Composition. apud BAUER, R.J.J. (1994) Genetic Algorithms and Investment Strategies. New York, John Wiley \& Sons Inc. Cap. 8.

HUNG, S.; ADELI, H. (1994). A Parallel Genetic Neural Learning Algorith for MIMD Shared Memory Machines. IEEE Transactions on Neural Networks, v. 5, n.6, p. 900-909.

IEEE INTERNATIONAL CONFERENCE ON NEURAL NETWORKS (1994). Proceedings. Orlando, IEEE Press.

INTEL (1991). 80170NX Specification booklet. Intel Corp, Jun. 
KLIMASAUSKAS, C. (1991) Applying Neural Networks. /reprinted/ In: TRIPPI, R.; TURBAN, E., eds. (1996). Neural Networks in Finance and Investing. Revised Edition. New York, Irwin. Cap. 3, p. 45-69.

LEE, K.; KIM, J. (1994). Hybrid Neural Network Reasoning Approach to Bankruptcy Prediction: Comparison with MDA, ACLS and Neural Network. Proceedings of the IEEE International Conference on Neural Networks, p. 1787-1792.

LEINWEBER, D. (1988). Knowledge-Based Systems for Financial Applications. IEEE Expert, v. 3, n. 3, p. 18-31, Fall Edition.

LLINÁS, R. ed. (1989). The Biology of the Brain - From Neurons to Networks. London, W.H. Freeman and Company.

LOWE, D. (1994). Novel Expectation of Neural Network Methods in Financial Markets. Proceedings of IEEE International Conference on Neural Networks, p. 3623-3628.

MANDISHER, M. (1993). Representation and Evolution of Neural Networks. University of Dortmund, Germany. (Technical Report).

MAROSE, R. (1990). Financial Neural-Network Application. AI Expert. v. 5, n. 5, p.50-53, May.

MCCARTOR, H. (1991). Backpropagation Implementation on the Adaptative Solutions CNAPS Neurocomputer Chip. Proceedings of NIPS 3. Morgan Kaufmann. p. 1028-1031.

MCCULLOCK, W.S.; PITTS, W.H. (1943). A Logical Calculus of Ideas Immanent in Nervous Activity. Bull Math Biophys, p.115-133.

MEDSKER, L; TURBAN, E.; TRIPPI, R. (1996). Neural Network Fundamentals for Financial Analysts. In: TRIPPI, R.; TURBAN, E., eds. (1996). Neural Networks in Finance and Investing. Revised Edition. New York, Irwin. Cap.1, p.03-24.

MENDES, E.; CARVALHO, A. (1996). NeurAval - Sistema Neural para Avaliação de Crédito. Anais do XXIX Congresso Nacional de Informática e Telecomunicações -SUCESU'96.

MENDES, E.; CARVALHO, A.; MATIAS, A. (1996). Utilização de Redes Neurais Artificiais na Análise de Risco de Crédito a Pessoas Físicas. Anais do III Simpósio Brasileiro de Redes Neurais, p.287-293.

MILLER, G.; TODD, P; HEDGE, S.U. (1989). Designing neural networks using genetic algorithms. Proceedings of the Third International Conference on Genetic Algoritms, p.379-384. Morgan Kaufmann.

MINSKY, M.; PAPERT, S. (1969). Perceptrons. Cambridge, MA, MIT Press. 
MONTANA, D. J.; DAVIS, L.(1989) Trainning feedforward neural networks using genetic algorithms. Proceedings of the Eleventh International Joint Conference on Artificial Intelligence, p. 762-767, Morgan Kauffman.

MURPHY, C.A.M; AHA, D.W. (1994). UCI Repository of Machine Learning Databases. Irvine CA, University of California.

MURRAY, D. (1994). Tuning Neural Networks with Genetic Algorithms. AI Expert. v. 9, n. 6, p.27-31, Jun.

NGUEYN, D.; WIDROW, B. (1990). Improving the Learning Speed of 2-Layer Neural Networks by Choosing Inicial Values of the Adaptive Weights. Internatinal Joint Conference on Neural Networks, v. 3, p. 21-26.

PARKER, D.B. (1985). Learning-logic: Casting the cortex of human brain in silicon. Center for Computational Research in Economics and Management Science, MIT, Cambridge, MA. (Technical Report TR-47).

PORTO, V.W.; FOGEL, D.B.; FOGEL, L.J. (1995). Alternative Neural Network Training Methods. IEEE Expert. v. 10, n. 3, p.16-22, Jun.

PRECHELT, L. (1994). Proben 1: A set of Neural Network Benchmark Problems and Benchmarking Rules. Universität Karlsruhe, Germany. (Technical Report: 21/94).

RIBEIRO, R.D. (1996) Ir mais além da modelagem: ser capaz de tirar as melhores vantagens de seus modelos de scoring por meio da automação, Proc. of the Conference Credit Scoring \& Behavioural Scoring, São Paulo, Jul.

RICH, E.; KNIGHT, K. (1991). Artificial Intelligence. New York, McGraw-Hill.

RIEDMILLER, M. (1994) "Rprop - Description and Implementation Details". Universität Karlsruhe, Germany. (Technical Report:1/94).

ROSENBLATT, F. (1958). The Perceptron: A probabilistic model for information storage and organization in the brain. Psycol. Rev. n. 65, p. 386-408.

RUMELHART, D.E.; HINTON, G.E.; WILLIAMS, R.J. (1986). Learning internal representation by error propagation. In Parallel Distributed Processing, p. 318-362, Cambridge, MA, MIT Press.

SCHIFFMANN, W.; JOOST, M.; WERNER, R. (1991) Performance evaluation of evolutionary created neural network topologies, Parallel Problem Solving From Nature 2, p. 292-296, Springer Verlag.

SIMON, H. (1960). The New Science of Managemnet Decision. New York, Harper and Row.

SIMPÓSIO BRASILEIRO DE REDES NEURAIS, 2. Anais. SBC. LABIC. ICMSC. São Carlos, 1995. 
SIMPÓSIO BRASILEIRO DE REDES NEURAIS, 3. Anais. SBC. DI. UFPE. Recife, 1996.

SIMS, K. (1993). Interactive Evolution of Equations for Procedural Models. The Visual Computer. v. 9, n. 1, p. 466-476, Springer Verlag.

SPEARS, W.M.; DE JONG, K.A.; BÄCK, T.; FOGEL, D.B.; GARIS, H. (1993). An Overview of Evolutionary Computation. Preceedings of the 1993 European Conference on Machine Learning.

STEIN, R. (1993). Selecting Data for Neural Networks. AI Expert. v. , n. , Feb.

TRELEAVEN, P.; GONNATILAKE S. (1992). Intelligent Financial Tecnologies. Proceedings of the Workshop on Parallel Problem Solving From Nature: Applications in Statistics and Economics.

TRIPPI, R.; TURBAN, E., eds. (1996). Neural Networks in Finance and Investing. Revised Edition. New York, Irwin.

VISA (1995). Visa using neural networks to identify cardholder fraud. Card News, v.10, n.5 p.3, Mar.

VISHWAKARMA, K.P. (1994). A Neural Network To Predict Multiple Economic Time Series. Proceedings of the IEEE International Conference on Neural Networks, p. 3674-3679.

WEI $\beta$, G. (1990). Combining neural and evolutionany learning: Aspects and Approaches., Technische Universität München. (Technical Report).

WERBOS, P.J. (1974). Beyond regression: New tools for prediction and analysis in the behavioral sciences. $\mathrm{PhD}$. Thesis, Cambridge, Ma., Harvard University.

WHITE, H. (1988). Economic Prediction Using Neural Networks: The Case of IBM Daily Stock Returns. Proceedings of the IEEE International Conference on Neural Networks, v. 2, p.451-459.

WHITLEY, D. (1989). The GENITOR Algorithm and Selection Pressure: Why Rank-Based Alloction of Reproductive Trials is Best. Proceedings of the Third International Conference on Genetic Algorithms, p.116-121, Morgan Kauffman.

WHITLEY, D.; SCHAFFER, J.D.; ESHELMAN, L.J. (1992). Combinations of genetic algorithms and neural networks: A survey of the state of the art. Proccedings of the International Workshop on Combinations of genetic algorithms and neural networks, p.137. IEEE Press.

WIDROW, B. HOFF, M.E. JR. (1960). Adaptative Switching Circuits. IRE WESCON Convention Record. p. 96-104.

WIDROW, B.; LEHR, M. (1990). 30 Years of Adaptative Neural Networks: Perceptron, Madaline and Backpropagation. Proceedings of the IEEE, v. 78, n. 9, p. 1415-1442. 
WINSTON, P.H. (1992). Artificial Intelligence. 3. ed. Reading, MA, Addison Wesley.

WONG, F. (1994). Genetically Optimized Neural Networks. (Nibs Technical Report).

WONG, F.; TAN, P.Y. (1994). Neural Networks And Genetic Algoritm For Economic Forecasting. AI in economics and business administration.

YOON, H., NANG, J.; MAENG, S. (1990). Parallel Simulation of Multilayred Neural Networks on Distribued Memory Multiprocessors. Microprocessing and Microprogramming. n. 29, p.185-195.

ZELL, A. et al. (1995). SNNS Stuttgart Neural Network Simulator - User Manual, Version 4.1, I.P.V.R., Universitåt Stuttgart, Germany, (Technical Report: 6/95). 